UNIVERSIDADE DE SÃO PAULO

INSTITUTO DE PSICOLOGIA

PEDRO FONSECA ZUCCOLO

Condicionamento respondente aversivo: Efeitos de diferentes intervalos de apresentação do CS durante a extinção sobre a ressurgência da CR

São Paulo

2014 
PEDRO FONSECA ZUCCOLO

\section{Condicionamento respondente aversivo: Efeitos de diferentes intervalos de apresentação do CS durante a extinção sobre a ressurgência da CR \\ (versão original)}

Dissertação apresentada ao Departamento de Psicologia Experimental do Instituto de Psicologia da Universidade de São Paulo, como parte dos requisitos para a obtenção do grau de Mestre em Psicologia.

Área de concentração: Psicologia Experimental

Orientadora: Profa. Dra. Maria Helena Leite Hunziker

Bolsista Fapesp: processo n ${ }^{\circ} 2011 / 16088-9$

São Paulo 
AUTORIZO A REPRODUÇÃO E DIVULGAÇÃO TOTAL OU PARCIAL DESTE TRABALHO, POR QUALQUER MEIO CONVENCIONAL OU ELETRÔNICO, PARA FINS DE ESTUDO E PESQUISA, DESDE QUE CITADA A FONTE.

Catalogação na publicação

Biblioteca Dante Moreira Sales

Instituto de Psicologia da Universidade de São Paulo

Zuccolo, Pedro Fonseca.

Condicionamento respondente aversivo: efeitos de diferentes intervalo de apresentação do CS durante a extinção sobre a ressurgência da CR / Pedro Fonseca Zuccolo; orientadora Maria Helena Leite Hunziker. -- São Paulo, 2014.

$105 \mathrm{f}$.

Dissertação (Mestrado - Programa de Pós-Graduação em Psicologia. Área de Concentração: Psicologia Experimental) - Instituto de Psicologia da Universidade de São Paulo.

1. Comportamento respondente 2. Extinção 3. Ressurgência I. Título. 


\section{FOLHA DE APROVAÇÃO}

Nome: Pedro Fonseca Zuccolo

Título: Condicionamento respondente aversivo: Efeitos de diferentes intervalos de apresentação do CS durante a extinção sobre a ressurgência da CR

Dissertação apresentada ao Departamento de Psicologia Experimental do Instituto de Psicologia da Universidade de São Paulo para a obtenção do grau de Mestre em Psicologia

Aprovada em:

Banca Examinadora:

Prof. Dr.

Instituição:

Assinatura:

Prof. Dr.

Instituição:

Assinatura:

Prof. Dr.

Instituição:

Assinatura: 


\section{AGRADECIMENTOS}

Já muito antes de ingressar neste curso de mestrado eu sabia que qualquer trabalho científico, independentemente se teórico ou experimental, nunca é feito sozinho. E de fato, se eu não tivesse tido o auxílio de diversas pessoas em diferentes momentos, este trabalho jamais teria saído do papel. $\mathrm{O}$ auxílio ao qual me refiro não foi somente acadêmico ou profissional, mas também das pessoas que acompanharam todo o processo, amigos, conhecidos, familiares, apoiando-me nos momentos difíceis ou aguentando as minhas intermináveis ausências. Tenho clareza de que é muito difícil enumerar todas essas pessoas, mas algumas delas não poderiam deixar de ser citadas. Portanto, um agradecimento especial:

- À minha orientadora, Maria Helena Leite Hunziker, por ter acreditado no projeto, por ter me apoiado e orientado ao longo de todo o processo, pela paciência para lidar com as minhas dificuldades e pelo enorme aprendizado que me proporcionou (e espero que continue a proporcionar) com suas discussões e análises críticas. Me sinto um profissional melhor depois de todos esses anos de contato.

- À Coordenação de Aperfeiçoamento de Pessoal de Nível Superior (CAPES), pela bolsa fornecida nos dois meses iniciais deste projeto.

- À Fundação de Amparo à Pesquisa do Estado de São Paulo (FAPESP), pelo grande apoio financeiro fornecido (proc. Auxílio Regular no 2011/ 18516-8), sem o qual esta pesquisa seria simplesmente impossível. No período da confecção do projeto, o Laboratório de Análise Biocomportamental (LABC) laboratório não tinha nenhum dos equipamentos necessários para o tipo de investigação aqui proposto. Fomos contemplados não somente com um auxílio nesse sentido, como também recebi uma bolsa de mestrado, que ajudou a me manter financeiramente durante a execução da pesquisa.

- Ao Comitê de Ética em Pesquisa da Faculdade de Filosofia, Ciências e Letras de Ribeirão Preto (CEP-FFCLRP), por ter avaliado este projeto de maneira muito comprometida e séria, forçando-nos a pensar criticamente sobre ele. Em especial, gostaria de agradecer à Juliana Silva Lins, técnica para assuntos administrativos do comitê de ética, que foi extremamente profissional ao me auxiliar com as questões burocráticas envolvidas na submissão e avaliação do projeto.

- Aos Drs. André Russowsky Brunoni e Clemente Isnard Ribeiro de Almeida, que muito gentilmente cederam seu tempo para analisar criticamente nosso projeto no que se refere à segurança dos procedimentos aqui utilizados.

- À Marianne Reddan, do Laboratório Schiller de Neurociência Afetiva (Mount Sinai School of Medicine), pelas valiosas sugestões de como os equipamentos deveriam ser montados. Nesse sentido, gostaria também de agradecer à Monika Torres e Hisham Abboud, da empresa Cedrus, que me auxiliaram a manusear o programa SuperLab na programação do experimento e prontamente trocaram uma peça que havia quebrado para que o experimento não atrasasse. 
- À Dra. Daniela Schiller, por ter aberto seu laboratório para que eu o visitasse e tivesse acesso à informações muito valiosas para o andamento do projeto. No mesmo sentido, Dorothee Bentz, aluna de pós-doutorado do laboratório da referida pesquisadora, pelas muitas horas de ajuda e paciência com as minhas dúvidas e questionamentos. Um agradecimento especial também à doutoranda Candace Raio e à assistente de pesquisa Catherine Stevenson, da Universidade de Nova Iorque, que se dispuseram a discutir dúvidas técnicas adicionais.

- À todos os membros e ex-membros do Laboratório de Análise Biocomportamental (LABC) que se dispuseram gentilmente a discutir incontáveis vezes o projeto (e seus problemas) e me sugerir caminhos possíveis: Angélica, Amílcar, Bia, Bruno, Carol, Diego, Eduardo, Fabiana, Flávio, Graziela, Kadu, Lígia, Lourenço, Luana, Mariana Castelli, Mariana Samelo, Tatiany e Tauane. Um especial agradecimento ao Marcos Yamada, que me possibilitou recrutar vários de seus alunos na UNINOVE para participarem da coleta de dados.

- Aos estatísticos Vinicius Frayze David e Jony Arrais, pelas supervisões em estatística e por terem me ajudado tanto nessa reta final.

- Aos alunos da pós-graduação do Instituto de Psicologia, alguns pela amizade, alguns por terem se disposto a participarem dos estudos pilotos, e outros por ambas as razões. Foram tantos e eu peço desculpas se esqueci alguém: Anderson, Adriana, Ângelo, Catalina, Clarissa, Diana, Emerson, Felipe, Adsson, Gabriela, Marina, Nicolas, Lorena, Paulo, Pedro, Saulo, Talita, Thiago, Victor e William.

- À todas as pessoas da USP UNINOVE e de outros lugares que se dispuseram a vir três dias seguidos para participar do experimento. Sem vocês não seria possível obter os dados aqui descritos

- Ao Emerson e Victor, grandes parceiros e amigos desde os tempos de especialização no Paradigma e até hoje.

-À todos os funcionários do Instituto de Psicologia (IP), por resolverem diversos problemas para mim e por seu bom humor e gentileza: Sônia, Valéria e Vilma do Departamento de Psicologia Experimental; à Alessandra e Sônia da direção do IP.

- À todos os professores da pós-graduação, pelo enorme aprendizado que me proporcionaram ao longo desses três anos de convívio. O amadurecimento de diversas ideias colocadas aqui saíram das discussões que tivemos durante as aulas.

- Aos colegas do Núcleo Paradigma, pelas inúmeras oportunidades profissionais que me deram: Roberto Banaco, Denis Zamignani, Roberta Kovac e Joana Singer Vermes. Também queria agradecer ao Denigés Regis Maurel Neto (Jazz) e Felipe Corchs.

Aos professores Lino Bueno e Roberto Banaco, pelas ótimas sugestões e discussões que tivemos na banca de qualificação.

- À minha família, que sempre esteve ao meu lado e que tiveram que aguentar várias horas de ausência porque eu estava em casa trabalhando neste projeto: aos meus pais, Antônio Carlos, Lucila e avô, Carlos, que fizeram com que meus estudos fossem possíveis; aos meus irmãos (Renata, Lara e Danilo) e à mulher do meu pai (Flávia); ao meu cunhado, Bruno, e sobrinho (e afilhado), Joaquim; à minha tia Lia, Mado e Tio Fernando, além do Fabinho e Fernanda; à Maria José; e, por fim, ao Orlandão, que 
infelizmente não está aqui entre nós para ver o final deste trabalho. Penso em você toda hora.

- Aos meus amigos, que embora não tenham participado diretamente do trabalho, são pessoas importante para mim: Beto Martello, Tiago e Lélio Borges, Guilherme Brunoni, Tatiana Sasaki, Marcelo Constantino, Marcelo Caro, Bel e Dante; à todos os dimas, pelo bom-humor e amizade. Além deles, Juliana Góes, Patrícia, Rzezak e Leandro Nunes. Por fim, um agradecimento especial pro Alexandre Maver, que além de ter acompanhado todo o processo deste trabalho, ainda teve a coragem de ser o primeiro sujeito a passar pelo primeiro estudo-piloto e pediu até para eu tirar uma foto dele!

- À família da minha mulher, que tão bem me acolheu: Lucila, Egberto, Marcos, Adriane, Fábio, Arnaldo e Marcelo, Fernando, Marina e Camila.

- Também gostaria de fazer um agradecimento aos Drs. Fernando Bacal, Elizabeth Sartori Crevelari e Luíz Guilherme Gomes Cardim Guerra (Lugui). Além disso, ao Arnaldo Baçoli e João Teixeira de Faria. Cada um deles, à sua maneira e dentro de um enfoque, auxiliam-se a superar problemas de saúde e dificuldades da vida.

- Por fim, como não poderia deixar de ser, um agradecimento imenso a uma pessoa chamada Mariana Flaks. Primeiro porque foi ela que aguentou, mais do que todo mundo, minhas crises de mau-humor e nunca saiu do meu lado, mesmo nos momentos em que isso seria totalmente compreensível. Depois, pelo companheirismo, amor e tudo mais que temos juntos. 


\section{RESUMO}

Zuccolo, P. F. (2014). Condicionamento respondente aversivo: Efeitos de diferentes intervalos de apresentação do CS durante a extinção sobre a ressurgência da $C R$. Dissertação de Mestrado, Instituto de Psicologia, Universidade de São Paulo, São Paulo

Pesquisas sobre condicionamento respondente envolvendo estímulos aversivos mostram que respostas condicionais (CRs) podem ressurgir depois de extintas. Schiller et al. (2010) demonstraram que as CRs podem ser inibidas de forma duradoura se durante a extinção for dado um intervalo entre a primeira apresentação do CS e as demais apresentações. Esta pesquisa consiste na replicação desse experimento como forma de iniciar uma série de estudos sobre extinção respondente no Laboratório de Análise Biocomportamental (LABC). Foram utilizados 11 participantes adultos, expostos a estimulação elétrica leve (US) e três quadrados coloridos (CSs). As alterações na condutância da pele frente à apresentação do US e dos CSs foram as medidas da UR e $\mathrm{CR}$, respectivamente. Os sujeitos, divididos em dois grupos (experimental e controle), passaram por três estágios consecutivos com intervalos de $24 \mathrm{hr}$ : condicionamento, extinção e teste de ressurgência. Eles diferiram entre si apenas quanto ao tratamento recebido na fase de extinção. No condicionamento, dois estímulos foram pareados com o US ( $\mathrm{CSa}+\mathrm{e} \mathrm{CSb}+$ ) e um nunca foi pareado (CS-) com o US. Na extinção, os participantes foram expostos apenas aos três CSs sem US. Apenas no grupo experimental foi dado um intervalo de 10 min entre a primeira e as demais apresentações do $\mathrm{CSa}+$. No teste de ressurgência, foram feitas quatro apresentações do US, seguidas de intervalo de $10 \mathrm{~min}$ e sucessivas apresentações dos três CSs sem o US. Na média, os grupos não diferiram entre si, apresentando igualmente condicionamento, extinção e aumento das amplitudes das CRs frente a todos os estímulos no teste. Porém, foi grande a variabilidade entre participantes em ambos os grupos: além de diferirem quanto ao padrão de condicionamento e extinção, nem todos apresentaram ressurgência. Esses dados não replicam o estudo de Schiller et al. (2010), sugerindo que mais análises são necessárias para que sejam identificadas as variáveis que controlam o condicionamento e a extinção respondentes.

Palavras-chave: condicionamento respondente, extinção, ressurgência, tempo. 


\begin{abstract}
Zuccolo, P. F. (2014). Aversive respondent conditioning: Effects of different intervals of CS presentation during extinction on the ressurgence of the CR. Dissertação de Mestrado, Instituto de Psicologia, Universidade de São Paulo, São Paulo.

Research on respondent conditioning involving aversive stimuli have shown that conditional responses (CRs) may reappear after extinction. Schiller et al., (2010) have demonstrated that $\mathrm{CR}$ inhibition may be long-lasting if there is a longer interval between the first and the remaining presentations of the CS during extinction. This research aimed at replicating the previously described experiment as a way of starting a series of investigations on respondent extinction in the Biobehavioral Analysis Laboratory (LABC). We recruited 11 adult participants who were exposed to a mild electrical stimulation (US) and were shown three colored squares (CSs). Skin conductance responses during US and CS presentations were used as measures of URs and CRs, respectively. The subjects were divided into two groups (experimental and control) and went through three consecutive stages separated by a $24 \mathrm{hr}$ interval: conditioning, extinction, and ressurgence test. These groups differed from each other only regarding the treatment received during extinction. In conditioning, two stimuli were paired with the CS $(\mathrm{CSa}+$ and $\mathrm{CSb}+)$ while a third stimulus was never paired with the US. In the extinction phase, participants were exposed to the three CSs without the US. There was a $10 \mathrm{~min}$ interval between the first and the remaining presentations of the $\mathrm{CSa}+$ only for the experimental group. In the test phase, the US was administered four times, which was followed by a 10 min interval and sucessive presentations of all CSs without the US. In average, groups did not differ from each other, presenting equivalent levels of conditioning, extinction, and an increase in CR amplitudes following presentation of all stimuli in the test phase. However, we observed significant between-subject variability within both groups: besides presenting different patterns of conditioning and extinction, not every subject showed CR ressurgence. These data do not replicate the findings reported by Schiller et al. (2010), suggesting that further analysis are needed to identify variables that control conditioning and extinction.
\end{abstract}

Key-words: respondente conditioning, extinction, ressurgence, time. 


\section{LISTA DE TABELAS}

Tabela 1 - Representação esquemática do delineamento do estudo 


\section{LISTA DE FIGURAS}

Figura 1 - Amplitude média (e erros-padrão) das respostas incondicionais (URs), medidas em $\mu \mathrm{S}$, ao longo das fases de condicionamento e teste apresentada por todos os sujeitos.

Figura 2 - Amplitude média (e erro-padrão) das respostas incondicionais (URs), medida em $\mu \mathrm{S}$, frente ao US, nas fases de condicionamento e teste, e amplitude média (e erropadrão) das respostas condicionais (CRs) frente ao $\mathrm{CSa}+, \mathrm{CSb}+$ e $\mathrm{CS}$ - nas fases de condicionamento (média das cinco apresentações dos CSs + sem US e das últimas cinco apresentações do CS-), extinção (última apresentação de cada CS) e teste (primeira apresentação de cada CS). * Diferença estatisticamente significante entre $\mathrm{CSa}+, \mathrm{CSb}+\mathrm{e}$ CS- no condicionamento em ambos os grupos $(p<0,05)$ e diferença estatisticamente significante entre grupos controle e experimental quanto às amplitudes médias das URs na fase de condicionamento $(\mathrm{p}<0,05)$.

Figura 3 - Amplitudes médias das $\mathrm{CRs}$, medida em $\mu \mathrm{S}$, frente ao $\mathrm{CSa}+, \mathrm{CSb}+$ e $\mathrm{CS}$ - ao longo das fases de condicionamento (cinco apresentações dos CSs sem US), extinção e teste apresentadas pelos sujeitos dos grupos controle (parte superior) e experimental (parte inferior). $\mathrm{O}$ ponto isolado refere-se à resposta frente ao $\mathrm{CSa}+$ apresentado isoladamente (com intervalo de $10 \mathrm{~min}$ ) no início da sessão de extinção apenas para os sujeitos do grupo experimental.

Figura 4 - Amplitudes das respostas condicionais (CRs), em $\mu \mathrm{S}$, frente ao $\mathrm{CSa}+, \mathrm{CSb}+$ e CS- ao longo das fases de condicionamento (cinco apresentações do $\mathrm{CSa}+\mathrm{e} \mathrm{CSb}+\mathrm{sem}$ US, e cinco últimas apresentações do CS-), extinção e teste apresentadas pelos sujeitos do grupo controle.

Figura 5 - Amplitudes das respostas condicionais (CRs), em $\mu \mathrm{S}$, frente ao $\mathrm{CSa}+, \mathrm{CSb}+\mathrm{e}$ $\mathrm{CS}-$ ao longo das fases de condicionamento (cinco apresentações dos $\mathrm{CSa}+\mathrm{e} \mathrm{CSb}+\mathrm{sem}$ US, e últimas cinco apresentações do CS-), extinção e teste para os sujeitos do grupo experimental. A apresentação isolada do $\mathrm{CSa}+$ entre o condicionamento e a extinção se refere à manipulação de interesse neste experimento. 


\section{LISTA DE SIGLAS}

$\mathrm{AC}$

Alternating current (corrente alternada)

APA American Psychological Association

FFCLRP Faculdade de Filosofia, Ciências e Letras de Ribeirão Preto

CS Conditional stimulus (estímulo condicional)

CS+ Estímulo condicional pareado ao US

CS- Estímulo condicional não pareado ao US

CR Conditional response (resposta condicional)

DC Direct current (corrente direta)

DP Desvio-padrão

EDA Electrodermal activity (atividade eletrodérmica)

EIR Entire-interval response (resposta do intervalo todo)

FIR First-interval response (resposta do primeiro intervalo)

IET Intervalo entre tentativas

IRPA International Radiation Protection Association

LABC Laboratório de Análise Biocomportamental

NIOSH National Institute for Occupational Safety

NS.SCR Non-specific skin conductance response

OMS Organização Mundial da Saúde

SC Skin conductance (condutância da pele)

SCL Skin conductance level (nível de condutância da pele)

SCR Skin conductance response (resposta de condutância da pele)

SCR. freq. Skin conductance response frequency (frequência da resposta de condutância da pele)

SCR. amp. Skin conductance response amplitude (amplitude da resposta de condutância da pele)

SCR. lat. Skin conductance response latence (latência resposta de condutância da pele) 
SCR ris.t. Skin conductance response rising time (tempo de ascensão da resposta de condutância da pele)

SCR. rec.t/2 Skin conductance response half-recovery time (meio tempo de recuperação da resposta de condutância da pele)

SCR rec. t. Skin conductance response total recovery time (tempo total de recuperação da resposta de condutância da pele)

SIR Second-interval response (resposta do segundo intervalo)

TEPT Transtorno do Estresse Pós-traumático

TIR Third-interval response (resposta do terceiro intervalo)

UR Unconditional response (resposta incondicional)

US Unconditional stimulus (estímulo incondicional)

USP Universidade de São Paulo

UNEP United Nations Environment Program

UNINOVE Universidade Nove de Julho

VD Variável dependente

VI Variável independente 


\section{SUMÁRIO}

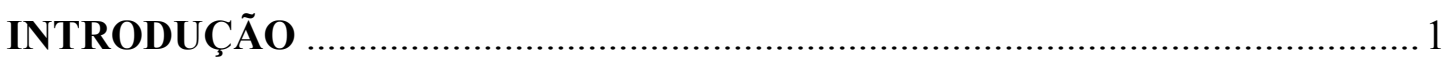

Condicionamento e extinção respondentes ........................................................ 2

Investigação da ressurgência do condicionamento respondente aversivo: dos estudos em ratos aos experimentos com humanos .................................................. 6

Estudos sobre ressurgência do comportamento respondente aversivo.................. 12

OBJETIVO

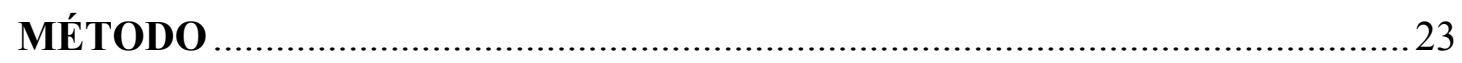

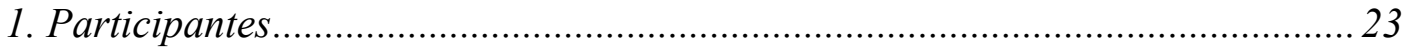

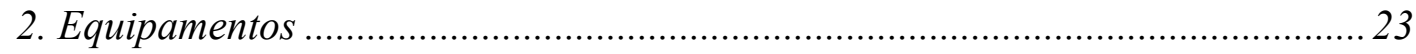

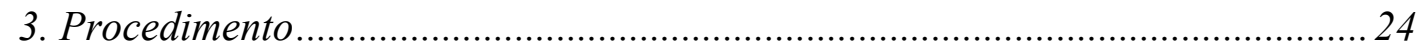

4. Avaliação das respostas de condutância da pele .............................................. 30

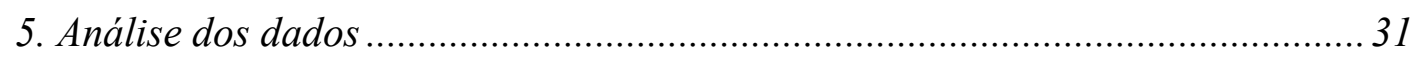

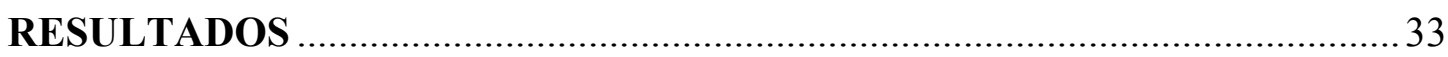

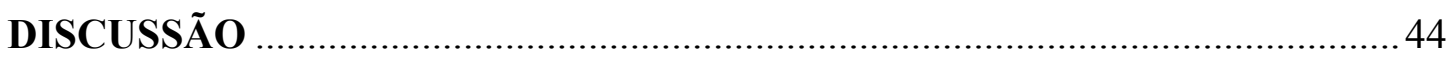

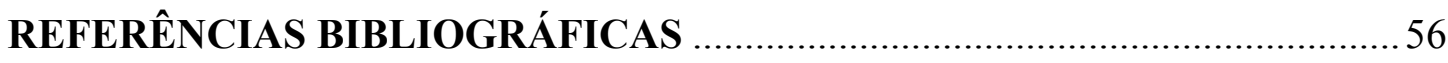

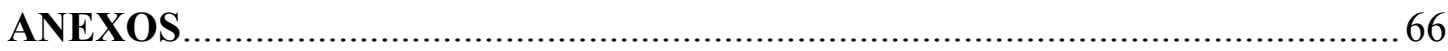


Tanto no nível teórico como no experimental, é sabido que a Análise do Comportamento tem se debruçado muito pouco sobre o estudo do comportamento respondente (Catania, 1999; Todorov, 2011). Segundo Todorov (2011), o desequilíbrio entre estudos operantes e respondentes é tamanho que hoje a Análise do Comportamento, como área da ciência, seria mais apropriadamente denominada "Análise do Comportamento Operante". Contudo, desde os estudos pioneiros de Pavlov, ficou demonstrado que a investigação de processos respondentes é fundamental para um entendimento mais completo sobre o comportamento. Assim, compreendêlos, isoladamente ou em interação com os operantes, é a função do analista do comportamento.

No nível aplicado, alguns procedimentos utilizados para tratar comportamentos emocionais em humanos (por exemplo, a ansiedade e o medo) foram baseados em dados experimentais sobre comportamento respondente (Davis, Ressler, Rothbaum \& Richardson, 2006; Hermans, Craske, Mineka \& Lovibond, 2006; Rauch, Shin \& Phelps, 2006). Este é o caso da terapia por exposição, cujo princípio é baseado na observação experimental da extinção do condicionamento respondente, sendo usada para tratar sujeitos com Transtorno do Estresse Pós-traumático (TEPT) (Cahill, Foa, Hembree, Marshall \& Naschasch, 2006; Nascasch et al., 2007; Powers, Halpern, Ferenschak, Gillihan \& Foa, 2010; Rachamin, Nascasch, Shafran, Tzur \& Gilboa-Schechtman, 2009). Essa terapia consiste na exposição gradual do sujeito a estímulos relacionados ao "trauma" que desencadeou o TEPT, de modo que o caráter aversivo dos mesmos seja paulatinamente diminuído.

Uma limitação dos tratamentos que envolvem exposição é que frequentemente há uma reincidência dos sintomas após uma intervenção aparentemente bem sucedida (Barlow, 2002; Foa, Franklin \& Moser, 2002; Vervliet, Craske \& Hermans, 2013). É por essa razão que diversos pesquisadores tem se interessado por investigações que possam esclarecer mecanismos envolvidos no reaparecimento de respostas após a sua extinção e nos modos pelos quais a extinção poderia ser mais duradoura (Rauch et al., 2006; Schiller et al., 2008; Schiller, Raio \& Phelps, 2012; Vervliet et al., 2013).

Desde a década de 60, diversos estudos realizados em animais não-humanos revelaram variáveis importantes para o reaparecimento de respostas após sua extinção (Bouton, 2002; Monfils, Cowansage, Klann \& LeDoux, 2009; Schiller et al., 2008). Dada a grande semelhança de alguns desses dados com a reincidência de sintomas ansiosos na clínica após tratamentos por exposição, o fenômeno de ressurgência, demonstrado em laboratório, tem sido considerado como um modelo experimental dos transtornos da ansiedade (Bouton, 2002; Monfils et al., 2009; Schiller et al., 2008; Vervliet et al., 2013). 
Embora revelem diversas variáveis importantes para a produção do fenômeno da ressurgência, os estudos com animais não-humanos não são suficientes para o entendimento dos Transtornos da Ansiedade. Em primeiro lugar, a produção de certos fenômenos comportamentais em uma espécie não necessariamente implica que o processo seja igual em outra (Vervliet et al., 2013). Além disso, não é possível estudar em outras espécies processos típicos de humanos e que sabidamente têm influência sobre a etiologia e manutenção dos Transtornos da Ansiedade como, por exemplo, os processos cognitivos ou verbais (Eifert \& Schermelleh, 1985; Hoffman, 2008).

De particular interesse nesse sentido são os estudos experimentais com humanos, que geralmente têm por objetivo verificar se dados obtidos em pesquisas básicas com animais nãohumanos são replicados em humanos (Schiller et al., 2012; Vervliet et al., 2013). Essas pesquisas em geral tomam por base procedimentos de pesquisas básicas com outras espécies (ratos principalmente) para criar situações de laboratório com participantes humanos em que há controle e manipulação das variáveis supostamente envolvidas no fenômeno de interesse. De acordo com Vervliet et al. (2013), pesquisas básicas com humanos cujas perguntas experimentais buscam uma relação com o fenômeno clínico seriam um passo intermediário entre os estudos básicos em outras espécies e os chamados estudos clínicos. Por estudo clínico, entende-se pesquisas nas quais a eficácia de diferentes análises e procedimentos é testada em amostras de sujeitos com diagnósticos psiquiátricos ou outros problemas comportamentais (Vervliet et al., 2013).

Consideramos que a identificação de condições que tornam a extinção mais efetiva, ou seja, com menor chance da resposta condicional ocorrer novamente poderia, além de trazer informações teóricas relevantes para a análise do comportamento, ser uma contribuição relevante para o entendimento de fenômenos clínicos, tais como o medo. Essas considerações sobre essa área de investigação, juntamente com outras descritas a seguir, supomos, justificará a presente proposta de pesquisa. Dentre os desenvolvimentos mais recentes, existem pesquisas com animais não-humanos e humanos que sugerem que certas mudanças no procedimento de extinção podem torná-lo mais efetivo, evitando o ressurgimento de respostas condicionais. A replicação de um desses procedimentos foi o objetivo principal deste projeto.

\section{Condicionamento e extinção respondentes}

Denomina-se comportamento respondente uma relação na qual um estímulo específico produz (elicia) de forma fidedigna uma resposta do organismo (Catania, 1999). Quando uma resposta é eliciada por um estímulo sem história prévia de aprendizagem, fala-se em uma relação 
respondente incondicional (Catania, 1999). Nesse caso, a resposta e o estímulo são chamados de incondicionais ou UR e US, respectivamente (do inglês, unconditioned response - UR e unconditioned stimulus - US) (Catania, 1999; Rescorla, 1988). Já uma relação respondente condicional envolve um comportamento respondente que surge a partir da experiência do sujeito, ou seja, é um comportamento aprendido. Especificamente, essa aprendizagem se dá quando um estímulo originalmente neutro ${ }^{1}$, ao ser previamente associado $^{2}$ com um US, passa a eliciar uma resposta que antes não era eliciada por ele (Catania, 1999; Rescorla, 1988). Nesse caso, o estímulo e a resposta eliciada por ele passam a ser denominados condicionais ou CS e CR, respectivamente (do inglês, conditioned stimulus - CS e conditioned response - CR) (Catania, 1999; Rescorla, 1988). O processo pelo qual um estímulo neutro passa a ser um CS tem sido chamado por analistas do comportamento de condicionamento respondente (Catania, 1999) ${ }^{3}$.

Os estudos sobre condicionamento respondente demonstraram alguns estímulos que podem ser associados a estímulos neutros e produzir condicionamento respondente (Pavlov, 1927; Rescorla, 1988). Este projeto tem como foco o condicionamento respondente que envolve a associação entre um estímulo originalmente neutro e um estímulo aversivo. $\mathrm{O}$ experimento típico para se estudar esse processo consiste no pareamento entre sons ou figuras (estímulos neutros, que terão depois função de CS) com choques elétricos (US aversivo). Como resultado, o CS passa a eliciar um conjunto variado de respostas. Por exemplo, em estudos com ratos, os sujeitos apresentam "congelamento" (imobilidade física, denominada freezing) ou supressão de um responder positivamente reforçado frente ao CS após este ter sido pareado com o US (Bouton \& Bolles, 1979a, 1979b; Monfils et al., 2009; Rescorla \& Heth, 1975; Schiller et al., 2008). Em estudos com humanos, a ocorrência do CS pode eliciar, dentre outras respostas, sudorese (Graeff, Parente, Del-Ben \& Guimarães, 2003; Schiller et al., 2008; Schiller et al., 2010).

Grande parte dos estudos produzidos sobre comportamento respondente envolvendo estímulos aversivos foi desenvolvida a partir de hipóteses cognitivas ou neurofisiológicas, sendo

\footnotetext{
${ }^{1}$ Quando se diz que um estímulo é neutro, entende-se que ele não tem, a princípio, a propriedade de eliciar as respostas em estudo, ou mesmo eliciá-las em determinada magnitude, e não que ele não tenha função para o comportamento do organismo. Embora seja muito usado na literatura, o termo "neutro" não explicita exatamente o que ocorre em todas as ocasiões de condicionamento. Por exemplo, o tom utilizado no pareamento com alimento no estudo clássico de Pavlov eliciava, antes desse pareamento, movimentos das orelhas, mas não alterava a salivação. Já no condicionamento da atividade eletrodérmica, o CS elicia respostas de condutância da pele antes mesmo de ocorrer qualquer pareamento com o US. O que ocorre após o pareamento é que esse estímulo passa a eliciar tais mudanças em maior grau (ver ANEXO A).

${ }^{2}$ Por associação prévia entre estímulos, entenda-se uma história em que a ocorrência de um determinado estímulo esteve associada a ocorrência de outro, seja ocorrendo ao mesmo tempo, instantes antes ou seguindo-o (Rescorla, 1968, 1988).

${ }^{3} \mathrm{O}$ condicionamento respondente também tem sido referido pelos termos condicionamento clássico ou pavloviano, pelo fato deste processo ter sido descrito pela primeira vez pelo fisiólogo russo Ivan P. Pavlov (Catania, 1999; Pavlov, 1927; Rescorla, 1988). Para os fins desta pesquisa, utilizar-se-á o termo condicionamento respondente.
} 
esse assunto tratado pela ótica e linguajar dessas duas abordagens (Aguado, 2003; Bouton, 2004; Bouton \& Moody, 2004; Lattal \& Lattal, 2012; Rescorla, 1988, 2003). Isso justifica que na literatura geral o condicionamento respondente envolvendo estímulos aversivos seja referido com grande frequência como "condicionamento de medo" (Bouton, 2004; Bouton \& Bolles, 1979a; LaBar \& Phelps, 2005; Milad, Orr, Pitman \& Rauch, 2005; Schiller et al., 2008). Além disso, é comum ver autores dessas áreas denominando uma CR eliciada por um CS aversivo como "estado de medo", "resposta de medo" ou até mesmo "memória de medo" (Monfils et al., 2009; Schiller et al., 2008; Schiller et al., 2010; Squire, 1992, 2004, 2009).

Independentemente da denominação utilizada, o estudo do condicionamento respondente aversivo foi feito por meio da experimentação, o que possibilitou compreender, entre outros fatores, diversos delineamentos experimentais necessários para se estabelecerem os pareamentos CS-US e outros tantos para produzir a quebra dessa relação (Lattal \& Lattal, 2012; Rescorla, 2003). Dentre as condições experimentais mais estudadas, pode-se citar a extinção respondente, que tem relação com a diminuição das CRs após condicionamento envolvendo USs aversivos (Rescorla, 2003).

Desde os estudos de Pavlov, sabe-se que se o CS for apresentado repetidas vezes sem o US, há uma redução progressiva do responder condicional (Catania, 1999; Monfils et al., 2009). A apresentação do CS sem o US após o condicionamento é denominada de procedimento de extinção respondente (Catania, 1999). No caso do "condicionamento de medo", a extinção equivale a apresentar os estímulos visuais ou auditivos previamente pareados com choque na ausência deste. Como resultado, há diminuição significativa da ocorrência das respostas condicionais frente ao CS. A essa diminuição da ocorrência da CR em função da quebra do pareamento CS-US dá-se o nome de processo de extinção. Portanto, o termo extinção vem sendo usado tanto para designar um procedimento como um processo comportamental (Catania, 1999; Lattal \& Lattal, 2012)..

Contudo, um dado importante é que a diminuição de ocorrência das respostas condicionais, após exposição ao procedimento de extinção, não é permanente: em diferentes condições, uma CR reduzida após extinção pode voltar a ser eliciada pelo CS, fenômeno este denominado de ressurgência ${ }^{4}$ (Catania, 1999; Monfils et al., 2009).

\footnotetext{
${ }^{4} \mathrm{O}$ termo ressurgência é comumente usado em Análise do Comportamento para se referir ao reaparecimento de uma resposta operante que deixou de ser emitida após procedimento de extinção (Catania, 1999). Nas investigações sobre comportamento respondente, quase não se usa esse termo, mas sim utilizam-se nomes específicos para as circunstâncias relacionadas ao reaparecimento da CR após extinção. Por exemplo, se a CR volta a ser eliciada pelo CS quando este é apresentado em um contexto diferente daquele onde foi feita a extinção, então fala-se em "renovação" (renewal, Bouton \& King, 1983); se a CR volta a ser eliciada pelo CS depois que houve uma apresentação do US sem o CS após extinção, fala-se em "restabelecimento" (reinstatement, Rescorla \& Heth, 1975); quando um tempo se passou e a CR voltou a ser eliciada pelo CS sem qualquer procedimento específico para esse fim, fala-se em "recuperação espontânea" (spontaneous recovery, Schiller et
} 
A demonstração desse fenômeno de ressurgência fez com que pesquisadores da área levantassem a hipótese de que a extinção não é uma "desaprendizagem” da relação anteriormente estabelecida, mas implica em uma nova aprendizagem que é inibitória, responsável pela supressão da eliciação das CRs frente ao CS (Schiller et al., 2008; Myers \& Davis, 2002). Contudo, ainda há grande controvérsia a respeito dos mecanismos envolvidos na extinção (Myers \& Davis, 2002; Myers, Ressler \& Davis, 2006). Existem hipóteses sobre os processos cognitivos que supostamente estariam envolvidos na extinção, das quais pode-se citar o bem divulgado modelo Rescorla-Wagner (1972), que serviu de base para o desenvolvimento de modelos cognitivos mais recentes (Aguado, 2003; Bouton, 2004; Lattal \& Lattal, 2012; Rescorla, 1988, 2003). Na literatura atual, muito destaque tem sido dado também para as hipóteses baseadas nas neurociências, das quais pode-se destacar a hipótese da reconsolidação da memória na amígdala (Duvarci \& Nader, 2004; Monfils et al., 2009; Nader, Schafe \& LeDoux, 2000; Squire, 2009). Como citado anteriormente, as pesquisas em análise do comportamento com base no behaviorismo radical têm se dedicado quase que exclusivamente ao estudo do comportamento operante, tendo contribuído pouco na investigação dos processos respondentes e formulação de hipóteses sobre a ressurgência do responder condicional após extinção (Lattal \& Lattal, 2012; Todorov, 2011). No entanto, conforme será discutido mais adiante, isso não significa que esses fenômenos do comportamento respondente não possam ser abordados pela mesma estratégia que tem sido usada para compreender o comportamento operante (Lattal \& Lattal, 2012).

Em relação à primeira interpretação, os modelos baseiam-se na hipótese de que o condicionamento e a extinção respondentes envolvem processos que ocorrem em um nível cognitivo e representacional. Especificamente, o condicionamento seria uma das maneiras pelas quais o organismo ajustaria o seu "conhecimento interno" sobre o mundo por meio de uma análise das mudanças que ocorrem à sua volta (Rescorla, 1988, 2003). Influenciada pelas chamadas teorias "associacionistas", de acordo com as quais os organismos fazem "associações" entre as ocorrências do mundo, a abordagem cognitiva propõe que essas associações ocorrem em um nível da representação do conhecimento. Dito de outro modo, os organismos associam a ocorrência do CS à ocorrência do US, sendo que é esse conhecimento, enquanto representação, que seria responsável pelo modo de agir do animal ou ser humano (Rescorla, 1988, 2003).

\footnotetext{
al., 2008). Optamos pelo termo ressurgência porque ele abarca o processo de reaparecimento da CR frente ao CS, após extinção, independente de qual das operações foi utilizada (Lattal \& Lattal, 2012). A escolha desse termo ocorreu por ele resumir todas as ocasiões acima. Além disso, os termos renovação, restabelecimento e recuperação espontânea, assim como o termo extinção, têm sido usados para se referir tanto a um procedimento (e.g., Monfils et al., 2009) como um processo resultante do procedimento (e.g., Rescorla, 2003), o que poderia acarretar em confusão por parte do leitor.
} 
Segundo Rescorla (1988, 2003), por ser relativamente bem descrito e organizado, o condicionamento respondente (e, em especial, o condicionamento respondente aversivo) foi e continua sendo usado como uma ferramenta para compreender os eventos neurofisiológicos envolvidos em processos de aprendizagem. Com o passar do tempo, os neurocientistas foram se familiarizando de tal modo com os processos respondentes que eles passaram então a explicar características do fenômeno por meio de um referencial neurofisiológico. É um fato que no âmbito das neurociências há uma grande influência das teorias cognitivas (Bouton \& Moody, 2004). Portanto, é comum que os dados oriundos das manipulações experimentais nas neurociências sejam interpretados com base em teorias cognitivas (Bouton, 2004; Bouton \& Moody, 2004).

No que diz respeito às possíveis contribuições da análise do comportamento para o estudo do comportamento respondente, uma possibilidade é usar estratégias análogas ao que tem sido feito no estudo do comportamento operante. Na pesquisa sobre comportamento operante, os diferentes processos comportamentais têm sido investigados por meio de uma análise experimental detalhada das condições sob as quais eles ocorrem (Lattal \& Lattal, 2012). Dito de outro modo, a estratégia nas pesquisas sobre comportamento operante consiste em identificar as variáveis das quais um determinado comportamento é função. Uma característica dessa abordagem é que ela evita inferir processos (cognitivos, por exemplo) com base em observações comportamentais (Donahoe \& Palmer, 1994; Skinner, 1953; Zílio, 2010). Portanto, em uma abordagem analítico-comportamental sobre o condicionamento respondente, não seriam feitas hipóteses a respeito de "associações" ou "representações do CS"; a estratégia seria entender em que condições experimentais o condicionamento respondente torna-se mais ou menos provável, sem fazer referência a conceitos cognitivos. Esta é a estratégia adotada no presente projeto que, mesmo abordando o tema, não tem o compromisso de adotar a explicação vigente (cognitiva) para o fenômeno da ressurgência. Isso significa que os dados revisados a seguir serão analisados com base em seus procedimentos e resultados, sem adotar neste momento uma interpretação teórica.

Posto isso, nas seções seguintes, será feita uma análise de trabalhos que investigavam variáveis envolvidas na ressurgência do responder condicional após extinção do condicionamento respondente aversivo.

\section{Investigação da ressurgência do condicionamento respondente aversivo: dos estudos em ratos aos experimentos com humanos}

Descrevemos anteriormente que os estudos experimentais sobre ressurgência do responder condicional em humanos baseiam-se em modelos desenvolvidos originalmente em animais não- 
humanos, sendo possível observar semelhanças entre essas duas formas de abordar o fenômeno (Schiller et al., 2012; Vervliet et al., 2013). Contudo, tendo em vista limitações éticas importantes quando se utiliza participantes humanos em pesquisas experimentais (por exemplo, a impossibilidade de usar certos fármacos por seu possível efeito deletério, Schiller et al., 2010; Kindt \& Soeter, 2013) e a presença de processos típicos da espécie (por exemplo, o comportamento verbal em humanos, Hoffman, 2008), pode-se também notar diversas diferenças entre essas pesquisas (Vervliet et al., 2013). Esta seção tem por objetivo introduzir o leitor aos aspectos mais gerais das pesquisas sobre ressurgência do condicionamento respondente, pontuando semelhanças e diferenças entre estudos com humanos e animais não-humanos.

É importante destacar que embora seja possível encontrar estudos sobre condicionamento respondente em diversas espécies, tais como ratos (Monflis et al., 2009), peixes (Eisenberg, Kobilo, Berman \& Dudai, 2003) ou caracóis (Sangha, Scheibenstock \& Lukowiak, 2003), esta revisão terá como foco apenas estudos com ratos. Essa escolha é justificada pelo fato da maior parte da literatura ser baseada em estudos com essa espécie. Além disso, os delineamentos experimentais em humanos foram baseados naqueles usados nos experimentos com ratos.

De uma maneira geral, pode-se apontar como semelhança entre estudos com ratos e humanos o uso de pelo menos três fases experimentais nas pesquisas: condicionamento, extinção e teste. No condicionamento, o experimentador arranja uma contingência em que um estímulo aversivo (US) é pareado com um outro estímulo (neutro). Uma vez que este outro estímulo tornase um CS (i.e., fica demonstrado que ele passa a eliciar uma resposta que antes do pareamento não era eliciada por ele), a etapa seguinte consiste em um procedimento de extinção. Isto é, o sujeito é exposto ao CS sem que este seja pareado com o US. Como resultado, ao final dessa fase, geralmente não há mais eliciação da CR frente ao CS.

Essas duas primeiras etapas (condicionamento e extinção) são apontadas como fundamentais para o estudo da ressurgência do responder condicional (Monfils et al., 2009; Schiller et al., 2008; Schiller et al., 2013; Schiller et al. 2012). Primeiramente, não é possível falar em ressurgência se não se demonstra que houve condicionamento; tampouco faz sentido falar em ressurgência de uma CR se não se demonstra que essa resposta deixou de ocorrer na presença do CS em função do procedimento de extinção. Conforme será discutido em maiores detalhes na próxima seção, a demonstração do condicionamento e extinção em estudos com humanos depende de delineamentos bem específicos a depender da medida utilizada. 
A última etapa, denominada aqui teste ${ }^{5}$, consiste em um novo procedimento de extinção: expõe-se o sujeito novamente ao CS, sem que este seja pareado ao US, e verifica-se se nessa condição ocorre a CR. Esse teste é realizado como um meio de avaliar a efetividade da primeira extinção em inibir o aparecimento de CRs frente ao CS: o procedimento de extinção terá sido tanto mais efetivo quanto menor for a ocorrência da CR (ressurgência) frente a essa reapresentação do CS isoladamente (Monfils et al., 2009; Nader et al., 2000; Schiller et al., 2010; Schiller et al., 2012).

Tanto nos estudos com ratos como com humanos, os procedimentos mais enfatizados são aqueles que ocorrem na fase de extinção. Nessa etapa, há estudos que descrevem manipulações do intervalo entre extinção e condicionamento (Maren \& Chang, 2006; Myers et al. 2006; Schiller et al., 2008; Schiller et al., 2010, Experimento 1), do intervalo entre cada uma das apresentações do CS durante o procedimento de extinção (Kindt \& Soeter, 2013; Monfils et al., 2009; Oyarzún et al., 2012; Schiller et al., 2010; Soeter \& Kindt, 2011) e da duração de cada exposição ao CS (Bouton \& King, 1983).

Destaque-se ainda manipulações que são realizadas no contexto das diferentes fases / etapas desses experimentos. Por exemplo, em alguns estudos com ratos, os pesquisadores realizaram a extinção em um contexto com caraterísticas físicas (i.e., cor, textura das paredes, cheiros, sons etc) diferentes daqueles onde foram realizados o condicionamento ou o teste de ressurgência (Bouton \& Bolles, 1979a, 1979b, 1980; Bouton \& King, 1983; Monfils et al., 2009; Rescorla \& Heth, 1975; Schiller et al., 2008; Thomas, Larsen \& Ayres, 2003). Em estudos com humanos, as chamadas manipulações de contexto são mais variadas: em alguns estudos, os autores realizaram as diversas fases do experimento em locais com características físicas diferentes (LaBar \& Phelps, 2005), às vezes localizados em edifícios separados (Schiller et al., 2008); em outras pesquisas, os estímulos visuais escolhidos para ter a função de CS foram apresentados com fundos de tela diferentes a depender da fase do experimento, sendo que esses fundos de tela foram chamados de contexto (Alvarez, Johnson \& Grillon, 2007; Milad et al., 2005; Neumann \& Kitlertsirivatana, 2010); ainda outros iluminaram as salas com cores diferentes a depender da fase do experimento (Effting \& Kindt, 2007).

\footnotetext{
${ }^{5}$ Nos trabalhos analisados, o nome dado a esta fase do experimento varia de acordo com as condições sob as quais o experimentador testa se ocorre a ressurgência. Assim, é comum nomear esta etapa como: a) teste de recuperação espontânea (spontaneous recovery test) se o experimentador deixa passar um certo período após a extinção e depois simplesmente apresenta o CS para ver se a CR volta a ocorrer (Schiller et al., 2010); b) teste de renovação (renewal test) se o experimentador apresenta o CS num contexto diferente daquele onde ocorreu extinção (Bouton \& King, 1983); c) teste de restabelecimento (reintatement test) se previamente à apresentação do CS o experimentador apresenta o US sem CS (Schiller et al., 2010); ou d) teste de memória de longo-prazo (long-term memory test), em estudos nos quais os autores utilizam a fase de teste para inferir processos de memória celular (Monfils et al., 2009). Utilizamos aqui simplesmente o nome teste porque ele é resumidor de todas essas circunstâncias, ou seja, esta é uma fase que, do ponto de vista experimental, verifica-se se certas condições podem aumentar a probabilidade da CR, que passou pela extinção, voltar a ser eliciada pelo CS.
} 
Os estudos com ratos e humanos tem ainda um outro aspecto em comum. Em sua grande maioria, utiliza-se um estímulo elétrico como estímulo aversivo incondicional (US), sendo que nos animais o choque elétrico é geralmente administrado na pata do animal através do piso da caixa e nos humanos a estimulação é dada no pulso do participante via um eletrodo sobre a pele (Bouton \& Bolles, 1979a, 1979b; Bouton \& King, 1983; Effting \& Kindt, 2007; LaBar \& Phelps, 2005; Maren \& Chang, 2006; Milad et al., 2005; Monfils et al., 2009; Myers et al., 2006; Neumann \& Kitlertsirivatana, 2010; Schiller et al., 2008; Schiller et al., 2013; Thomas et al., 2003).

Contudo, uma diferença importante entre os estudos com ratos e humanos diz respeito à intensidade da estimulação elétrica. Na maioria dos estudos com ratos, a intensidade da corrente elétrica é intensa e igual para todos os sujeitos (Bouton \& Bolles, 1979a, 1979b; Bouton \& King, 1983; Maren \& Chang, 2006; Monfils et al., 2009; Schiller et al., 2008). Essa intensidade difere apenas em estudos em que ela é a variável independente investigada, tais como nos estudos de Rescorla e Heth (1975), que testaram diferentes intensidades do US para verificar os seus efeitos sobre a ressurgência.

Por razões éticas, nos estudos mais atuais em humanos é feito um ajuste de intensidade do estímulo elétrico para cada participante, respeitando-se o limiar de tolerância de cada um (Alvarez et al., 2007; Kindt \& Soeter, 2013; Schiller et al., 2008; Schiller et al., 2010; Soeter \& Kindt, 2011). Esse ajuste é feito, por exemplo, apresentando o estímulo elétrico ao participante em uma intensidade muito baixa e aumentando-o gradativamente até que o sujeito o considere “desconfortável, porém não doloroso" (Schiller et al., 2008, p. 400). Portanto, apesar da natureza igual dos estímulos, há diferenças no grau de aversividade ao comparar estudos com ratos e humanos. Essa limitação no uso da estimulação elétrica torna muito mais difícil a demonstração robusta do fenômeno do condicionamento em humanos (Schiller et al., 2008; Schiller et al., 2013). Isso fica especialmente claro quando se utilizam as medidas de condutância da pele como variável dependente nos estudos sobre ressurgência (Boucsein, 2012).

Apesar da estimulação elétrica ser usada com frequência, há relatos de uso de estímulos aversivos alternativos. Por exemplo, em alguns estudos com ratos, utilizou-se o ruído estridente de uma buzina (Rescorla \& Heth, 1975, Experimento 3). Em algumas pesquisas com humanos, utilizou-se um ruído branco estridente (LaBar \& Phelps, 2005, Experimento 1), o som de uma criança ou porco gritando (Oyarzún et al., 2012), ou então o uso de um jato de ar quente direcionado à garganta do participante (Golkar, Bellander, Olsson \& Öhman, 2012).

Tanto nos experimentos com ratos como nos humanos, há uma variação no número de vezes em que um CS é pareado com o US na fase de condicionamento. Por exemplo, com 
humanos, em alguns estudos o CS é pareado com o US em aproximadamente um terço de suas apresentações (Schiller et al., 2010), enquanto que em outros o CS é sempre pareado com o US na fase de condicionamento (Schiller et al., 2008, experimento sobre restabelecimento com humanos). Com ratos, em geral a fase de condicionamento consiste em $100 \%$ de pareamentos entre CS e US, porém o número de pareamentos pode também variar (Bouton \& Bolles, 1979a; Rescola \& Heth, 1975).

Como estímulo condicional (CS), é comum nos estudos com ratos o uso de sons em frequência e intensidade não aversivas que são pareados com o US (Bouton \& Bolles, 1979a, 1979b; Bouton \& King, 1983; Maren \& Chang, 2006; Monfils et al., 2009; Rescorla \& Heth, 1975; Schiller et al., 2008) ou uma luz (Myers et al., 2006; Thomas et al., 2003); com humanos, normalmente utilizam-se imagens apresentadas na tela de um computador (Golkar et al., 2012; Kindt \& Soeter, 2013; Kindt, Soeter \& Vervliet, 2009; LaBar \& Phelps, 2005; Nelson, Sanjuan, Vadillo-Ruiz, Pérez \& León, 2010; Neumann \& Kitlertsirivatana, 2010; Oyarzún et al., 2012; Schiller et al. 2008; Schiller et al., 2013; Schiller et al., 2010; Sevenster, Becker \& Kindt, 2012; Soeter \& Kindt, 2011), mas também há relatos de apresentação de luzes coloridas (Agren et al., 2012) ou sons (Alvarez et al., 2007). No caso do uso de imagens, estas podem ser formas geométricas simples de diferentes cores (LaBar \& Phelps, 2005; Oyarzún et al., 2012; Schiller et al., 2013; Schiller et al., 2010), imagens fractais (Schiller et al., 2008, experimento sobre restabelecimento com humanos), fotografias (por exemplo, de aranhas, como utilizado por Kindt \& Soeter, 2013, Kindt et al., 2009; cogumelos, como usado por Soeter e Kindt, 2011; ou cobras, como usado por Schiller et al., 2008,) ou desenhos de faces (usado por Effting \& Kindt, 2007 e Golkar et al., 2012).

Um aspecto importante dos estudos com humanos é que muitas vezes utiliza-se mais de uma imagem, sendo que o paramento com o US ocorre somente para algumas delas e outras nunca são pareadas com o estímulo aversivo (e.g., Effting \& Kindt, 2007; Golkar et al., 2012; Kindt \& Soeter, 2013; Oyarzún et al., 2012; Schiller et al. 2008; Schiller et al., 2010; Soeter \& Kindt, 2011). O uso deste tipo de delineamento em geral ocorre nas pesquisas que se utilizam de respostas de condutância da pele como medida de respostas condicional (Bousein, 2012) (ver ANEXO A).

Uma das maiores diferenças entre estudos com ratos e humanos dizem respeito às medidas. Nos estudos com ratos, os métodos mais comuns de avaliação das CRs consistem em quantificar a resposta de congelamento (freezing) frente ao CS (Monfils et al., 2009; Schiller et al., 2008), ou então, medir a CR indiretamente pela supressão de um responder positivamente reforçado (Rescorla \& Heth, 1975). A medida de congelamento (freezing) envolve avaliar o tempo no qual o 
animal permanece com imobilidade física, padrão que envolve encolhimento do corpo e ausência dos movimentos das vibrissas durante a apresentação do CS (Bouton \& Bolles, 1980; Monfils et al., 2009). Já a avaliação da supressão condicionada é feita treinando-se o animal a emitir uma dada resposta operante consequenciada por um estímulo reforçador (por exemplo, treinando-o a pressionar uma barra em função da obtenção da água). Dada uma situação em que o animal pode emitir o comportamento (por exemplo, quando ele está na caixa experimental com uma barra), apresenta-se o CS aversivo e observa-se os efeitos sobre a taxa do responder na sua presença: se houver uma diminuição na taxa do responder na presença desse CS, em comparação à taxa nos minutos que antecederam sua apresentação, diz-se então que o comportamento está sendo suprimido (Estes \& Skinner, 1941). Embora este delineamento envolva uma relação entre comportamento operante e respondente, ele tem sido muito utilizado em estudos sobre ressurgência do condicionamento respondente após extinção (Bouton \& Bolles, 1979a, 1979b; Bouton \& King, 1983; Rescorla \& Heth, 1975) ${ }^{6}$.

Em humanos, o método mais comum de avaliar se o CS elicia uma CR é mensurar a atividade eletrodérmica, isto é, a condutância elétrica da pele. Sabe-se por diversos estudos eletrofisiológicos que uma vez que um US ou CS são apresentados, há um aumento na atividade das glândulas sudoríparas das mãos, as quais são inervadas por fibras colinérgicas do sistema nervoso simpático (Dawson, Schell \& Fillion, 2000; Graeff et al., 2003). A secreção dessas soluções iônicas aumenta a condutância elétrica da pele, sendo que essa mudança na condutância é uma das medida de CR (Boucsein, 2012; Dawson et al., 2000; Graeff et al., 2003). Até onde vimos na literatura, a maioria dos estudos sobre condicionamento respondente aversivo em humanos utiliza-se dessas medidas (Agren et al., 2012; Effting \& Kindt, 2007; Oyarzún et al., 2012; Schiller et al., 2008; Schiller et al., 2013; Schiller et al., 2010; Soeter \& Kindt, 2011; Vervliet, Vansteenwegen, Bayens, Hermans \& Eelen, 2005; Vervliet, Vansteenwegen \& Eelen, 2004).

Outro método, menos comum, para se avaliar se uma CR é eliciada pelo CSs, tanto em humanos como em ratos, é o chamado "sobressalto potencializado pelo medo" (fear potentiated startle) (Geyer \& Swerdlow, 1998; Kindt \& Soeter, 2013; Kindt et al., 2009). Em ratos, esse método consiste em avaliar por meio de um acelerômetro a magnitude de encolhimento do corpo inteiro frente a um CS (normalmente um som) que foi previamente pareado com um US aversivo (Geyer \& Swerdlow, 1998). Em humanos, mede-se a diferença no reflexo de piscar (eyeblink

\footnotetext{
${ }^{6}$ Há aqui um aspecto que merece ser comentado. Embora tenhamos destacado que o delineamento da supressão condicionada tenha sido originalmente pensado por Estes e Skinner (1941), este destaque não é uma prática comum na literatura. Na verdade, há uma omissão por parte dos autores de pesquisas sobre ressurgência do condicionamento respondente após extinção, que não apontam a origem desse delineamento.
} 
startle reflex) do músculo ocular frente a um som alto antes e após apresentação do CS (Vervliet et al., 2013). Se houver um aumento na magnitude da resposta de piscar frente ao som após apresentação do CS, diz-se que houve eliciação de uma CR (Kindt \& Soeter, 2013; Weike, Schupp \& Hamm, 2007).

Outro aspecto que diferencia as pesquisas em ratos e humanos são as instruções. Diferentemente dos estudos com ratos, não há como evitar o uso de instruções verbais em experimentos conduzidos com humanos. Há variações das instruções entre experimentos. Por exemplo, há estudos em que os sujeitos foram avisados de que a atividade avaliaria as suas glândulas de suor em reação a eventos sensórios, auditivos e visuais, e que a tarefa era passiva, não sendo necessária nenhuma resposta aberta (LaBar \& Phelps, 2005); em outras pesquisas, o participante foi instruído a prestar atenção à tela e tentar descobrir se havia uma relação entre a estimulação visual e os choques (Schiller et al., 2008; Schiller et al., 2010). A literatura demonstra que as instruções fornecidas aos participantes pode alterar a maneira como eles respondem à certos estímulos (Eifert \& Schermelleh, 1985; Hugdahl \& Öhman, 1977), o que torna esta uma diferença relevante entre as pesquisas com ratos e humanos, e uma variável que deve ser levada em conta na hora de analisar os resultados das pesquisas.

Nesta seção, foram descritos alguns procedimentos utilizados no estudo da ressurgência do responder condicional tanto em ratos como em humanos. Pode-se perceber que apesar de haver semelhanças entre as duas abordagens ao fenômeno, diversas adaptações tiveram de ser feitas ao transpor os estudos de um lado ao outro.

Como descrito anteriormente, a maior parte dos estudos com humanos utiliza-se da atividade eletrodérmica como forma de mensurar o condicionamento. Essa medida é complexa e repleta de nuances, que não serão abordadas aqui para não se quebrar a análise em curso. Porém, para o leitor interessado em tais nuances, o ANEXO A apresenta uma breve abordagem sobre questões técnicas e metodológicas envolvidas no uso dessa medida comportamental no estudo do condicionamento e extinção respondentes.

\section{Estudos sobre ressurgência do comportamento respondente aversivo}

As pesquisas sobre ressurgência do responder condicional demonstraram que, tanto com humanos ou com ratos, a CR pode voltar a ser eliciada pelo CS após extinção. São três os arranjos experimentais mais utilizados nessa demonstração. O primeiro deles diz respeito ao tempo transcorrido entre as etapas da extinção e o teste de ressurgência: alguns experimentos demonstraram que respostas condicionais frente a CSs aversivos podem ressurgir na etapa de teste 
após a mera passagem de um tempo considerável desde a extinção (por exemplo, intervalo de 30 dias entre a extinção e o teste de ressurgência) (Pavlov, 1927; Robbins, 1990; Schiller et al., 2008; Schiller et al., 2010).

Em outro arranjo, a ressurgência da CR após extinção também foi observada quando houve algumas reapresentações do US isoladamente antes do teste de ressurgência (Bouton \& Bolles, 1979b; Milad et al., 2005; Rescorla \& Heth, 1975; Schiller et al., 2008; Westbrook, Iordanova, McNally, Richardson \& Harris, 2002). Este último resultado foi obtido tanto ao se apresentar o US no mesmo contexto onde foi realizada a extinção (Bouton \& Bolles, 1979b; Westbrook et al., 2002), como em um contexto com características físicas diferentes (Milad et al., 2005; Rescorla \& Heth, 1975; Schiller et al., 2008).

O último arranjo experimental diz respeito a manipulações no contexto das diferentes fases experimentais. Em diversas investigações com ratos, houve ressurgência da CR quando o CS foi apresentado em um contexto com características físicas diferentes daquele onde foi realizada a extinção (Bouton \& Bolles, 1979a, 1979b, 1980; Bouton \& King, 1983; LaBar \& Phelps, 2005; Neumann \& Longbottom; Rescorla \& Heth, 1975; Schiller et al., 2008; Thomas et al. 2003). Em estudos com humanos, o mesmo fenômeno foi observado em diversas ocasiões: quando o contexto da extinção era fisicamente diferente de onde foi realizado o teste de ressurgência (por exemplo, em uma sala diferente, como utilizado por Schiller et al., 2008 e LaBar e Phelps, 2005); no caso de CSs visuais (imagens), quando havia fundos de tela diferentes (por exemplo, paisagens diferentes, como demonstrado por Alvarez et al., 2007; Neumann e Logbottom, 2008; e Milad et al., 2005); ou então, quando a iluminação da sala tinha uma cor diferente durante o teste de ressurgência em relação à fase de extinção (Effting \& Kindt, 2007).

Recentemente, alguns estudos demonstraram que a ressurgência pode ser evitada nesses três arranjos experimentais desde que, durante a etapa de extinção, seja estabelecido um intervalo entre a primeira apresentação do CS e as demais, adicionando-se um estímulo "neutro" durante esse intervalo. Por exemplo, Monfils et al. (2009) conduziram diversos experimentos de condicionamento respondente aversivo com ratos, nos quais o CS era um tom, o US um choque elétrico e as CRs eram o congelamento após apresentação do CS. Em um desses experimentos, 24 hr após o condicionamento, os sujeitos foram submetidos à extinção recebendo 19 apresentações do CS, que tinham, em geral, $180 \mathrm{~s}$ entre si. Os sujeitos foram distribuídos em cinco grupos, que diferiam quanto ao tamanho do intervalo entre a primeira e a segunda apresentações do CS: 10 min (Grupo 1), 1 hr (Grupo 2), 6 hr (Grupo 3), 24 hr (Grupo 4) e nenhum intervalo, ou seja, apenas $180 \mathrm{~s}$ entre todos os CS (Grupo 5). Todos os sujeitos cujo intervalo entre a primeira e segunda apresentações do CS foi maior que $180 \mathrm{~s}$ eram retirados da caixa, colocados nas suas 
gaiolas, onde permaneciam durante o intervalo previsto, e depois recolocados na caixa experimental. Os resultados mostraram que todos os sujeitos apresentaram respostas de congelamento quando da primeira apresentação do CS sem o US na extinção, porém essas respostas diminuíram igualmente para todos os grupos ao final dessa etapa. Um mês depois, todos os sujeitos foram submetidos a um teste de ressurgência que consistiu em uma apresentação única do CS e mensuração da resposta de congelamento. Obteve-se que os sujeitos dos Grupos 1 e 2, cujo intervalo entre a primeira e segunda apresentações do CS na extinção foi de $10 \mathrm{~min}$ e $1 \mathrm{hr}$, respectivamente, não mostraram ressurgência da $\mathrm{CR}$, enquanto que os sujeitos dos demais grupos apresentaram respostas de congelamento frente ao CS.

Esses resultados foram replicados por Monfils et al. (2009) com algumas alterações no delineamento experimental em outro experimento, no qual todos os sujeitos (ratos) foram submetidos ao procedimento de pareamento CS-US (tom e choque elétrico, respectivamente), sendo a CR avaliada a resposta de congelamento. Vinte e quatro horas após foram expostos ao procedimento de extinção com 19 apresentações do CS sem o US. Dois grupos diferiram entre si quanto ao intervalo entre a primeira e segunda apresentações do CS e ao que ocorria nesse intervalo: um deles foi submetido às 19 apresentações do CS com um intervalo regular de $180 \mathrm{~s}$ entre elas; o outro teve uma apresentação do CS seguida por um intervalo de $10 \mathrm{~min}$, durante o qual foram removidos para as gaiolas-viveiro e depois recolocados na caixa experimental, onde foram expostos às 18 apresentações restantes do CS com $180 \mathrm{~s}$ de intervalo entre cada apresentação. Vinte e quatro horas após esse procedimento de extinção, todos os sujeitos receberam quatro apresentações não sinalizadas do US. Após novo intervalo de $24 \mathrm{hr}$, foram expostos a quatro CSs frente aos quais foi registrada a ocorrência ou não da CR (teste de ressurgência). Como resultados, os sujeitos não diferiram entre si nas fases de condicionamento e extinção. No entanto, houve diferença no teste de ressurgência: apenas o grupo sem manipulação do intervalo entre a primeira e segunda apresentações do CS apresentou ressurgência. Portanto, a inclusão desse intervalo com retirada dos animais da caixa experimental, evitou a ressurgência de uma CR previamente extinta.

Em um terceiro experimento, Monfils et al. (2009) realizaram o condicionamento com dois grupos de ratos. Passadas $24 \mathrm{hr}$ do condicionamento, os sujeitos de um dos grupos foi exposto uma única vez ao CS e em seguida retornados à suas gaiolas-viveiro; os sujeitos do outro grupo foram expostos somente ao contexto onde foi realizado o condicionamento (contexto A), não tendo contato com o CS. No mesmo dia, uma hora após esse procedimento, todos os sujeitos foram submetidos à extinção, porém em um contexto com características físicas diferentes de onde foi realizada a etapa de condicionamento (contexto B). Após $24 \mathrm{hr}$, foi feito um primeiro teste de 
ressurgência no contexto B (onde havia sido realizada a extinção) e no dia seguinte foi feito um novo teste no contexto A (onde havia sido realizada a etapa de condicionamento). Como resultados, durante a extinção os sujeitos dos dois grupos mostraram diminuição semelhante das respostas de congelamento nas quatro últimas tentativas dessa etapa. No primeiro teste, realizado no mesmo contexto onde havia sido feita a etapa de extinção, os sujeitos de ambos os grupos não apresentaram ressurgência. Contudo, no segundo teste, realizado em um contexto diferente da extinção, apenas os sujeitos do grupo que não havia sido exposto ao CS previamente à extinção apresentaram ressurgência das respostas de medo; os do grupo que havia sido exposto ao CS antes da extinção não apresentaram esse efeito.

Resultados similares foram obtidos em uma série de estudos com humanos realizados Schiller et al. (2010). No primeiro estudo, quadrados amarelos antecediam a apresentação do US (CS+) e quadrados azuis nunca eram seguidos pelo US (CS-). Esses CSs eram apresentados na tela de um computador por quatro segundos cada. O US manipulado foi um choque elétrico de $200 \mathrm{~ms}$, cuja intensidade era determinada pelos próprios participantes antes do experimento. A resposta de condutância da pele (SCR) foi avaliada frente ao US e aos CSs. Em todas as etapas, a instrução fornecida ao sujeito era para que olhasse para a tela e tentasse entender a relação entre os estímulos que apareciam e a estimulação elétrica. No primeiro estudo, 65 participantes foram distribuídos em três grupos $(\mathrm{n} \cong 22)$ de maneira randômica, sendo todos expostos a três fases experimentais. Na primeira (Dia 1), todos os grupos passaram pelo condicionamento, no qual o CS+ e o CS- foram apresentados aleatoriamente na tela do computador, com um intervalo entre tentativas (IET) de 10 a 12 s: o CS+ foi pareado com o choque em $38 \%$ das tentativas, enquanto o CS- nunca antecedeu o choque. Na segunda fase (Dia 2), todos os sujeitos passaram por um procedimento de extinção, no qual o CS+ e o CS- foram apresentados sem o US, 11 vezes cada e em ordem alternada. Nessa fase, dois grupos foram submetidos a uma apresentação isolada do CS+, seguida por um intervalo de 10 min durante os quais assistiram a um episódio de um programa de televisão selecionado previamente pelos pesquisadores. Esses dois grupos diferiram quanto ao momento da extinção: o primeiro foi submetido à extinção logo após o intervalo de 10 min (Grupo $10 \mathrm{~min}$ ); o segundo passou pela extinção $6 \mathrm{hr}$ após esse intervalo (i.e., passaram pelo intervalo de 10 min e depois esperaram mais $6 \mathrm{hr}$ para realizar a extinção) (Grupo $6 \mathrm{hr}$ ). O grupo para o qual não foi feita a apresentação isolada do CS+ (grupo não-manipulado) foi dividido em dois subgrupos: metade dos sujeitos foi submetida ao intervalo de $10 \mathrm{~min}$, durante o qual assistiam ao mesmo programa televisivo que os Grupos $10 \mathrm{~min}$ e $6 \mathrm{hr}$, e depois ao procedimento de extinção (11 apresentações de cada CS sem US); a outra metade foi submetida ao intervalo de 10 min e depois de seis horas à extinção. Na terceira fase (Dia 3), todos os sujeitos foram expostos a um 
novo procedimento de extinção, ou seja, 11 apresentações de cada CS sem US, com IET de 10-12 S.

Os resultados mostraram que sujeitos de todos os grupos não apresentaram diferenças significantes nas CRs nas fases 1 e 2: todos apresentaram evidências de condicionamento e diminuição da CR após extinção. Contudo, no terceiro estágio do experimento (Dia 3), os pesquisadores observaram ressurgência das CRs apenas nos sujeitos dos Grupos não-manipulado e 6 hr; não houve ressurgência da CR para sujeitos do Grupo 10 min.

Schiller et al. (2010, Experimento 1) convidaram os participantes desse experimento a voltar ao laboratório após aproximadamente um ano para avaliar a persistência do bloqueio das CRs extintas. Eles conseguiram localizar 19 dos 65 participantes e conduziram um novo teste de ressurgência, que consistiu em quatro apresentações não-sinalizadas do US, seguidas do procedimento de extinção. Como resultados, os sujeitos dos Grupos 6 hr e não-manipulado, que mostraram ressurgência da CR na re-extinção (Dia 3, no ano anterior), apresentaram ressurgência das CR frente ao CS; os do Grupo 10 min não apresentaram ressurgência.

Em vista do potencial uso do procedimento de extinção para aplicação clínica (em especial para o Transtorno do Estresse Pós-Traumático), Schiller et al. (2010) conduziram um segundo experimento, que tinha como objetivo avaliar a especificidade do bloqueio das CRs. O racional usado pelos pesquisadores foi o de que, na vida cotidiana, eventos traumáticos podem estar associados a diferentes eventos ambientais, de forma que cada um desses últimos pode adquirir a propriedade de eliciar respostas condicionais (chamadas, por eles, de "respostas de medo"). Assim, o intuito desse experimento era verificar se o bloqueio da propriedade eliciadora de um determinado CS pode interferir com a propriedade eliciadora de outro CS. Ele também consistiu em três fases consecutivas separadas por intervalos de $24 \mathrm{hr}$. Os mesmos equipamentos do primeiro experimento foram usados mas, diferentemente do experimento anterior, foi utilizado um delineamento intrasujeitos. No primeiro estágio da pesquisa (Dia 1), os sujeitos foram submetidos ao condicionamento respondente com três quadrados coloridos como CS. Dois desses quadrados $(\mathrm{CSa}+\mathrm{e} \mathrm{CSb}+)$ foram pareados em 38\% das apresentações com choques elétricos de $200 \mathrm{~ms}$ (US). Os quadrados eram apresentados por quatro segundos cada, com um IET de 10 a 12 s. No Dia 2, todos foram submetidos a um procedimento de extinção, com manipulação do intervalo entre a primeira e segunda apresentações do CS. Especificamente, o CSa+ e o CS- foram apresentados separadamente uma única vez (sem o US), sendo em seguida dado um intervalo de 10 min, durante o qual os participantes assistiam a um episódio de um programa de televisão selecionado previamente pelos experimentadores. Após esse intervalo, os sujeitos passavam pelo restante do procedimento de extinção, no qual os três estímulos (CSa+, $\mathrm{CSb}+$ e CS-) foram apresentados 11 
vezes cada sem o US. No Dia 3, foram administrados aos sujeitos quatro choques nãosinalizados, seguidos de 10 min de intervalo, durante o qual assistiam ao mesmo episódio de televisão. Após esse intervalo, os sujeitos eram submetidos ao procedimento de re-extinção, no qual os três estímulos ( $\mathrm{CSa}+, \mathrm{CSb}+$ e $\mathrm{CS}-)$ eram apresentados sem o US repetidamente. Como resultados, observaram que os níveis de $\mathrm{CRs}$ foram equivalentes entre o $\mathrm{CSa}+$ e $\mathrm{CSb}+$, tanto $\operatorname{logo}$ após pareamento como depois da extinção. Contudo, observaram ressurgência das CRs no Dia 3 apenas frente ao $\mathrm{CSb}^{+}$, que não teve manipulado o intervalo entre sua primeira apresentação e as demais durante a extinção.

Desde a publicação dos estudos de Monfils et al. (2009) e Schiller et al. (2010), diversos laboratórios procuraram replicar os dados relatados. Dado que os processos envolvidos na extinção do condicionamento respondente aversivo têm sido usados para compreender os chamados transtornos da ansiedade, muitas dessas pesquisas têm sido realizadas com sujeitos humanos (Agren et al., 2012; Golkar et al., 2012; Kindt \& Soeter, 2013; Oyarzún et al., 2011; Soeter \& Kindt, 2011) supondo-se que, com isso, já se chegue mais perto da transposição do fenômeno básico de extinção e ressurgência para a ansiedade analisada clinicamente.

Alguns estudos replicaram os achados de Schiller et al. (2010), enquanto outros não obtiveram essa replicação. Dentre os primeiros, Agren et al., (2012) usaram estímulos visuais (lâmpadas de diferentes cores) como CSs, choques elétricos como USs a resposta de condutância da pele (SCRs) como medida de CR e UR replicando os dados do Experimento 1. Em outro laboratório, Oyarzún et al. (2012) realizaram uma replicação do segundo experimento de Schiller et al. (2010,), no qual dois quadrados coloridos foram pareados com choques elétricos (CSa+e $\mathrm{CSb}+$ ) e um outro quadrado nunca foi pareado com o mesmo estímulo (CS-), e no qual o intervalo entre a primeira apresentação de CS sem US na extinção e as demais foi manipulado para apenas um desses estímulos $(\mathrm{CSa}+)$. A única diferença de procedimento entre o estudo de Oyarzún et al. (2012) e o de Schiller (2010, Experimento 2), é que os primeiros usaram dois sons estridentes (de uma criança gritando ou um porco grunhindo) como USs e havia um grupo controle, para o qual não houve manipulação de intervalo para nenhum dos CSs.

Dentre os estudos que não replicaram esses dados encontram-se os de Golkar et al., (2012), Kindt e Soeter, (2013) e Soeter e Kindt, (2011). Nesses estudos, assim como no de Schiller et al. (2010), foi realizada uma manipulação do intervalo entre a primeira apresentação do CS e as demais na extinção, porém houve ressurgência da CR no teste. Um aspecto importante a ser observado, contudo, é que houveram diferenças metodológicas que podem ter influenciado nos resultados. Por exemplo, Kindt e Soeter (2013) realizaram uma replicação do segundo 
experimento de Schiller et al. (2010) utilizando fotos de aranhas como CSs. Ou seja, utilizaram-se de estímulos com os quais alguns participantes já poderiam ter uma história. Além disso, é descrito na literatura que fotos de aranhas, quando pareadas a USs aversivos, passam muito mais rapidamente a ter função de CS e eliciam CRs que demoram muito mais para diminuir em procedimentos de extinção em comparação estímulos tais como fotos de cogumelos, flores ou formas geométricas (Öhman, Fredikson, Hugdahl \& Rimmö, 1976), o que poderia em tese influenciar o teste de ressurgência. No entanto, Golkar et al. (2012), usaram tanto estímulos "neutros" (quadrados coloridos) como estímulos que supostamente teriam função aversiva (faces de medo, Ekman, Sorenson \& Friesen, 1969). Portanto, essas não replicações não podem ser descartadas por variações no procedimento, sugerindo que o fenômeno em estudo precisa ter identificado com maior precisão as variáveis das quais ele é função.

De uma maneira geral, o conjunto de estudos apresentados anteriormente sugere uma estratégia que com alguma frequência tem evitado a ressurgência de CRs após extinção. No aprofundamento desses estudos, é relevante isolar as variáveis independentes que são, de fato, responsáveis pela abolição da ressurgência das CRs. Para isso, o presente estudo ficará centrado na análise das contingências relacionadas ao fenômeno da ressurgência, isto é, das condições sob as quais o fenômeno ocorre. Com isso, espera-se que fique mais destacados os aspectos a serem manipulados na condição de impedi-la.

Com base nos estudos citados, não é possível dizer com precisão qual é(são) a(s) variável(eis) crítica(s) para o enfraquecimento da ressurgência da CR. Os estudos descritos manipularam explicitamente o intervalo entre a primeira apresentação do CS e as demais, mas também houve, mesmo sem ser objeto de análise, uma variação do contexto no qual estava inserido o sujeito. Por exemplo, no estudo de Monfils et al. (2009), após a apresentação do primeiro CS isolado, os ratos foram removidos da caixa experimental, colocados em suas gaiolasviveiro, onde permaneceram durante todo o intervalo programado, sendo em seguida recolocados na caixa experimental, onde foram expostos às apresentações subsequentes do CS sem US. De forma análoga, nos experimentos com sujeitos humanos, após a exposição a um CS sem US, os aparelhos foram desconectados dos participantes e, ao longo de $10 \mathrm{~min}$, ficaram assistindo a um programa de televisão (Oyarzún et al., 2012; Schiller et al., 2010) ou foram removidos para uma sala adjacente, onde ficaram lendo revistas (Kindt \& Soeter, 2013). No estudo de Schiller et al. (2010, Experimento 1), houve um grupo de participantes que assistiu a $10 \mathrm{~min}$ de programa televisivo, e depois esperaram completar 6 horas para retomar o procedimento de extinção. Como não foram descritas as características do ambiente onde esses participantes permaneceram durante 
o intervalo, nem o que poderiam ou não fazer (ou seja, que respostas poderiam ser emitidas, se poderiam sair do laboratório etc), não há como analisar as possíveis relações aí estabelecidas com o ambiente que, ao menos em tese, podem ser responsáveis pelo efeito descrito. O que pode ser concluído pela leitura desses estudos é que tanto os ratos como os humanos foram expostos a um procedimento de extinção respondente pouco convencional que envolveu um maior intervalo entre o primeiro e o segundo CS apresentados sem o US, além de serem removidos do contexto experimental que havia sido pareado repetidas vezes ao US aversivo. Qual dessas variáveis foi a responsável pelo efeito descrito? Os autores atribuem os resultados obtidos ao intervalo entre primeiro e segundo CS, mas não foram realizadas manipulações sistemáticas da mudança de ambiente.

Ao analisar as diferenças entre os estudos que demonstram ressurgência do responder condicional após extinção e aqueles que demonstram inibição duradoura da $\mathrm{CR}$, fica destacada a suposição de que manipulações no contexto durante a extinção podem ser tão importantes quanto o intervalo temporal entre a primeira apresentação do CS sem US e as demais. Especificamente, nos estudos que demonstram ressurgência da CR (em humanos ou ratos), embora diferentes parâmetros de exposição ao CS sem US tenham sido usados (número de exposições, tempo de cada exposição, intervalo entre cada exposição etc), não havia manipulações no contexto durante a extinção. Em alguns casos, a extinção era feita em um contexto diferente de onde havia sido feita a fase da aquisição (Bouton \& Bolles, 1979a, 1979b, 1980), porém o contexto não foi manipulado entre uma exposição ao CS sem US e as demais. Sendo assim, novos estudos precisam ser conduzidos para explorar a relevância das múltiplas variáveis que ficaram misturadas nesse procedimento, tais como o intervalo temporal entre os dois CSs, a retirada temporária do ambiente experimental aversivo condicionado, as características do novo ambiente (nunca pareado ao US aversivo), as atividades possíveis nesse contexto onde o sujeito permanece durante o intervalo, entre outras.

É também merecedor de consideração para novos estudos o fato de que no trabalho original com humanos (Schiller et al., 2010), durante a fase de condicionamento, o CS+ foi pareado ao US apenas em 38\% das tentativas, enquanto o CS- não foi seguido pelo US em 100\% das suas apresentações. Assim, esse delineamento manipulou um CS- de alto poder preditivo (de não-choque), e um CS + de baixo poder preditivo de evento aversivo (cerca de 1/3 de possibilidade de ser seguido por choque). Há demonstração na literatura de que a possibilidade previsão dos estímulos pode ser uma variável que altera a sua aversividade (Badia, Cocker \& Harsh, 1973; Overmier, 1985; Seligman, Maier \& Solomon, 1971). Por exemplo, em humanos, quanto maior o 
grau de imprevisibilidade de um estímulo aversivo, maior a resposta de condutância da pele frente a eles (Shankman, Robison-Andrew, Nelson, Altman \& Campbell, 2011). Em paralelo, alguns estudos demonstraram que $100 \%$ de pareamento entre CS-US pode ter como efeito um decréscimo muito rápido da CR durante a extinção (LaBar, Gatenby, Gore, LeDoux \& Phelps, 1998). Por outro lado, pareamentos intermitentes entre CS-US tornaram a CR mais resistente à extinção (Schiller et al., 2008).

Levando esses aspectos em consideração, a verificação do processo de extinção e da ressurgência da CR não pode deixar de lado essa questão do grau de previsibilidade do US dado o CS. Por exemplo, uma questão a ser respondida experimentalmente é como se daria a ressurgência da CR usando-se as mesmas manipulações de Schiller et al. (2010) durante a extinção se o CS+ tivesse $100 \%$ das suas apresentações seguidas de choque. Ou seja, é importante verificar como que a variação paramétrica dessa porcentagem de pareamento pode se relacionar com a extinção e ressurgência dos fenômenos estudados.

Outra questão importante a ser explorada diz respeito às características físicas dos estímulos manipulados. Conforme descrito anteriormente, no Experimento 2 de Schiller et al. (2010), utilizou-se um delineamento intrasujeito com dois CSs+ (quadrados de diferentes cores), onde se buscou verificar se o procedimento de inibição da ressurgência aplicado a apenas um desses CS+ teria efeito sobre o CS+ não manipulado. Como resultados, os autores obtiveram inibição da ressurgência da CR frente apenas ao estímulo manipulado. Um aspecto a ser destacado é que, nesse estudo, os estímulos podiam ser diferenciados com base em uma propriedade física única (a sua cor). Porém, em um estudo recente, ficou demonstrado que a extinção feita com estímulos que compartilham algumas características físicas (mas não todas) com o CS não é suficiente para evitar a ressurgência do responder condicional (Vervliet \& Greens, 2013). Isso sugere que características físicas discretas dos CSs controlam a ressurgência do responder condicional. Sendo assim, pode-se questionar se os resultados de Schiller et al (2010, Experimento 2) seriam os mesmos caso os estímulos usados como CSs tivessem mais de uma propriedade física que os diferenciasse, ou então, alternativamente, caso compartilhassem diferentes propriedades físicas. Além disso, na fase de teste de ressurgência, seria interessante investigar se um estímulo novo, que tenha uma ou mais propriedades físicas semelhantes com os CSs usados nas fases de condicionamento e extinção, poderia eliciar uma CR (e se essa resposta seria quantitativamente diferente da CR eliciada pelo CS original). Especificamente, pode-se perguntar qual é o efeito de manipulações das semelhanças e diferenças entre os múltiplos $\mathrm{CSs}+$ sobre a generalização da extinção e ressurgência da CR. Além do interesse inerente ao maior conhecimento de processos 
comportamentais, essa questão é de grande relevância para a clínica psicológica, na medida em que estímulos eliciadores presentes na vida são complexos e podem compartilhar propriedades físicas com outros estímulos que fazem parte de múltiplas relações comportamentais. 


\section{OBJETIVO}

O objetivo geral deste trabalho foi dar início a uma série de investigações que permitam isolar experimentalmente algumas das variáveis que podem ser determinantes na maior eficácia do procedimento de extinção, evitando a ressurgência das CRs aversivas. Como o nosso laboratório ainda não tem uma tradição nesse tipo de pesquisa, fez-se necessário iniciar essa linha de investigação com uma replicação (Sidman, 1975) de um dos experimentos protótipos anteriormente citados (Schiller et al., 2010, Experimento 2). Ou seja, procuramos reproduzir no nosso laboratório as condições o mais possivelmente semelhantes às descritas pelos autores. Considerávamos que apenas após termos replicado a inibição da ressurgência relatada por esses estudos é que poderíamos dar início às manipulações que apontamos como necessárias para identificar as variáveis independentes responsáveis por essa inibição. Consideramos a priori que, caso os resultados aqui obtidos não replicassem os descritos na literatura, a etapa seguinte da pesquisa seria identificar os motivos dessa não replicação.

Portanto, o objetivo específico deste projeto foi realizar a replicação do segundo experimento descrito por Schiller et al. (2010), tendo como meta verificar se a ressurgência da CR pode ser alterada pela manipulação do intervalo entre a primeira e as demais apresentações de um dos estímulos condicionais durante extinção. 


\section{MÉTODO}

\section{Participantes}

\subsection{Recrutamento}

Foram convocados trinta e cinco (35) voluntários adultos entre 18 e 38 anos (idade média 26,2 anos, $\mathrm{DP} \pm 6,5$ anos), dos quais 20 eram mulheres, alunos da Universidade de São Paulo (USP), Universidade Nove de Julho (UNINOVE) ou indicados por participantes que haviam participado dos estudos piloto. A convocação foi feita convidando-se os sujeitos a participarem de um experimento sobre comportamento.

\subsection{Critérios de inclusão}

Previamente ao experimento, todos os participantes passaram por uma breve entrevista de triagem que visava garantir que eles preenchiam os seguintes critérios de inclusão: ausência de marca-passo cardíaco ou outros implantes metálicos; ausência de cardiopatia grave ou histórico de crises epilépticas; no caso das mulheres, não ter suspeita de gravidez; não estar em uso de medicações psicoativas (antidepressivos, medicações para ansiedade etc). Esses aspectos foram avaliados por meio de um questionário de triagem, aplicado pelo próprio bolsista (ANEXO B). Durante essa entrevista, o experimentador também verificou que nenhum sujeito tinha lesões cutâneas nas áreas de colocação dos eletrodos, o que inviabilizaria sua participação na pesquisa.

\subsection{Termo de Consentimento Livre e Esclarecido}

Todos os sujeitos foram informados sobre as condições desta pesquisa, concordaram com elas e assinaram o Termo de Consentimento Livre e Esclarecido (ANEXO C) no qual se explicitava que podiam solicitar a interrupção da sua participação a qualquer momento da pesquisa.

\section{Equipamentos}

Foram utilizadas como variáveis independentes a estimulação elétrica (US) e três estímulos condicionais (CSs). A variável dependente foi a resposta de condutância da pele.

A estimulação elétrica foi liberada no pulso direito do participante por meio de um eletrodo bipolar de $8 \mathrm{~mm}$ de diâmetro e $21 \mathrm{~mm}$ de separação entre polos, com presilha de 
borracha, conectado a um estimulador S48 da marca Grass Medical Instruments (West Warrick, Rhode Island, USA) e um estabilizador SIU5 da mesma marca. Para limpeza desse eletrodo e da pele do participante onde o mesmo era fixado, utilizou-se álcool em gel antibacteriano da marca Protex.

Os estímulos condicionais foram três quadrados de diferentes cores. Para controle do efeito da cor, utilizaram-se dois conjuntos diferentes: amarelo, vermelho e azul (conjunto 1); ou laranja, roxo e verde (conjunto 2), que teriam função de $\mathrm{CSa}+, \mathrm{CSb}+$ e $\mathrm{CS}-$, respectivamente. Independente das cores, os quadrados tinham igual tamanho, medindo $11,5 \mathrm{~cm}$ de lado, apresentados na tela de um monitor de 21,5 polegadas com fundo preto. Na ausência desses estímulos, a tela permanecia preta.

A resposta de condutância da pele (SCR) foi registrada por meio de dois eletrodos Ag$\mathrm{AgCl}$ descartáveis, pré-umedecidos com gel condutor da marca Biopac Systems (Goleta, Califórnia) ou eletrodos adesivos Kendall (Covidien, Mansfield, MA, EUA), equivalentes quanto à qualidade de registro (conforme verificado em Estudo Piloto). Foi utilizado esparadrapo para melhor fixação dos eletrodos na pele dos participantes. Esses eletrodos estavam ligados a um módulo de registro GSR100C e ao software AcqKnowledge 4.2, ambos da marca BIOPAC Systems Inc. (Goleta, California, USA), funcionando em um notebook Vaio/Sony com processador Intel(r) Core i5. A apresentação dos CSs, assim como a liberação da estimulação elétrica foi controlada pelo software Superlab 4.5.3 com stimtracker, da marca Cedrus (San Pedro, California, USA), instalado separadamente em um computador PC com processador Intel.

Todos esses equipamentos ficavam alojados em uma sala do Laboratório de Análise Biocomportamental (LABC), no Instituto de Psicologia da USP, a mesma onde se deu a coleta de dados. Ela era dotada de janela, mesa e cadeiras, com ventilação e iluminação adequadas ao conforto humano.

\section{Procedimento}

Em todas as sessões, os participantes permaneceram sentados à frente do monitor que apresentava os estímulos visuais, ficando de costas para os equipamentos de registro/controle da sessão e o experimentador, que acompanhava toda a coleta. À exceção de intervalos fornecidos nas sessões de extinção e teste (detalhados mais adiante), os sujeitos permaneceram toda a sessão, 
conectados aos eletrodos. Ao iniciar a sessão, a sala era escurecida apagando-se a luz ambiente e fechando-se as persianas das janelas.

$\mathrm{O}$ procedimento preparatório era o mesmo em todas as sessões. $\mathrm{O}$ participante era solicitado a lavar as mãos somente com água (sem sabão) no banheiro vizinho à sala de coleta de dados, secando-as com papel toalha. Em seguida, o pesquisador instalava os eletrodos de aquisição seguindo as recomendações do Comitê $A d H o c$ sobre medidas eletrodérmicas da Sociedade para pesquisa psicofisiológica (Society for Psychophysiological Research Ad Hoc Committee on Electrodermal Measures, 2012). Especificamente, os mesmos eram posicionados nas superfícies volares das falanges distais dos dedos indicador e médio da mão esquerda. $\mathrm{O}$ módulo de condutância da pele era conectado a esses eletrodos e o software AcqKnowledge iniciado. Era feito um teste de respiração para verificar se os aparelhos eram capazes de detectar mudanças na atividade elétrica da pele. Esse teste consiste em solicitar ao sujeito que inspire profundamente e solte o ar rapidamente. Este é um procedimento que produz um aumento súbito no nível de condutância da pele que pode ser detectado por inspeção visual do registro gráfico, sendo o método recomendado para verificar a qualidade do sinal durante a aquisição de dados (Dawson et al., 2000; Society for Psychophysiological Research Ad Hoc Committee on Electrodermal Measures, 2012). Quando era possível detectar uma mudança súbita no nível de condutância da pele com esse teste, era iniciada a próxima etapa; em caso negativo, o experimentador verificava a fonte do problema (se algum cabo estava desconectado, por exemplo) e o processo era repetido até que fosse garantido que o sinal estivesse sendo transmitido adequadamente. Os voluntários para os quais na primeira sessão experimental não foi possível detectar mudanças na condutância da pele com esse procedimento não deram continuidade ao experimento. Como o sujeito precisaria ficar parado durante o experimento, era solicitado que ele apoiasse o braço na mesa de modo que ficasse o mais confortável possível e não sentisse necessidade de movimentar-se ao longo da sessão.

Os eletrodos que conduziam o estímulo elétrico (US) eram instalados no início das sessões após a alocação dos eletrodos de registro. Esses eletrodos de estimulação, que tinham formato retangular, eram colocados no pulso direito do participante em posição paralela ao sentido do antebraço, e de modo que ambos os polos estivessem em contato com a pele. Era feita uma esterilização do eletrodo e da pele usando o álcool em gel.

Na primeira sessão experimental de cada participante, era feito um procedimento para ajustar o grau da estimulação elétrica. Especificamente, após a instalação dos equipamentos, era 
feita uma estimulação inicial de $10 \mathrm{~V}$, classificada como muito leve por Schiller et al. (2010), que era gradualmente aumentada em degraus de $5 \mathrm{~V}$ até que o sujeito a considerasse "desconfortável, porém não dolorosa". Essa regulagem foi feita com os participantes sentados olhando para a tela do computador e já com as luzes da sala apagadas, de modo que não pudessem observar em que momento eram feitas as estimulações e nem os valores dos parâmetros do equipamento (voltagem, duração, frequência etc). Independentemente do julgamento dos participantes, o limite máximo da estimulação aceito nessa pesquisa era de $60 \mathrm{~V}$, parâmetro este abaixo do limiar a partir do qual pode haver dano em tecidos do corpo $^{7}$ (UNEP/WHO/IRPA, 1993; Zeidan et al., 2012). O procedimento de ajuste da corrente elétrica foi realizado somente na primeira sessão experimental de cada participante; nas demais sessões, o aparelho foi calibrado de acordo com o ajuste de cada participante antes do experimento (i.e., a estimulação foi mantida constante individualmente para cada participante ao longo do experimento).

Os participantes foram distribuídos aleatoriamente em dois grupos, denominados (experimental e controle). Todos foram submetidos a três sessões (condicionamento, extinção e teste), espaçadas entre si por $24 \mathrm{hr}$, conforme segue.

\section{Dia 1 - Condicionamento.}

Ao ser introduzido no laboratório e sentado frente ao monitor, o participante recebia a seguinte instrução:

"O objetivo deste experimento é examinar como a glândula de suor reage frente a estímulos sensoriais, visuais e táteis. Você não precisa fazer nada com as suas mãos e nem mexer no computador, você só tem que olhar para a tela do computador e prestar atenção nas coisas que você está vendo e nas coisas que você sentir. Alguma dúvida?"

Uma vez que ele/ela se dizia estar pronto para iniciar, o experimentador acionava o programa de controle da sessão, ao longo da qual eram feitas 48 apresentações de estímulos condicionais. Cada apresentação de um estímulo condicional durava $4 \mathrm{~s}$ e compreendia uma tentativa. Ao término de cada tentativa, iniciava-se um intervalo (IET) que variava de $12 \mathrm{~s} \mathrm{a} 14 \mathrm{~s}$. Dois dos CSs apresentados (que eram sempre as cores amarelo e vermelho para os participantes

\footnotetext{
${ }^{7}$ Tendo em vista a voltagem utilizada $(10-60 \mathrm{~V})$ e a resistência da pele humana quando seca, a corrente elétrica aplicada aos participantes ficou entre $1 \mathrm{~mA}$ a $4 \mathrm{~mA}$. O limiar de corrente que produz contração involuntária de grandes grupos musculares gira em torno de 8 a $16 \mathrm{~mA}$ e um choque grave, que produz dificuldades de respiração gira em torno de 12 a $23 \mathrm{~mA}$ (UNEP/WHO/IRPA 1993; Zeidan et al., 2012). Para maiores detalhes, consultar ANEXO D.
} 
expostos ao conjunto 1 de cores; e laranja e roxo para sujeitos expostos ao conjunto 2) foram pareados com o US (CSa+ e $\mathrm{CSb}+$ ); o terceiro quadrado (azul para os participantes expostos ao conjunto 1 de cores e verde para os expostos ao conjunto 2) nunca foi pareado com o US (CS-). Nas tentativas em que houve pareamento, o US foi apresentado durante os últimos $0,2 \mathrm{~s}$ da apresentação do CS, com uma corrente de 50 pulsos/segundo, com as apresentações do US e CS terminando concomitantemente. Ou seja, o CS era apresentado por 3,8 s sem o US, o que era imediatamente seguido de um período de 0,2 s em que CS e US eram apresentados juntos. Terminado esse período, o US terminava concomitantemente ao desaparecimento do CS, com a tela do computador se apagando. O período em que a tela do computador ficava compreendia o IET.

A sessão ocorreu em três etapas ininterruptas e não sinalizadas. Na primeira etapa, todos os $\mathrm{CSs}(\mathrm{CSa}+, \mathrm{CSb}+$ e CS-) foram apresentados três vezes cada sem o US (habituação). Em seguida, todos foram apresentados quatro vezes cada, sendo que o $\mathrm{CSa}+$ e $\mathrm{CSb}+$ foram pareados com o US em 100\% das suas apresentações (condicionamento 100\%). Na última etapa, todos os CSs foram apresentados nove vezes cada, sendo que o $\mathrm{CSa}+$ e o $\mathrm{CSb}+$ pareados intermitentemente com o US, em quatro dessas apresentações (45\% de pareamento). Nas três etapas, os CSs foram apresentados de maneira pseudorrandômica, de modo que nenhum estímulo foi apresentado mais do que duas vezes seguidas $\mathrm{Na}$ terceira etapa, além desses critérios, foi feita a distribuição garantindo-se que os pareamentos dos $\mathrm{CSa}+$ e $\mathrm{CSb}+$ com o US se dessem de forma relativamente equilibrada ao longo do período.

Essa sessão teve duração aproximada de 20 min (dos quais sete eram de instalação dos aparelhos e regulagem do US, e 13 min rodando o experimento).

\section{Dia 2 - Extinção}

Nesta sessão, o sujeito era solicitado a se sentar frente ao monitor, os eletrodos eram conectados nele como na sessão anterior, sendo fornecida a seguinte instrução:

"Da mesma forma que ontem, você não precisa fazer nada com as mãos durante o experimento, apenas olhar para a tela do computador e prestar atenção nas coisas que você está vendo e nas coisas que você sentir." 
Ao longo da sessão, foram feitas 45 apresentações dos estímulos condicionais, sendo 15 apresentações de cada, porém nenhuma apresentação do US. Os CSs foram apresentados por quatro segundos cada, com um intervalo entre apresentações variando entre 12 s e 14 s. Essa apresentação se deu de forma diferenciada entre os grupos, conforme segue: No grupo experimental, a sessão iniciava com a apresentação de um $\mathrm{CSa}+$ e um CS-, em ordens alternadas entre sujeitos, seguidos pela tela do monitor que ficava preta e o experimentador que dava a seguinte instrução:

"Agora temos um intervalo programado de $10 \mathrm{~min}$. Aqui estão algumas revistas que você pode escolher para ler durante esse intervalo. Se você não quiser, não precisa ler nada, o importante é fazer um intervalo em um outro local que eu vou te levar. Mas antes, vou desligar os aparelhos."

Os eletrodos eram retirados do participante e o estimulador elétrico desligado. Em seguida, o participante era levado até uma área próxima ao laboratório, dotada de poltronas e cadeiras, onde aguardava o experimentador chamá-lo de volta à sessão. Durante esse intervalo, ele podia ler alguma das revistas que eram disponibilizadas pelo experimentador, porém essa atividade não era obrigatória. O participante também não era obrigado a ficar sentado, podendo se movimentar durante o intervalo. Contudo, recomendava-se que ele não ficasse passeando pelo instituto. Se fosse ao banheiro, recomendava-se que retornasse logo em seguida ao local designado. Além disso, solicitava-se que ele/ela não consumisse comida ou bebidas (incluindo café) e nem fizessem uso de cigarros. Terminado o intervalo, o experimentador o levava de volta à sala experimental e as seguintes instruções eram fornecidas:

“Terminamos o intervalo. Vou religar os aparelhos e nós vamos fazer o restante da sessão."

Os aparelhos eram religados e reconectados ao participante. A partir de então, o experimentador dizia que a sessão teria continuidade e dava o comando para começar. Retomavase à apresentação dos $\mathrm{CSs}(\mathrm{CSa}+, \mathrm{CSb}+$ e CS-) com os parâmetros anteriormente especificados, completando-se as 45 apresentações de cada um. Como já havia sido feita uma apresentação dos $\mathrm{CSa}+$ e CS- antes do intervalo, nessa etapa seguiram-se $14 \mathrm{CSa}+, 15 \mathrm{CSb}+$ e $14 \mathrm{CS}$-. Os estímulos foram apresentados de maneira pseudorrandômica, de modo que nenhum estímulo fosse apresentado mais do que duas vezes seguidas.

Os participantes do grupo controle passaram por procedimento semelhante, porém sem a interrupção de 10 min descrita para o grupo anterior. Para esse grupo, a sessão foi contínua. 
Essa sessão teve duração aproximada de 15 min para o grupo controle (três min de instalação e 12 de rodagem do programa) e 25 min para o grupo experimental (três min de preparação do experimento, $10 \mathrm{~min}$ de intervalo, e $12 \mathrm{~min}$ rodando o programa).

\section{Dia 3 - Teste}

Após o sujeito ter sido ligado aos aparelhos, o experimentador apresentou a seguinte instrução:

"Da mesma forma que ontem, você não precisa fazer nada com as mãos durante o experimento, apenas olhar para a tela do computador e prestar atenção nas coisas que você está vendo e nas coisas que você sentir."

A tela do computador permaneceu preta, porém o US foi apresentado quatro vezes, sendo cada estimulação uma corrente de 50 pulsos/segundo e duração de $200 \mathrm{~ms}$. A intensidade do estímulo elétrico foi a mesma ajustada pelo participante na primeira sessão experimental. Após esses quatro USs, o experimentador forneceu as mesmas instruções usadas na extinção (Dia 2) para avisar aos sujeitos de que haveria um intervalo de $10 \mathrm{~min}$, ficando os sujeitos na mesma área utilizada na segunda sessão, fora da sala experimental, com revistas disponibilizadas pelo experimentador. Após esse intervalo, os sujeitos foram reconduzidos à sala de experimentação e os aparelhos foram religados. $\mathrm{O}$ experimentador informou que a sessão teria continuidade e deu o comando para iniciar. Os sujeitos passaram por um novo procedimento de extinção, no qual os estímulos $\mathrm{CSa}+, \mathrm{CSb}+$ e CS- foram apresentados sem o US 15 vezes cada, com duração e intervalo semelhantes aos já descritos, completando 45 apresentações de CS.

Os critérios de randomização foram os mesmos usados na sessão de extinção, com a diferença que o primeiro estímulo apresentado no teste foi o CS- e a resposta frente a ele não foi incluída na análise. Esse procedimento foi utilizado pelo fato de a primeira apresentação de estímulo geralmente eliciar um aumento na condutância da pele independentemente se CS+ou CS-, efeito esse denominado "respostas de orientação" (Boucsein, 2012). Ou seja, há alta probabilidade de o sujeito responder a qualquer primeiro estímulo que seja apresentado, não necessariamente sendo essa resposta dependente de uma relação com a história anterior de pareamento com o US (Schiller et al., 2013; Schiller et al., 2010; Schiller et al., 2012). 
Esta sessão teve duração aproximada de 28 min (dos quais cinco min eram de instalação dos aparelhos, 13 min rodando o programa e 10 min de intervalo).

O delineamento do estudo é apresentado esquematicamente na Tabela 1.

Tabela 1 - Representação esquemática do delineamento do estudo

\begin{tabular}{|c|c|c|c|}
\hline $\begin{array}{c}\text { Dia } 1 \\
\text { (condicionamento) }\end{array}$ & $\begin{array}{c}\text { Dia } 2 \\
\text { (extinção }\end{array}$ & & $\begin{array}{c}\text { Dia } 3 \\
\text { (teste de ressurgência) }\end{array}$ \\
\hline $\begin{array}{c}\text { Grupos } \\
\text { experimental e controle }\end{array}$ & Grupo experimental & Grupo controle & $\begin{array}{c}\text { Grupos } \\
\text { experimental e controle }\end{array}$ \\
\hline $\begin{array}{c}3 \mathrm{CSa}+, 3 \mathrm{CSb}, 3 \mathrm{CS}- \\
\text { ( sem US) } \\
\downarrow \\
4 \mathrm{CSa}+\mathrm{e} 4 \mathrm{CSb}+ \\
(100 \% \text { pareamento com US), } \\
4 \mathrm{CS}- \\
\downarrow \\
\text { 9CSa+, } 9 \mathrm{CSb}+ \\
\text { (45\% pareamento com US), } \\
\text { 9CS- }\end{array}$ & $\begin{array}{c}1 \mathrm{CSa}+1 \mathrm{CS}- \\
\text { (sem US) } \\
\downarrow \\
\text { (intervalo } 10 \mathrm{~min}) \\
\downarrow \\
\begin{array}{c}14 \mathrm{CSa}+, 15 \mathrm{CSb}+\mathrm{e} 14 \mathrm{CS}- \\
\text { (sem US) }\end{array}\end{array}$ & $\begin{array}{c}15 \mathrm{CSa}^{+}, 15 \mathrm{CSb}^{+}, 15 \mathrm{CS}- \\
\text { (sem US) }\end{array}$ & $\begin{array}{c}4 \mathrm{US} \\
\text { (sem CS) } \\
\downarrow \\
\text { (intervalo } 10 \mathrm{~min} \text { ) } \\
\downarrow \\
15 \mathrm{CSa}+, 15 \mathrm{CSb}+, 15 \mathrm{CS}- \\
\text { (sem US) }\end{array}$ \\
\hline
\end{tabular}

Conforme mostrado no ANEXO E, os procedimentos descritos neste projeto foram aprovados pelo Comitê de Ética em Pesquisa Envolvendo Seres Humanos, da Faculdade de Filosofia Ciência e Letras de Ribeirão Preto (FFCLRP), Universidade de São Paulo, em 03/08/2011 (Processo CEP-FFCLRP n ${ }^{0}$ 594/2011 - 2011.1.1817.59.3).

\section{Avaliação das respostas de condutância da pele}

Os registros gráficos das respostas de condutância da pele foram analisados offline com o software AcqKnowledge 4.2 (BIOPAC Systems Inc.). Previamente à análise dos dados, esses registros foram filtrados com um filtro de baixa frequência (Low-Pass Filter) e suavizados de modo a eliminar artefatos e interferências no sinal. A amplitude dessas respostas frente ao US ou CS foram as medidas da UR e CR, respectivamente. Essas amplitudes foram determinadas manualmente selecionando a diferença entre a base e o pico do maior formato de onda (medido em microsiemens, $\mu \mathrm{S}$ ) cujo início tivesse ocorrido num intervalo entre 0,5 e 4,5 s após a apresentação de um estímulo. Por formato de onda, entende-se um aumento no nível condutância da pele até um pico seguido de um decréscimo mais lento (Boucsein, 2012; Dawson et al., 2000). O critério mínimo de resposta era $0,02 \mu \mathrm{S}$, isto é, se no intervalo de interesse houvesse um 
aumento mínimo de $0,02 \mu \mathrm{S}$ após apresentação do US ou CS, considerou-se que houve eliciação de resposta e o valor da diferença entre a base e o pico foi computado. Aumentos na condutância da pele menores que $0,02 \mu \mathrm{S}$, diminuição da condutância da pele ou um registro estável durante o intervalo de interesse não eram considerados como respostas e eram categorizados como valor zero.

Conforme feito por Schiller et al. (2010), as respostas condicionais (CRs) foram mensuradas apenas frente aos CSs não pareados com o US. As respostas incondicionais (URs) foram mensuradas após a apresentação do US. Neste caso, foi medida a diferença pico-base do maior comprimento de onda que ocorreu no intervalo de $0,5 \mathrm{~s}$ a 4,5 s após a apresentação do US. Dado que as análises foram feitas manualmente, foi feita uma avaliação cega em relação ao tipo de CS para evitar um viés de análise. Isto é, no momento em que os formatos de onda foram selecionados, o experimentador sabia apenas que havia ocorrido um CS ou um CS pareado a um US; sem indicações sobre qual CS havia sido o apresentado (se $\mathrm{CSa}+, \mathrm{CSb}+$ ou $\mathrm{CS}-$ ). O experimentador só teve acesso a essa informação após os formatos de onda terem sido avaliados.

Seguindo ainda os procedimentos de Schiller et al. (2010), os valores brutos das respostas de condutância da pele foram transformados em raízes quadradas de modo a normalizar as distribuições. Em seguida, os valores resultantes foram transformados dividindo-se cada um pela média das raízes quadradas das respostas incondicionais. Este último procedimento foi realizado como uma forma de obter uma medida de resposta condicional relativa associada às respostas incondicionais de cada participante (Olsson, Ebert, Banaji, \& Phelps, 2005).

\section{Análise dos dados}

Tomando-se por base os estudos produzidos na área, conduzimos primeiramente análises qualitativas e quantitativas com base nos resultados dos grupos. Porém, consideramos também relevante fazer essas análises sobre dados individuais. Em ambas, o critério mínimo para se dizer que havia uma diferença entre estímulos (ou entre fases) foi de $0,1 \mu \mathrm{S}$, conforme utilizado por Schiller et al. (2010).

Por se tratarem de dados de poucos indivíduos, com distribuição da amostra não conhecida, as análises estatísticas foram realizadas com uma série de testes não-paramétricos para identificar possíveis tendências dentro das variáveis de interesse (Brunner \& Langer, 2000; Rosa, 2001). Em todas essas análises, adotou-se nível de significância de $\alpha=5 \%$. Os testes utilizados foram: 1) 
Teste de Friedman, na fase de condicionamento, sendo as médias das CRs frente aos CSs comparadas em cada grupo separadamente; 2) Teste de Wilcoxon, utilizado para comparar as fases de condicionamento e extinção, e extinção e teste, tanto para as CRs frente aos $\mathrm{CSa}+, \mathrm{CSb}+$ e CS-, como para as URs frente ao US; 3) Teste de Mann-Whitney para comparação entre grupos em relação às respostas a cada estímulos ( $\mathrm{CSa}+, \mathrm{CSb}+$ e $\mathrm{CS}-)$ e ao US. A análise dos dados foi feita com o pacote estatístico SPSS (Statistical Package for Social Sciences) para Windows versão 20.0 ou software $R$ versão 2.6.0 ( $R$ Development Core Team, 2007) ${ }^{8}$.

\footnotetext{
${ }^{8}$ Essa análise foi feita com a supervisão de dois especialistas nesse tipo de tratamento de dados de pesquisa: o Dr. Vinicius Frayze David, estatístico disponibilizado pelo IPUSP para auxílio aos pesquisadores, e pelo Prof. Jony Arrais, professor assistente do Departamento de Estatística do Instituto de Matemática e Estatística da Universidade Federal Fluminense.
} 


\section{RESULTADOS}

Dos 35 sujeitos recrutados para participar do experimento, dois não foram submetidos aos procedimentos experimentais, um porque não foi possível observar mudanças visíveis na condutância da pele no teste de respiração na primeira sessão experimental (não respondedor) e outro porque não foi possível obter respostas frente ao US (estimulação elétrica) mesmo com o estimulador regulado na voltagem máxima $(60 \mathrm{~V})$. Outros dois sujeitos não retornaram às sessões experimentais após o primeiro dia do experimento (dropout). Sendo assim, 31 sujeitos efetivamente participaram de todas as fases experimentais.

Dentre eles, apenas 11 foram selecionados para a análise de ressurgência a ser aqui efetuada. O motivo dessa seleção foi coerência com a lógica do delineamento aqui proposto: para se analisar a ressurgência, era necessário que o participante houvesse demonstrado condicionamento na primeira sessão e extinção na segunda. Além disso, foi critério de seleção que a resposta condicional ocorresse de forma indiscriminada frente aos dois $\mathrm{CSs}^{+}+$. Assim, tomandose por base o estudo de Schiller et al. (2010), foram excluídos os participantes que na primeira sessão (Dia 1) não mostraram condicionamento, ou seja, apresentaram 1) maior CR frente ao CSque a um ou ambos os $\mathrm{CS}+(\mathrm{CS}->\mathrm{CSa}+\mathrm{e} / \mathrm{ou} \mathrm{CS}->\mathrm{CSb}+)$; 2) pouca diferença na $\mathrm{CR}$ frente aos CSs+ em comparação ao CS- (menor que $0,1 \mu \mathrm{s}$ ). Também foram excluídos os participantes que mostraram responder diferenciado entre ambos os $\mathrm{CSs}^{+}$, ou seja, diferença maior que $0,1 \mu$ s entre $\mathrm{CSa}+\mathrm{e} \mathrm{CSb}+$. Para calcular essas diferenças, foram utilizadas as médias das cinco tentativas em que os CSs+ ocorreram sem o US, ao final da sessão de condicionamento; foram usadas também as cinco últimas apresentações do CS-. Na sessão de extinção (Dia 2), foram excluídos da análise final os sujeitos cujos resultados mostraram CR de maior amplitude na presença dos CS + do que do CS- (CSa+ > CS- ou CSb+ > CS-). Para essa avaliação, foi utilizado o dado da última apresentação de cada estímulo na sessão de extinção.

Aplicados esses critérios, 17 participantes foram excluídos da análise de ressurgência em função dos seus resultados na primeira sessão: oito porque não cumpriram critérios mínimos de condicionamento, e nove porque havia evidência de condicionamento somente para um CS+ e não para o outro, ou havia evidência de condicionamento diferencial para um dos CSs + . Três participantes foram removidos da análise em função dos seus resultados na sessão de extinção. Portanto, a amostra final, que será aqui analisada, foi composta por 11 sujeitos com idade média 
25,1 anos, DP \pm 5 anos, sendo três mulheres e oito homens. Desses participantes, cinco estavam alocados no grupo controle e seis no grupo experimental ${ }^{9}$.

Conforme descrito anteriormente, foram usados dois conjuntos de cores de modo a controlar a variável cor dos CSs. Ao analisar os 11 sujeitos que compuseram a amostra final, não identificamos nenhum efeito sistemático com uma ou outra cor em nenhum dos dois grupos.

Antes de iniciar o experimento, obteve-se que, em média, os sujeitos de ambos os grupos não apresentaram diferenças quanto à regulagem da voltagem do US (grupo controle: média 28,3, $\mathrm{DP} \pm 3,5$; grupo experimental: média $25,08 \mathrm{DP} \pm 6,3$ ). A Figura 1 mostra as amplitudes médias das URs (frente ao US) ao longo das fases de condicionamento e teste apresentadas pelos sujeitos. A UR foi emitida com alguma variação na sua amplitude, com médias mínimas e máximas entre 0,6 e $1,1 \mu \mathrm{S}$.

${ }^{9}$ Os dados dos demais 20 sujeitos não foram utilizados neste estudo, mas servirão para análises posteriores da eficácia dos procedimentos empregados, dado que $2 / 3$ dos participantes produziram resultados que não atenderam ao critério básico de evidências de condicionamento e extinção respondentes. 


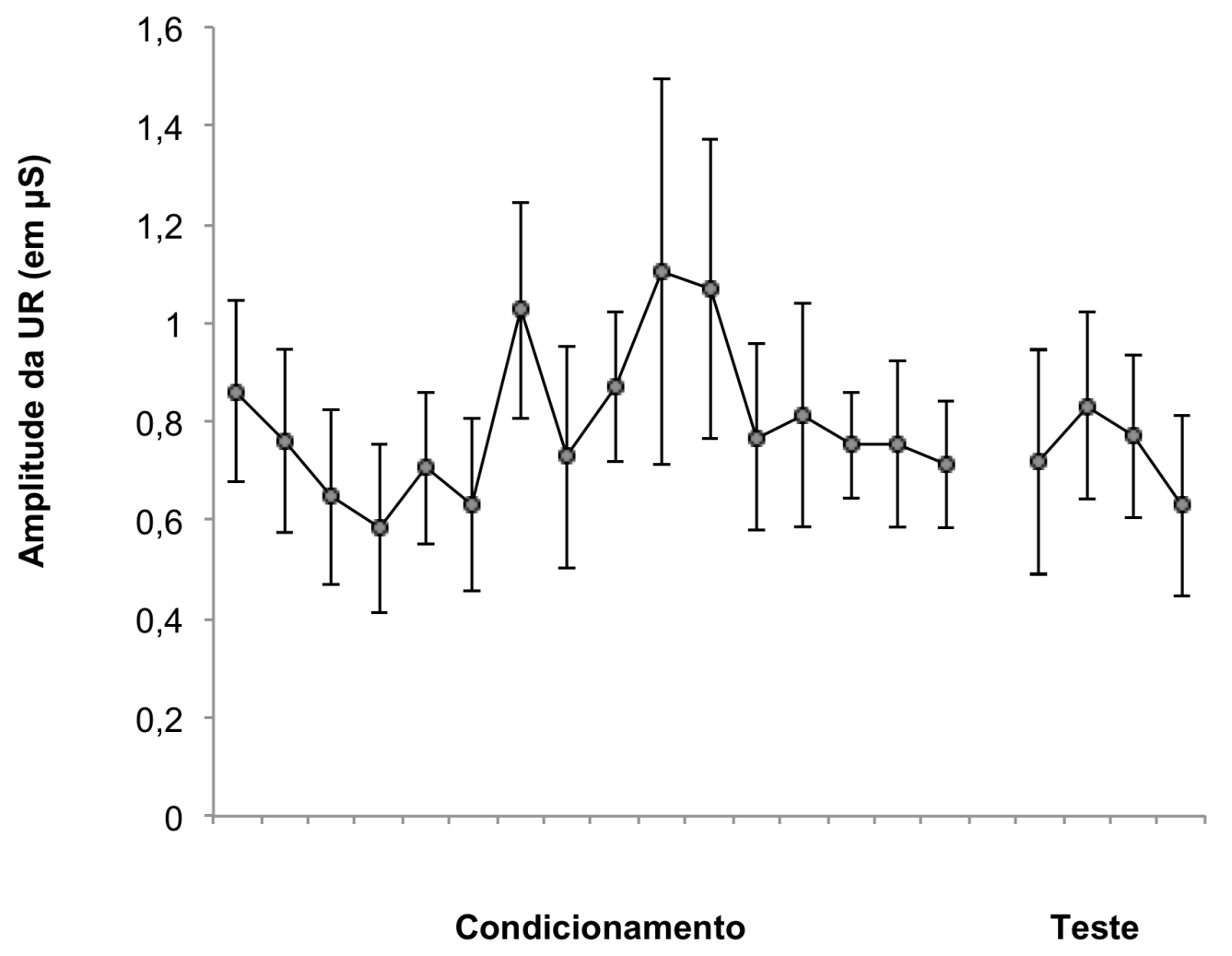

Figura 1 - Amplitude média (e erros-padrão) das respostas incondicionais (URs), medidas em $\mu \mathrm{S}$, ao longo das fases de condicionamento e teste apresentada por todos os sujeitos.

A Figura 2 apresenta as amplitudes médias (e erros-padrão) das respostas incondicionais nas fases de condicionamento e teste, e as amplitudes médias das respostas condicionais frente aos estímulos condicionais ( $\mathrm{CSa}+, \mathrm{CSb}+, \mathrm{CS}-)$ nas fases de condicionamento (média das cinco apresentações do $\mathrm{CSa}+$ e $\mathrm{CSb}+$ sem US e das cinco últimas apresentações do CS-), extinção (última apresentação de cada CS) e teste (primeira apresentação de cada CS) dos sujeitos dos grupos controle e experimental. Os resultados apontam que em média as amplitudes das URs são maiores que as amplitudes médias das CRs na fase de condicionamento em ambos os grupos (grupo controle: $\mathrm{UR}=0,79, \mathrm{CSa}+=0,44, \mathrm{CSb}^{+}=0,53$ e $\mathrm{CS}-=0,08 \mu \mathrm{S}$; grupo experimental: $\mathrm{UR}=1,35, \mathrm{CSa}+=0,45, \mathrm{CSb}+=0,47, \mathrm{CS}-=0,12 \mu \mathrm{S})$. O mesmo ocorreu na fase de teste, com as amplitudes médias das URs sendo maiores que as amplitudes médias das CRs (grupo controle: $\mathrm{UR}=0,73, \mathrm{CSa}+=0,58, \mathrm{CSb}+=0,44, \mathrm{CS}-=0,38 \mu \mathrm{S}$; grupo experimental: $\mathrm{UR}=0,87, \mathrm{CSa}+=0,49$, $\mathrm{CSb}+=0,58, \mathrm{CS}-=0,29 \mu \mathrm{S})$. Na fase de condicionamento, as amplitudes médias das URs do grupo experimental foram maiores que as amplitudes médias das URs no grupo controle (UR grupo 
controle $=0,79 \mu \mathrm{S}$, UR grupo experimental $=1,35 \mu \mathrm{S}$ ). O mesmo ocorre na fase de teste, porém as diferenças são mais discretas (UR grupo controle $=0,73 \mu \mathrm{S}$, UR grupo experimental=0,87 $\mu \mathrm{S}$ ).

Quanto às CRs, nas duas primeiras sessões os sujeitos de ambos os grupos tiveram desempenho semelhante entre si: amplitudes médias maiores das CRs frente ao $\mathrm{CSa}+\mathrm{e} \mathrm{CSb}+\mathrm{do}$ que frente ao CS- no final da fase de condicionamento, e queda para zero da amplitude de todas as CRs na fase de extinção. Na última sessão, ambos os grupos mostraram aumento da amplitude da CR média frente a todos os estímulos, inclusive frente ao CS-, que nunca foi pareado ao choque. Comparativamente, na fase de teste, a amplitude média da CR foi menor frente ao CS- (mais acentuadamente no grupo experimental), sendo relativamente equivalente frente aos dois CS+.

Estatisticamente, não foram significantes as diferenças entre a amplitude média da UR no condicionamento e a amplitudes média da UR no teste para o grupo controle. Para o grupo experimental, a diminuição na amplitude média da UR do condicionamento para o teste foi significante $(p<0,05)$. Embora haja uma diferença observada entre os grupos controles e experimental quanto às amplitudes médias das URs no condicionamento, esses resultados não atingiram significância estatística. Tampouco foram significantes as diferenças entre os grupos experimental e controle quanto às amplitudes médias das URs na fase de teste.

Quanto às CRs, em ambos os grupos foram diferentes as amplitudes da CR em função do CS apresentado (Controle: $\chi^{2}(2)=7,6, p=0,022$; Experimental: $\chi^{2}(2)=9,0, p=0,011$ ), sendo que essa diferença se deu entre a CR frente ao CS- e ambas as CRs frente aos CSs $+(p<0,05)$, que não diferiram entre si. As CRs diferiram entre as fases de condicionamento e extinção em ambos os grupos $(p<0,05)$. Na fase de teste, não foram encontradas diferenças entre as CRs frente aos três estímulos. Em todas as sessões, não foram encontradas diferenças entre os grupos. 


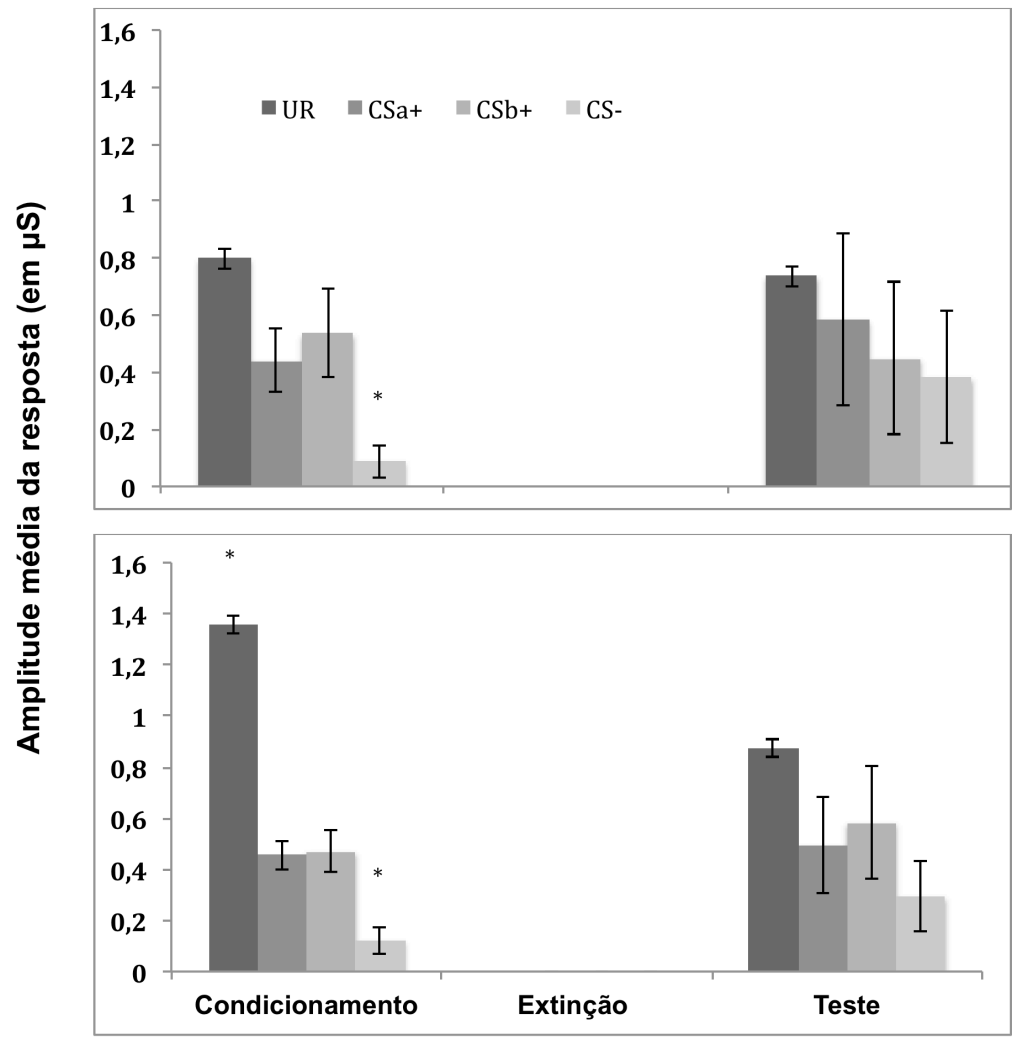

CONTROLE

EXPERIMENTAL

Figura 2 - Amplitude média (e erro-padrão) das respostas incondicionais (URs), medida em $\mu \mathrm{S}$, frente ao US, nas fases de condicionamento e teste, e amplitude média (e erro-padrão) das respostas condicionais (CRs) frente ao $\mathrm{CSa}+, \mathrm{CSb}+$ e CS- nas fases de condicionamento (média das cinco apresentações dos CSs + sem US e das últimas cinco apresentações do CS-), extinção (última apresentação de cada CS) e teste (primeira apresentação de cada CS). * Diferença estatisticamente significante entre $\mathrm{CSa}+, \mathrm{CSb}+$ e CS- no condicionamento em ambos os grupos $(p<0,05)$ e diferença estatisticamente significante entre grupos controle e experimental quanto às amplitudes médias das URs na fase de condicionamento $(p<0,05)$.

Em resumo, esses resultados da Figura 2 confirmam que a amostra final foi composta por sujeitos que apresentaram evidências de condicionamento e extinção respondentes, com igual proporção de resposta frente aos dois CS+, indicando que havia as condições necessárias ao estudo da ressurgência na última sessão. Porém, os resultados nesse teste não confirmaram a ressurgência: embora a comparação entre as amplitudes das CRs apresentadas na última tentativa de extinção com a primeira tentativa da fase de teste mostre aumento das CRs, esse aumento não pode caracterizar o fenômeno de ressurgência, dado que se deu de forma indiscriminada frente aos três CSs, inclusive o CS-, que nunca foi pareado ao choque.

A Figura 3 expande os dados apresentados anteriormente, aqui sendo mostradas as amplitudes médias das CRs frente a todas as apresentações dos estímulos ao longo do experimento. $\mathrm{Na}$ sessão de condicionamento, ambos os grupos mostram maiores amplitudes de CRs iguais 
frente aos $\mathrm{CSa}+$ e $\mathrm{CSb}+$ (nas cinco apresentações não pareadas ao US), e menores amplitudes frente ao CS- (nas últimas cinco apresentações desse estímulo). Na fase de extinção, ambos os grupos mostram decréscimo do responder condicional ao longo das apresentações dos três CSs, mostrando ausência da resposta (amplitude zero) frente à última apresentação de cada CS. Na fase de teste, houve aumento das amplitudes das CRs frente aos três estímulos condicionais, não apenas em comparação à fase final da extinção como também em relação à fase de condicionamento. Ao longo dessa sessão, repetiu-se o padrão visto na fase de extinção, ou seja, redução sistemática das amplitudes das CRs frente à apresentação dos CSs sem o US. Porém, esse efeito no teste não foi igual nos dois grupos: embora não difiram quanto à magnitude da CR na primeira apresentação dos três CSs, essa medida foi reduzida em maior intensidade, e em menos tentativas, no grupo experimental comparativamente ao grupo controle. Em ambos os grupos, é notável o fato de que as CRs na última fase do estudo (teste) se deram de forma indiscriminada frente aos três CS. Em relação ao CS-, destaque-se que as CRs eliciadas por ele no teste foram de maior magnitude do que na fase de condicionamento. 


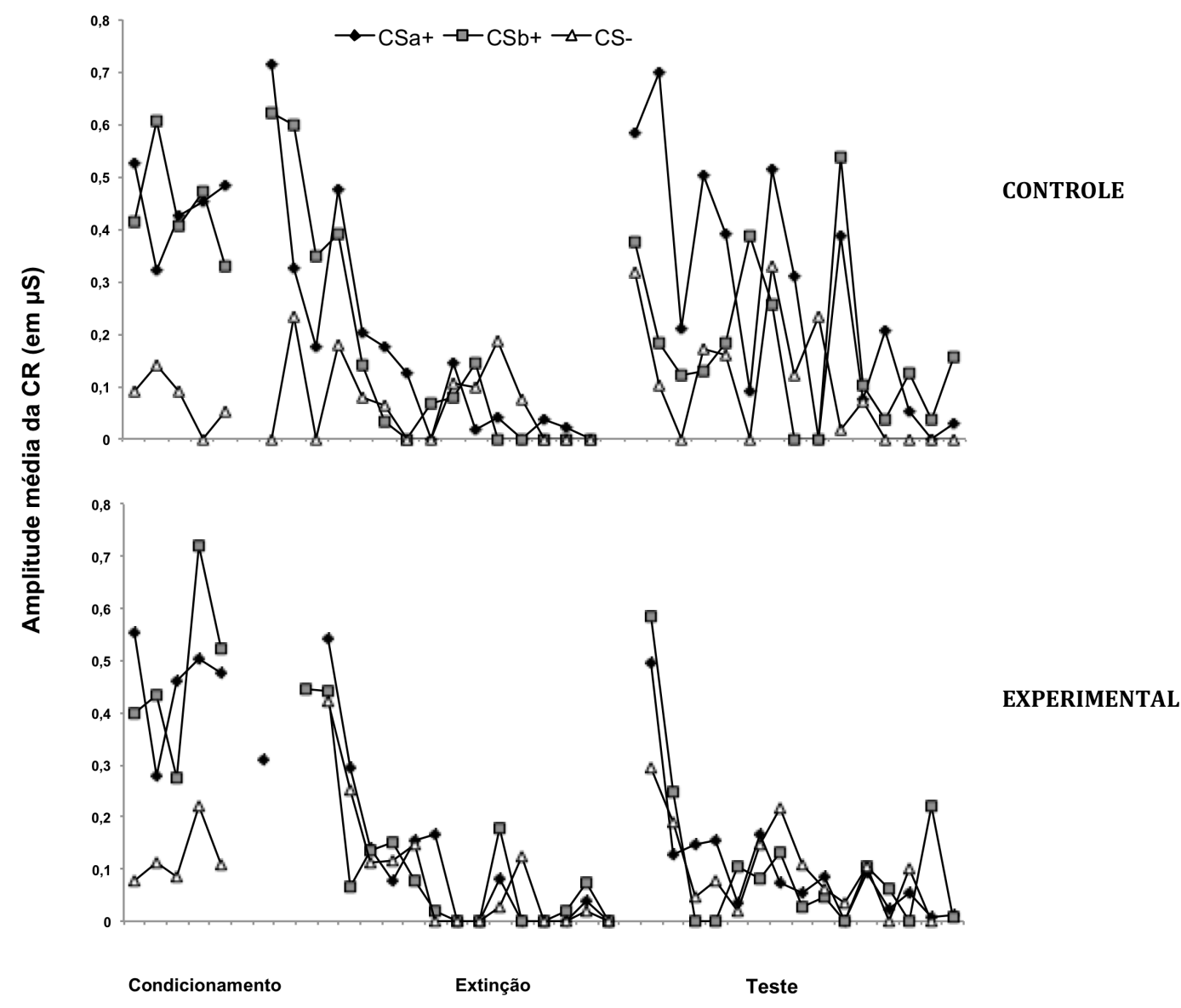

Figura 3 - Amplitudes médias das CRs, medida em $\mu \mathrm{S}$, frente ao $\mathrm{CSa}+, \mathrm{CSb}+$ e CS- ao longo das fases de condicionamento (cinco apresentações dos CSs sem US), extinção e teste apresentadas pelos sujeitos dos grupos controle (parte superior) e experimental (parte inferior). O ponto isolado refere-se à resposta frente ao CSa+ apresentado isoladamente (com intervalo de $10 \mathrm{~min}$ ) no início da sessão de extinção apenas para os sujeitos do grupo experimental.

Os resultados individuais (Figuras 4 e 5) mostram que os padrões comportamentais descritos anteriormente para os grupos não se aplicam a todos os participantes, que mostram diversas diferenças entre si. Como os participantes diferiram entre si principalmente na fase de teste, essas figuras mostram os dados apresentados em ordem decrescente de acordo com a amplitude da CR nessa fase. Na Figura 4, estão plotados os dados dos cinco participantes que compuseram o grupo controle, relativos às amplitudes das CRs ao longo das fases de condicionamento (cinco apresentações dos $\mathrm{CSa}+\mathrm{e} \mathrm{CSb}+\mathrm{sem} \mathrm{US}$, e últimas cinco apresentações do CS-), extinção e teste. Comparando-se as amplitudes das CRs na última e na primeira apresentações de cada CS, na extinção e no teste, respectivamente, verifica-se que dois participantes (Sujeitos 6 e 10) não mostram alteração na CR, mantendo praticamente em todas as apresentações dos CSs o padrão da extinção (não ressurgência). Algumas CRs foram eliciadas, 
mas de forma esporádica, não sistemática. Nas fases de condicionamento, o Sujeito 6 apresentou mais claramente um padrão de condicionamento diferencial em comparação ao Sujeito 10. Além disso, o sujeito 6 demorou mais para apresentar o efeito da extinção em comparação ao sujeito 10 na segunda sessão experimental.

Os outros três sujeitos (Sujeitos 1, 5 e 34) apresentaram aumento da amplitude da CR (mínimo de $0,1 \mu \mathrm{S}$ ) no teste. Os Sujeitos 1 e 5 mostraram esse aumento mais acentuado e de forma indiscriminada frente aos três CSs, com redução mais acentuada apenas no terço final. Diferentemente, o Sujeito 34 apresentou aumento (com baixa magnitude) da CR apenas frente ao $\mathrm{CSa}+$ na primeira apresentação de estímulos no teste $(\mathrm{CSa}+=0,30, \mathrm{CSb}+=0,0$ e $\mathrm{CS}-0,0 \mu \mathrm{S})$. Contudo, é notável que, para esse sujeito, o $\mathrm{CSa}+$ eliciou responder nas últimas tentativas do condicionamento, enquanto que o $\mathrm{CSb}+$ não.

Apesar de terem um padrão parecido na fase de teste, os sujeitos 1 e 5 diferiram entre si nas duas fases iniciais: as médias das CRs cumpriram os critérios de condicionamento e extinção aqui usados, mas é notável que o Sujeito 1 não apresentou CRs frente aos $\mathrm{CSs}+$ todas as vezes que esses estímulos foram apresentados sem o US na fase de condicionamento. Além disso, nota-se nos dados apresentados por esse sujeito que já no início da extinção há um aumento no responder frente aos três estímulos condicionais, incluindo o CS-, que não havia sido pareado ao US na fase anterior. O Sujeito 5, por outro lado, apresentou diferenças consistentes entre os CSs+ e o CS- no condicionamento, mas não na extinção. 

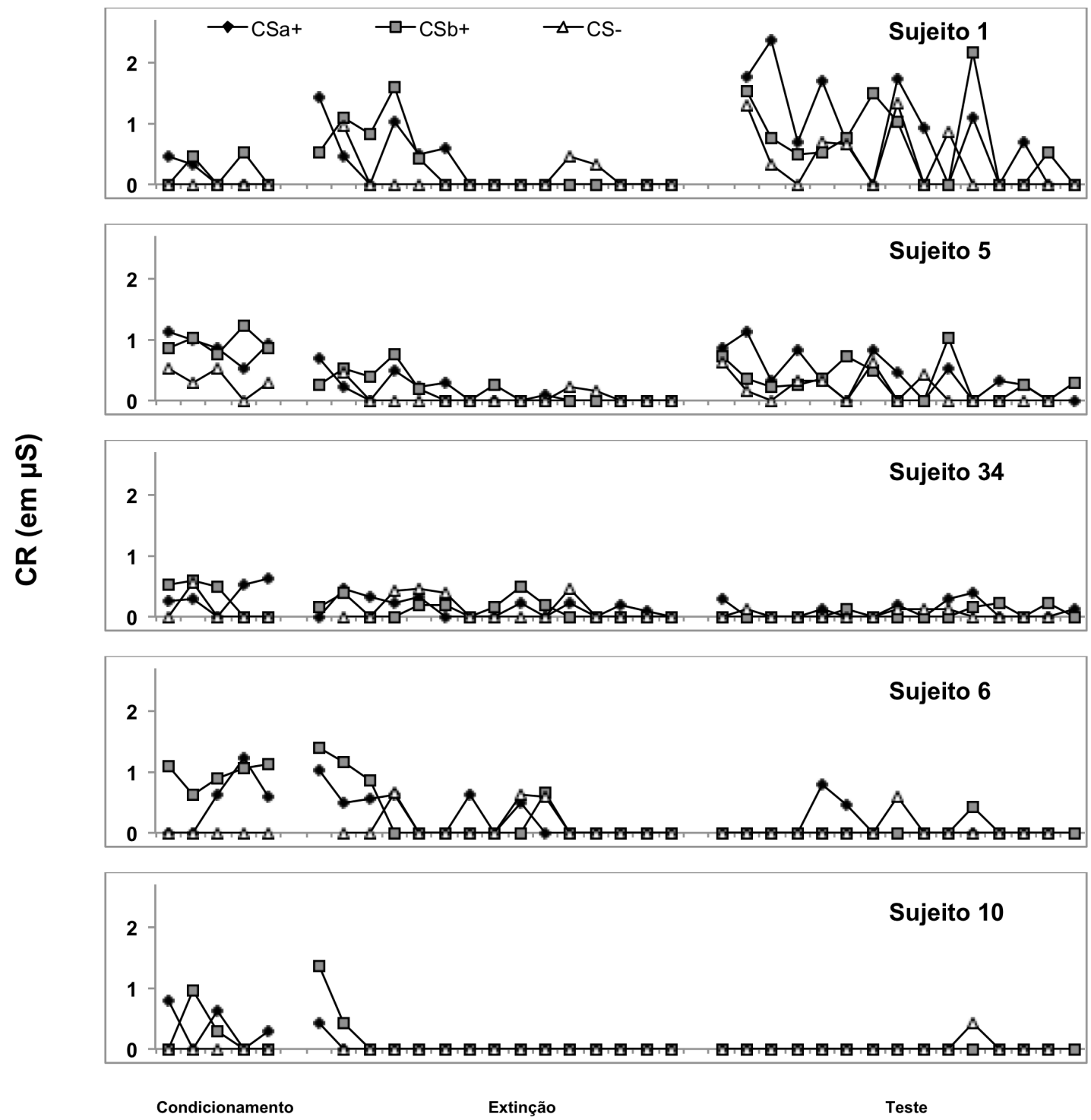

Figura 4 - Amplitudes das respostas condicionais (CRs), em $\mu \mathrm{S}$, frente ao $\mathrm{CSa}+, \mathrm{CSb}+\mathrm{e} \mathrm{CS}-$ ao longo das fases de condicionamento (cinco apresentações do $\mathrm{CSa}+$ e $\mathrm{CSb}+$ sem US, e cinco últimas apresentações do CS-), extinção e teste apresentadas pelos sujeitos do grupo controle.

A Figura 5 mostra que quatro dos seis sujeitos do grupo experimental apresentaram um aumento na amplitude das CRs no início da fase de teste em comparação ao final da fase de extinção (Sujeitos 13, 12, 27 e 32). O Sujeito 13 apresentou aumento das respostas frente aos dois $\mathrm{CSs}^{+}$, porém não frente ao $\mathrm{CS}-(\mathrm{CSa}+=1,08, \mathrm{CSb}+=0,7, \mathrm{CS}-=0,0 \mu \mathrm{S}$ na fase de teste $)$, caracterizando ressurgência. O Sujeito 13 apresentou maior ressurgência do responder condicional frente ao $\mathrm{CSa}+$ em comparação ao $\mathrm{CSb}+$, com uma diferença maior que $0,1 \mu$ s entre eles. Isso ocorreu apesar de ter havido $\mathrm{CR}$ apenas frente ao $\mathrm{CSb}+$ na última apresentação dos estímulos na fase de condicionamento. O sujeito 14 mostrou aumento da CR frente a todos o CSs em 
comparação ao final da extinção, porém com maior magnitude frente ao $\mathrm{CSa}+$, praticamente não havendo diferença entre $\mathrm{CSb}+$ e $\mathrm{CS}-(\mathrm{CSa}+=1,09, \mathrm{CSb}+=0,57, \mathrm{CS}-=0,49 \mu \mathrm{S}) . \mathrm{Um}$ aspecto em comum entre os Sujeitos 13 e 14 é que ambos mostram redução rápida das CRs frente aos três estímulos nessa fase de teste. O sujeito 32 apresentou aumento significativo das CRs frente a todos os estímulos na primeira tentativa do teste, porém mais acentuado frente ao $\mathrm{CSb}+$ $(\mathrm{CSa}+=0,53, \mathrm{CSb}+=1,61, \mathrm{CS}-=0,37 \mu \mathrm{S})$. O Sujeito 27 , mostrou o maior aumento frente ao CS-. Os dois sujeitos restantes (Sujeitos 16 e 17) apresentaram uma rápida extinção que se manteve na fase de teste.

Portanto, analisando-se individualmente os resultados dos 11 participantes, pode-se dizer que apenas o Sujeito 32, do grupo experimental, mostrou resultado que pode ser caracterizado como ressurgência da maneira como descrito por Schiller et al. (2010). No entanto, no mesmo grupo, o sujeito 13 apresentou ressurgência das CRs frente a ambos os CSs (manipulado e nãomanipulado). 

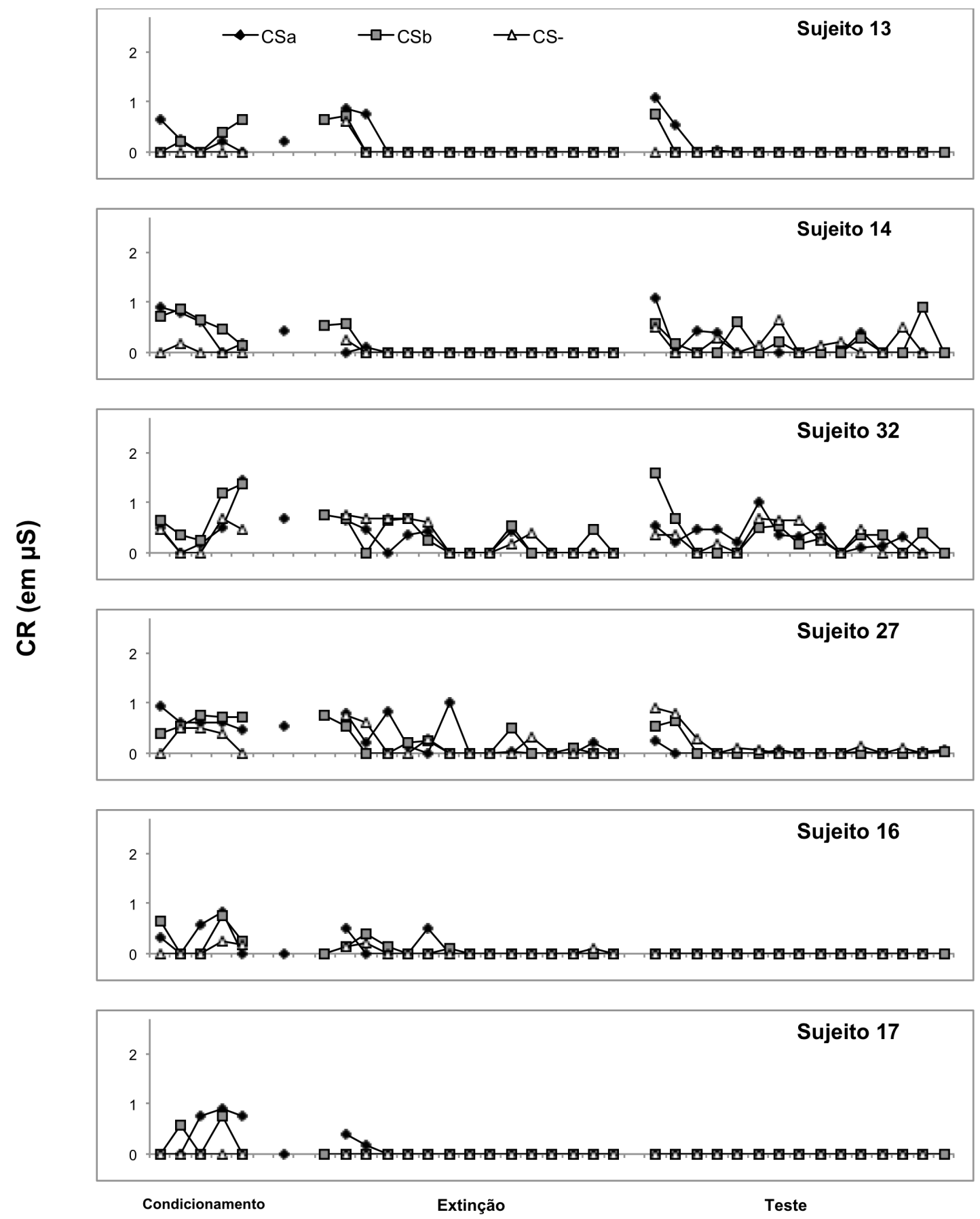

Figura 5 - Amplitudes das respostas condicionais (CRs), em $\mu \mathrm{S}$, frente ao $\mathrm{CSa}+, \mathrm{CSb}+$ e $\mathrm{CS}$ - ao longo das fases de condicionamento (cinco apresentações dos $\mathrm{CSa}+$ e $\mathrm{CSb}+$ sem US, e últimas cinco apresentações do CS-), extinção e teste para os sujeitos do grupo experimental. A apresentação isolada do CSa+ entre o condicionamento e a extinção se refere à manipulação de interesse neste experimento. 


\section{DISCUSSÃO}

\section{Sobre a obtenção de condicionamento e extinção respondentes}

Antes de analisar os dados relacionados aos objetivos específicos deste estudo, temos que nos reportar ao fato de que cerca de $2 / 3$ dos participantes iniciais precisaram ser excluídos do estudo aqui realizado. Isso se deu porque, atendendo à lógica do delineamento aqui proposto, a análise de ressurgência só poderia ser feita com sujeitos que mostrassem condicionamento e extinção respondentes equivalentes para o $\mathrm{CSa}+\mathrm{e} \mathrm{CSb}+$. Foram utilizados nessa triagem critérios de exclusão citados por outros estudos da literatura (Agren et al., 2013; Kindt \& Soeter, 2013; Oyarzún et al., 2012; Schiller et al., 2008; Schiller et al., 2013; Schiller et al., 2010), que selecionaram os 11 participantes do estudo da ressurgência.

Essa necessidade de selecionar os participantes, descartando muitos deles, tem sido o padrão na literatura sobre condicionamento respondente em humanos. No estudo de Schiller et al. (2010, Experimento 2) que buscamos replicar aqui, relata-se que foram convocados 21 sujeitos, dos quais apenas três não preencheram critérios para condicionamento ou extinção (em torno de $15 \%$ da amostra). Contudo, alguns desses mesmos pesquisadores, ao replicarem esse estudo, encontraram necessidade de maior descarte dos sujeitos: segundo Schiller et al. (2013), foi necessário avaliar 72 sujeitos para que se retirasse uma amostra de 24 participantes que preenchiam critérios de condicionamento e extinção (ou seja, exclusão de 65\% dos participantes iniciais). De acordo com o relato desses pesquisadores, 43 sujeitos foram excluídos após a sessão de condicionamento porque não mostraram evidências de condicionamento igual para ambos os $\mathrm{CSs}^{+}$, enquanto que outros cinco foram excluídos porque não mostraram evidências de extinção equivalente entre os $\mathrm{CSs}^{+}$. Esses 65\% dos sujeitos excluídos do estudo de Schiller et al. (2013) correspondem a uma proporção relativamente similar à nossa. Portanto, embora seja insatisfatório que tenhamos excluído tantos sujeitos para obter uma amostra adequada para o estudo da ressurgência, nossos dados são compatíveis com os produzidos em um dos laboratórios referência nessa área de estudo.

O mesmo vem sendo relatado em outros estudos. Por exemplo, usando dois CSs (CS+e CS-) de duração de 8s ou mais, Milad et al. (2005) excluíram 11 de 41 voluntários. Kindt e Soter (2013), usando um procedimento muito parecido com o de Milad et al. (2005), relatam que na avaliação do condicionamento por resposta de sobressalto, foi necessário excluir 17 dos 40 sujeitos para obter evidências estatística de condicionamento. Usando dois CSs (CS+ e CS-) com 
duração de 4 a 6 s, Agren et al. (2013) excluíram 8 dos 30 participantes; Golkar et al. (2012) excluíram 6 em 19 (no Experimento 1) e 5 em 20 (no Experimento 2); LaBar e Phelps (2005) excluíram 10 de 43; Schiller et al. (2008) excluíram 6 em 40 (nos Experimentos 1) e 3 em 17 (no Experimento 2).

Há relatos de alguns estudos nos quais não houve exclusão de dados de participantes com base em critérios de condicionamento e extinção (e.g., Effting \& Kindt, 2007; Kindt \& Soeter, 2013; Neumann \& Longbottom, 2008; Severster et al., 2012; Vervliet et al., 2004). Nessas pesquisas, os autores usaram os dados de todos os sujeitos e basearam suas interpretações nos resultados de análises estatísticas. Contudo, justamente em função dessa enorme variação no fenômeno básico, considera-se que o uso dos critérios de condicionamento e extinção, embora reduza a amostra, garante maior possibilidade de análise sobre os dados finais do estudo.

Ao que tudo indica, portanto, os fenômenos de condicionamento e extinção, embora muito robustos em ratos, não são tão fáceis de produzir em humanos usando-se a resposta de condutância da pele como variável dependente. Essa dificuldade tem sido atribuída à baixa intensidade da estimulação elétrica utilizada com humanos, bem como às diferenças na intensidade entre sujeitos (Boucsein, 2012; Effting \& Kindt, 2007; Schiller et al., 2008). Por razões éticas, mais recentemente, tornou-se prática comum que os participantes humanos regulem a intensidade do US, ao invés do experimentador regular a mesma intensidade para todos, conforme se fazia em estudos anteriores (e.g., Spence, Haggard \& Ross, 1958). Embora esse procedimento atenda a considerações éticas, sugere-se que ele possa diminuir a robustez do fenômeno de condicionamento. Além de utilizar baixa intensidade do estímulo elétrico, consideramos que a possibilidade do sujeito regular o US a ele aplicado é uma forma de aumentar a controlabilidade da situação, variável esta que sabidamente interfere na aversividade de um estímulo: quanto mais controlável, menos aversivo é o estímulo (Seligman et al., 1971). Portanto, é possível que, ao menos em parte, o grande descarte de sujeitos tenha relação com o fato de o participante poder controlar a intensidade do US que, com isso, não seria suficientemente aversivo para eliciar respostas de condutância da pele na magnitude suficiente para produzir o condicionamento em relação aos estímulos a ele pareados.

Um dado que fortalece a hipótese de que a intensidade do US interfere sobre a demonstração do condicionamento foi relatado por Effting e Kindt (2007). Esses autores realizaram dois experimentos. No primeiro, dois CSs foram apresentados 10 vezes cada, sendo um deles seguido de US por $0,2 \mathrm{~s}$ em todas as suas apresentações (CS+) e outro não sendo pareado ao 
US (CS-). Dada a longa duração dos CSs (8 s), eles fizeram uma avaliação tanto das respostas no primeiro intervalo (FIR, respostas cujo início se dá entre 1-4 s após início do CS) e respostas no segundo intervalo (SIR, isto é, respostas cujo início se dá entre 4-9 s após início do $\mathrm{CS}^{10}$ ). Usando esses parâmetros, eles encontraram evidências fracas de condicionamento apenas para as SIRs; os resultados das FIRs não cumpriram critérios para condicionamento respondente. Tendo isso em vista, eles fizeram um segundo experimento com quase todos os parâmetros iguais. As únicas diferenças é que a regulagem do US foi feita requisitando-se aos participantes que regulassem a estimulação elétrica de modo que a mesma demandasse "algum esforço para tolerar" (Effting \& Kindt, 2007, p. 2010). Como resultado, os participantes escolheram intensidades do US em média 20\% maiores do que no primeiro experimento. Nessas circunstâncias, os resultados se inverteram: não mais foram encontradas evidências de condicionamento das SIRs, mas apenas das FIR. Além disso, do ponto de vista estatístico, as evidências de condicionamento foram muito mais claras em comparação ao experimento anterior.

Portanto, nossos dados das duas primeiras fases, coincidentes com outros relatos da literatura, sugerem que é necessário que sejam aperfeiçoados os procedimentos para estudo do condicionamento respondente em humanos. Pondera-se a necessidade de estudar tecnicamente duas variáveis: a variável dependente (VD) e o US manipulado (VI). Quando à VD, a resposta de condutância da pele sofre interferência de muitas variáveis presentes na situação experimental, o que "suja" os dados quando se manipulam US e/ou CS. No que diz respeito à VI, como as questões éticas restringem a intensidade do choque elétrico a ser utilizado como US, seria importante buscar outros USs alternativos. Como exemplo disso, há um estudo conduzido em um laboratório da Universidade de Barcelona (Espanha), no qual o delineamento de Schiller et al. (2012) foi replicado mantendo-se a resposta de condutância da pele como VD, porém utilizando som alto (som de uma criança ou porco gritando) como US. Contudo, embora aparentemente bem sucedido na replicação dos dados de Schiller et al. (2012), esse estudo não evitou o descarte de sujeitos: dentre 21 participantes convocados inicialmente, quatro foram excluídos porque não preencheram critérios para condicionamento e / ou extinção respondentes, o que corresponde a aproximadamente $20 \%$ da amostra. Outro estudo utilizou ruído branco (LaBar et al., 1998), relatando-se a necessidade de descarte de 1 dentre 6 sujeitos, cerca de $17 \%$ da amostra inicial.

\footnotetext{
10 Embora o CS no estudo em questão tivesse 8s de duração, considerou-se que as respostas de segundo intervalo (SIR) eram aquelas cujo início se dava até 9s após o início do CS. Isto é, mediu-se respostas cujo início se deu até 1s após a interrupção do CS. Para maiores detalhes, consultar ANEXO A.
} 
Outra questão relevante é o procedimento de pareamento empregado na fase de condicionamento. No presente estudo, o procedimento na fase de condicionamento teve duas características que merecem análise: 1) utilizar dois $\mathrm{CSS}^{+}$e um CS-, e 2) parear apenas intermitentemente os $\mathrm{CSs}+$ ao choque. Consideramos uma vantagem metodológica o uso de dois CSs + pelo fato disso permitir utilizar o sujeito como seu próprio controle (Sidman, 1975), possibilitando uma análise individual além da análise de grupo que caracteriza o delineamento geralmente utilizado nas publicações da área. Ou seja, além das comparações dos dados médios de cada grupo, poderíamos comparar as CRs do mesmo participante frente aos diferentes estímulos. Essa comparação permitiu analisar individualmente se havia igual condicionamento frente a ambos os $\mathrm{CSs}^{+}$, o que nos direcionou a uma seleção estrita dos sujeitos a serem levados até a fase de teste da ressurgência (objetivo principal desse estudo). Dentre a amostra inicial, não obtivemos condicionamento semelhante frente ao $\mathrm{CSa}+\mathrm{e} \mathrm{o} \mathrm{CSb}+$ em nove sujeitos, o que representa aproximadamente $37 \%$ das exclusões. Ou seja, diversos sujeitos mostraram respostas condicionais apenas frente a um dos $\mathrm{CS}+$, ou com uma diferença entre eles maior do que a esperada nessa suposta igualdade de funções $(>0,1 \mu \mathrm{S})$.

Os motivos dessa não igualdade funcional precisam ser investigados, não sendo possível concluir apenas com base nos dados aqui obtidos. A manipulação das cores nos dois conjuntos de CSs utilizados visou diluir o efeito das cores em si. Não identificamos nenhum efeito sistemático com uma ou outra cor, e por isso nos ativemos à sua função decorrente dos pareamentos com o US. Uma hipótese especulativa seria um possível efeito de bloqueio (blocking-Catania, 1999), ou seja, o condicionamento estabelecido frente a um estímulo inibindo o condicionamento frente ao outro estímulo manipulado. Porém, essa interpretação precisa ser testada. O fato é que esse delineamento não possibilitou que todos os participantes mostrassem igual condicionamento frente aos dois $\mathrm{CSs}^{+}$. Esse resultado, embora teoricamente inesperado, é coincidente com os descritos em outros laboratórios. Por exemplo, Schiller et al. (2013), usando dois CSs+ e um CS-, relatam que uma grande parcela das exclusões ocorreu por conta de não haver igual condicionamento frente aos dois CSs+.

No que diz respeito ao pareamento intermitente, esse procedimento foi aqui escolhido para replicar o descrito por Schiller et al. (2010). Contudo, deve-se destacar que nos estudos piloto realizados antes do presente experimento verificamos que o condicionamento tornava-se mais provável quanto maior a porcentagem de CSs pareados ao US. Não cabe aqui analisar os motivos de Schiller utilizar pareamentos intermitentes nos seus diferentes estudos. O fato é que essa vem sendo uma característica considerada relevante por essa autora e, assim, optamos por manter a 
intermitência como procedimento básico nessa replicação. Mas, com base em nossos estudos piloto, aumentamos a porcentagem de pareamentos CS-US comparativamente a Schiller et al. (2010): enquanto eles utilizaram 38\% dos CSs pareados ao US, nós utilizamos aproximadamente $65 \%$. Consideramos que em futuras pesquisa, nas quais vamos buscar aprimorar o procedimento de produção do condicionamento e a extinção respondentes de forma a obter maior replicação entre sujeitos, essa seja uma das variáveis a ser sistematicamente manipulada.

Considerando essas duas variáveis apontadas, em estudos futuros sobre ressurgência parece importante testar, por exemplo, comparações entre grupos onde cada um seja exposto a um único $\mathrm{CS}+$, além do CS-. Outra alternativa seria testar se o condicionamento se dá de forma equivalente se forem feitas sessões separadas para condicionar o $\mathrm{CSa}+\mathrm{e} \mathrm{o} \mathrm{CSb}+$ para um mesmo sujeito. Uma alternativa a mais pode ser alterar as instruções, tornando-as mais explícitas a respeito das contingências, entre outras manipulações possíveis para se obter iguais CRs frente aos dois $\mathrm{CSs}+$.

Em relação à essa última manipulação sugerida, Golkar et al. (2012) realizaram um experimento no qual dois CSs foram pareados com estímulo elétrico e um terceiro CS nunca foi pareado com esse estímulo. Nesse estudo, os participantes eram informados de que apenas dois dos três estímulos poderiam ser acompanhados da estimulação elétrica. Segundo eles, o descarte de sujeitos que não apresentaram condicionamento ficou em torno de $20 \%$, valor mais baixo do cerca de $60 \%$ ocorrido aqui e no estudo de Schiller et al., (2013). Contudo, pode-se também apontar outros estudos em que essa instrução não foi dada e acabaram por ter índices menores de descarte que os nossos (Oyarzún et al., 2012; Schiller et al., 2010). Isso significa que essa variável precisaria ser sistematicamente manipulada para se supor que ela possa afetar a probabilidade de se estabelecer condicionamento respondente.

A manipulação de instruções pode envolver interações entre processos comportamentais verbais e o condicionamento respondente ainda pouco conhecidos. De fato, a literatura sobre controle instrucional vem demonstrando que a "tarefa" dada ao sujeito de identificar uma possível relação entre eventos pode ser, por si, uma variável independente relevante nos mais diferentes procedimentos (Baumann, Abreu-Rodrigues \& Souza, 2009; Rosenfarb, Newland, Brannon \& Howey, 1992). Por esse motivo, evitamos introduzí-la: no presente estudo, nossos sujeitos eram instruídos apenas a olhar para a tela do computador e não mexer os braços. Porém, essa é uma possível linha de investigação a ser feita no futuro, mesclando controle instrucional com pareamento de estímulos para se avaliar o condicionamento respondente. 
Concluindo, podemos dizer que esse nosso primeiro contato com o estudo do comportamento respondente em humanos nos mostrou que há ainda muito a ser investigado até chegarmos ao ponto de poder apontar as VIs mais relevantes e replicar sistematicamente os processos de condicionamento e extinção respondentes.

\section{Sobre a replicação aqui proposta}

Neste estudo, utilizamos análises de resultados médios de grupo conforme descrito na literatura, especificamente no estudo de Schiller et al. (2010, Experimento 2) que visamos replicar. Porém adicionamos a análise de processos comportamentais individuais ao longo de todo o experimento em função de um entendimento sobre a sua relevância metodológica / filosófica defendida entre os analistas do comportamento. Tantos nos resultados médios como nos individuais, não obtivemos ressurgência da CR na fase de teste. A única possível exceção, ou seja, efeito de ressurgência, se deu no comportamento de dois sujeitos expostos ao procedimento proposto por Schiller et al. (2010) que, em tese, deveria potencializar dos efeitos da extinção para o CS manipulado (ou seja, promover não ressurgência). Nesse caso, houve maior ressurgência justamente para o estímulo manipulado para um sujeito; para o outro, há um padrão parecido com o descrito por Schiller et al. (2010). Portanto, não apenas não obtivemos a ressurgência como efeito inerente à extinção respondente, como não replicamos o efeito da manipulação proposta por Schiller et al. (2010).

Poderia ser argumentado que essa replicação não se deu justamente pela falta do efeito básico, a ressurgência. Contudo, é de se destacar que, depois de demonstrado individualmente o condicionamento e a extinção frente aos dois $\mathrm{CSs}^{+}$, o resultado obtido na fase de teste foi o aumento das CRs médias frente a todos os estímulos condicionais, incluindo o CS-. Portanto, a nossa análise sobre a ausência da ressurgência não decorre de não eliciação da CR no início do teste, mas sim pela eliciação de todas a CRs, independente da história de pareamento do CS com o US. Da mesma forma, o procedimento proposto por Schiller et al. (2010) não produziu resultados diferencias das CRs frente ao CSa+: o esperado pela proposta de Schiller et al. (2010) seria que o $\mathrm{CSa}+$ eliciaria menos $\mathrm{CRs}$ que o $\mathrm{CSb}+$, resultado esse que não constatamos.

Assim, nossos resultados médios na sessão de teste da ressurgência diferem ao menos em dois pontos do que seria esperado com base na literatura: 1) CRs frente ao CS-, e 2) CR indiscriminada frente ao $\mathrm{CSa}+\mathrm{e}$ ao $\mathrm{CSb}+$ no grupo experimental exposto à manipulação proposta 
por Schiller et al. (2010). Contudo, nosso estudo demonstrou os requisitos básicos para estudo da ressurgência, conforme defendido por alguns autores (Kindt \& Soeter, 2013; Oyarzún et al., 2012; Schiller et al., 2010): 1) a demonstração de condicionamento e 2) a demonstração de extinção respondentes.

É bastante possível que algumas diferenças em relação à literatura se devam a questões metodológicas. Por exemplo, considera-se que houve condicionamento quando as respostas frente aos $\mathrm{CSs}+$ são maiores do que as respostas frente ao CS-, isto é, quando há responder diferencial entre os estímulos, desde que essa diferença seja função do pareamento estabelecido previamente (Boucsein, 2012). Como os estudos na área relatam apenas dados médios de grupos, essas diferenças são geralmente avaliadas por meio de análises estatísticas (e.g., Schiller et al., 2010), sem uma descrição pormenorizada dos resultados individuais que tanto interessam ao analista do comportamento. Conforme vimos nos resultados aqui apresentados, as médias, mesmo que avaliadas estatisticamente, pouco dizem sobre o desempenho dos indivíduos. Os dados individuais são apenas descritos pelos autores como um modo de selecionar os participantes que acabaram por compor a amostra final. No entanto, há variações de como os dados individuais são considerados para essas seleções prévias ao tratamento de grupo. Por exemplo, alguns estudos não apenas descrevem a seleção como também o critério mínimo para se apontar que há diferenças entre duas CRs (pelo menos 0,1 $\mu \mathrm{S}$ para se dizer que duas CRs são diferentes (Schiller et al., 2010). No entanto, em outro, relata-se que foram previamente selecionados para as análises de grupos apenas os dados dos sujeitos que apresentaram diferenças entre CSs + e CS-, sem especificar o critério de diferença (Kindt \& Soeter, 2013; Oyarzún et al., 2012).

A análise da extinção é feita, geralmente, com base em dois parâmetros: a) as diferenças entre CRs frente aos CSs+ e CS- ao final da fase de extinção, e / ou b) as diferenças entre CRs frente a cada CS no final da extinção comparativamente ao final do condicionamento. Assim como ocorre com o condicionamento, os sujeitos são primeiro triados com base nos resultados individuais para depois serem conduzidas análises estatísticas com base nas médias dos grupos. Diz-se que ocorre extinção quando não há mais diferenças nas respostas eliciadas frente aos CSs+ e CS-, e/ou quando há uma diminuição das CRs no final da extinção comparativamente ao que havia no final do condicionamento.

Para se analisar a ressurgência do condicionamento respondente, analisam-se dois efeitos: a) a diferença entre CRs frente aos diferentes estímulos ( $\mathrm{CSs}^{+}$e $\mathrm{CS}-$ ) no início do teste (geralmente a primeira tentativa) e b) diferenças entre CRs frente a cada estímulo condicional no 
início do teste comparando-as ao obtido no final da extinção. Diz-se que ocorreu ressurgência quando no início do teste há um aumento das CRs somente frente aos $\mathrm{CSs}^{+}$, esperando-se que o CS- não elicie, na fase de teste, respostas significantemente diferentes das eliciadas ao final da extinção. Nos trabalhos que encontramos na literatura sobre a ressurgência não vimos nenhum que descrevesse resultados individuais (tais como a proporção de ressurgência dentro do grupo de sujeitos), mas somente análises estatísticas das médias dos grupos (e.g., Kindt \& Soter, 2013; Oyarzún et al., 2012; Schiller et al., 2013; Schiller et al., 2010).

Ao analisar aqui os dados individualmente, vimos que é muito grande a variabilidade intragrupo, o que ressalta a inadequação de se fazer apenas a análise da média do grupo. Por exemplo, no grupo controle, apenas três dos cinco sujeitos (ou seja, 60\%) apresentaram aumento da CR frente aos estímulos na sessão de teste em comparação à sessão extinção. Desses três sujeitos, dois apresentaram um aumento do responder indiscriminado, ou seja, tanto aos CSa+e $\mathrm{CSb}+$, como também diante do CS-, pareado com o US. Pode-se chamar essa resposta diante do CS- de condicional? Outro resultado que observamos foi que no grupo experimental houve aumento da CR na fase de teste para quatro dos seis sujeitos (cerca de 67\% deles), sendo que em dois casos houve um aumento não somente das respostas frente aos $\mathrm{CSa}+\mathrm{e} \mathrm{CSb}+$, mas também ao CS- . É digno de nota que um sujeito do grupo experimental apresentou CR maior frente ao CSdo que aos outros estímulos $(\mathrm{CSa}+$ e $\mathrm{CSb}+)$ na fase de teste. Portanto, se o objetivo da ciência é previsão e controle (Skinner, 1953), tivemos aqui que a manipulação efetuada na fase de extinção, proposta por Schiller et al. (2010), não permitiu nem boa previsão e nem bom controle da eliciação das CRs na fase de teste.

Muitas questões trazidas por esses resultados precisam ser respondidas. Por exemplo, o que significa o aumento da amplitude da resposta frente ao CS-? Pode-se chamar essa resposta de CR e o fenômeno de ressurgência? O que estaria "ressurgindo" se antes essa resposta não era eliciada pelo estímulo? Ela é condicional a quê se o US nunca foi pareado ao CS-? Ou seria mais apropriado tratar esse fenômeno como uma instância de generalização de estímulos em função de características comuns a eles (todos quadrados, coloridos etc)? Na literatura sobre respondente, entende-se generalização como um processo por meio do qual estímulos não pareados ao choque passam a eliciar CRs (Soeter \& Kindt, 2010). Aparentemente esse foi o efeito encontrado aqui. Então, que implicações teria essa análise da generalização de estímulos no estudo da ressurgência?

De acordo com alguns autores, há uma correlação positiva entre nível de ansiedade crônico, medida por meio de relato verbal (referido na literatura como "ansiedade traço", Kindt \& Soeter, 
2013; Spielberger, Gorsuch \& Lusthene, 1970) e aumento da CR frente ao CS- após choques incontroláveis e imprevisíveis (Kindt et al., 2009; Soeter \& Kindt, 2011). Em nosso trabalho, não foi realizado nenhum tipo de triagem psiquiátrica ou medida de ansiedade, então não podemos fazer análises nesse sentido. No entanto, seria importante para estudos futuros examinar sob quais condições esse aumento da CR frente ao CS-, na fase de teste ,é mais provável de ocorrer. Há descrições de que o aumento nas respostas de condutância da pele frente ao CS- foi observado em procedimentos que utilizaram apresentação do US sem o CS na fase inicial do teste, como feito no presente experimento (Golkar et al., 2012; Kind \& Soeter, 2013; Milad et al., 2005; Oyarzún et al., 2012). Porém, em outros estudos, o mesmo efeito ocorreu quando o teste de ressurgência foi feito apresentando-se o CS em um contexto físico diferente daquele onde foi feita a extinção (Effting \& Kindt, 2007). Assim, seria importante em estudos futuros comparar esses procedimentos para verificar as condições que tornam esse fenômeno mais provável de ocorrer.

Outra questão suscitada pelos dados individuais é que o padrão encontrado por Schiller et al. (2010) não foi reproduzido aqui. Foi notável que em ambos os grupos ocorreram dois casos (dentre cinco ou seis sujeitos) em que o $\mathrm{CSa}+$ (manipulado) eliciou mais respostas no teste do que $\mathrm{CSb}+$, efeito contrário ao esperado por Schiller et al. Embora casos individuais como esses também sejam relatados em outros estudos (e.g., Schiller et al., 2013), descreve-se que, na média, os resultados apontam na direção de maior ressurgência frente ao CS+ não manipulado. Não foi o que obtivemos aqui.

Ao analisarmos em mais detalhes o procedimento dos estudos que manipularam o intervalo entre a primeira apresentação do CS e as demais na extinção, fica a sugestão de que é possível que não somente o intervalo possa ter influência sobre a ressurgência, mas também o que ocorre nesse intervalo (que não é controlado experimentalmente). Por exemplo, no estudo de Monfils et al. (2009), conduzido com ratos, após a apresentação do primeiro CS isolado, os animais foram removidos da caixa experimental, colocados em suas gaiolas-viveiro, onde permaneceram durante todo o intervalo programado, sendo em seguida recolocados na caixa experimental, onde foram expostos às apresentações subsequentes do CS sem US. De forma análoga, nos experimentos com sujeitos humanos, após a exposição a um CS sem US, os aparelhos foram desconectados dos participantes e, ao longo de 10 minutos, ficaram assistindo a um programa de televisão, não ficando claro se na mesma sala ou em outra (Oyarzún et al., 2012; Schiller et al., 2010). Em outros estudo, descreve-se que os participantes foram removidos para uma sala adjacente, onde ficaram lendo revistas (Kindt \& Soeter, 2013). 
Em nosso estudo, após a apresentação isolada do $\mathrm{CSa}+$, os sujeitos foram removidos para uma sala adjacente, onde deveriam ficar pelo intervalo programado. O sujeito tinha a opção de ler algumas revistas disponibilizadas pelo experimentador, porém essa atividade não era obrigatória. Será que tanto o ambiente no qual o indivíduo ficou durantes esses $10 \mathrm{~min}$, como as atividades que ele fez, podem ser variáveis relevantes para o processos de extinção? Por que supor que é o intervalo e não o que ele fez e o que está pareado com o que ele fez nesse intervalo? Usando um procedimento parecido ao nosso, Kindt e Soeter (2013) também não obtiveram diferenças entre os grupos experimental e controle, isto é, não demonstraram que a manipulação do intervalo entre a primeira a segunda apresentações de $\mathrm{CSa}+$ diminuiu a probabilidade de ressurgência. Portanto, nossos resultados não replicam os dados de Schiller et al (2010) mas replicam os de Kindt e Soeter (2013).

Uma possibilidade de interpretação dos nossos resultados é que a atividade desenvolvida durante o intervalo de 10 min não impede que os sujeitos emitam comportamentos verbais sobre o experimento, o que poderia, em tese, alterar os efeitos da manipulação. Essa consideração é congruente com um estudo recente que sugeriu a relação entre o comportamento verbal e as respostas de sobressalto: a ressurgência da $\mathrm{CR}$, medida por meio da resposta de sobressalto, foi maior quando os sujeitos eram solicitados a verbalizar, a cada apresentação de CS, se achavam que o estímulo seria pareado ao US naquela tentativa em particular (Warren et al., 2013). Esses autores avaliaram os efeitos de um comportamento verbal durante as apresentações dos CSs mas não o que ocorre no intervalo entre tentativas, conforme sugerimos anteriormente na análise dos nossos dados. Ainda assim, o fato de eles terem encontrado efeitos do comportamento verbal sobre a ressurgência da CR levanta a possibilidade, a ser confirmada futuramente em novas pesquisas, de que alguns de nossos sujeitos tenham emitido comportamentos verbais (por exemplo, ficar descrevendo as contingências ou o próprio comportamento) durante o intervalo programado que poderiam ter alterado os efeitos da manipulação. Uma maneira de testar essa hipótese é dividir os sujeitos do experimento em vários grupos, que fariam diferentes atividades ao longo do intervalo programado. Por exemplo, um grupo faria uma atividade de resolução de problemas, enquanto que outros sujeitos seriam solicitados a ficar descrevendo o que ocorreu no experimento.

Até onde revisamos a literatura, encontramos que os estudos que analisam a ressurgência do responder condicional só o fazem com base nas médias de grupos, sem análises individuais (Alvarez et al., 2007; Effting \& Kindt, 2007; LaBar \& Phelps, 2005; Milad et al., 2005; Neumann \& Kitlertsirivatana, 2010; Schiller et al., 2008; Schiller et al., 2013; Schiller et al., 2010). Em muitos trabalhos recentes, não se reportam os desvios-padrões das médias, mas sim medidas de 
erro-padrão (e.g., Alvarez et al. 2007; Kindt \& Soeter, 2011; LaBar \& Phelps, 2005; Milad et al., 2005; Neumann \& Longbottom, 2008; Schiller et al., 2008; Schiller et al., 2013; Schiller et al., 2010; Soeter \& Kindt, 2011). Embora o erro-padrão permita julgar o quanto a média da população se dispersa em relação à média da amostra analisada, ele não permite julgar diretamente o quanto os dados coletados se dispersam em torno da média da amostra. Visto que esses erros-padrões são apenas apresentados na forma de gráficos, sem apresentação de dados numéricos, não há como calcular os desvios-padrões da média para esses estudos.

Um estudo recente conduzido em 287 cadetes da polícia e corpo de bombeiros nos EUA sugere que há de fato uma variabilidade inerente na resposta galvânica da pele em procedimentos de condicionamento respondente (Pineles, Orr \& Orr, 2009). Nessa investigação, todos os participantes passavam por um procedimento que envolvia a apresentação de dois círculos coloridos na tela de um computador por 8s cada e a SCR era mensurada. Após um fase de habituação, em que os CSs eram apresentados sem US, havia uma fase de condicionamento, na qual um dos CSs era pareado a uma estimulação elétrica que servia como US (CS+) e outro CSnão era pareado ao US. Por fim, havia uma terceira fase, na qual os sujeitos viam os CSs sem US (extinção). Como esses autores tinha por objetivo discutir a validade de diferentes métodos de seleção SCRS (EIR versus FIR/SIR, conforme descrito no ANEXO A) para demonstração de condicionamento, foram calculadas as médias e desvios-padrões das SCRs frente à cada um dos CSs em todas as fases experimentais. O que fica evidente pelos dados desses pesquisadores é que mesmo usando amostras grandes, há uma ampla variabilidade em torno das médias, com os desvios-padrões tendo valores maiores que a metade da média. Se há variabilidade grande para condicionamento e extinção dessa resposta em humanos, fenômenos muito pesquisados na literatura, pode-se pressupor que o mesmo ocorra para os dados da ressurgência, cujas condições para a produção ainda estão sendo esclarecidas. Sendo assim, a variabilidade observada aqui reflete o descrito na literatura e, do ponto de vista estatístico, ela é um entrave para a verificação da significância das diferenças obtidas.

Um dado que fortalece a indicação de que há, na literatura, uma grande variabilidade nos resultados foi publicado por Schiller et al. (2013). Nesse trabalho, os autores fizeram uma replicação do Experimento 2 de Schiller et al. (2010), tendo obtido que dentre os sujeitos que preencheram critérios para condicionamento e extinção $(n=24)$, cinco apresentaram resultados opostos aos esperados na sessão de teste (isto é, ressurgência da CR frente ao CS+ cujo intervalo não foi manipulado em comparação à $\mathrm{CR}$ frente ao $\mathrm{CS}+$ manipulado). A despeito dessa demonstração, os autores não analisam comportamentalmente o que significa esse tipo de 
discrepância intragrupo, ficando centrados apenas na demonstração estatística. De acordo com Schiller et al. (2013), a inclusão desses participantes na amostra final não alterou os resultados estatísticos, dado que a maioria dos sujeitos teve o mesmo desempenho que no estudo original (Schiller et al., 2010, Experimento 2). Contudo, esses dados mostram que a grande variabilidade nesse fenômeno, ficando em aberto que sejam identificados motivos dessa variação.

\section{CONSIDERAÇÕES FINAIS E DIRECIONAMENTOS FUTUROS}

Considerando-se os dados aqui obtidos, parece-nos que os procedimentos utilizados nesta pesquisa (e que são comumente usados na literatura atual), necessitam refinamentos para aumentar o controle experimental sobre os fenômenos em estudo. Conforme Sidman (1975), a grande variabilidade intragrupo reflete falta de controle experimental ou interferência exagerada de variáveis estranhas. Isso é diferente do que ocorre, por exemplo, no estudo comportamento operante, no qual todos os sujeitos pode ter seus comportamentos reforçados, por mais que existam diferenças individuais. Isso é demonstrável com sujeitos normais, com desenvolvimento atípico, com humanos e não humanos. Logo, é um processo comportamental bem conhecido e passível de boa margem de previsão e controle. A produção do comportamento respondente aversivo em humanos, ao menos com o procedimento utilizado aqui, não se mostrou tão robusta. Considerando que o objetivo geral deste projeto era dar início a uma série de investigações sobre as condições envolvidas na ressurgência do condicionamento respondente, um dos rumos possíveis para projeto futuros tem que ser o refinamento dos procedimentos para produção desse fenômeno. 


\section{REFERÊNCIAS BIBLIOGRÁFICAS ${ }^{11}$}

Agren, T., Engman, J., Frick, A., Björkstrand, J., Larsson, E., Furmark, T., \& Fredrikson, M. (2012). Disruption of reconsolidation erases a fear memory trace in the Human amygdala. Science, 337, 1550-1552.

Aguado, L. (2003). Neuroscience of pavlovian conditioning: A brief review. The Spanish Journal of Psychology, 6(2), 155-167.

Alvarez, R. P., Johnson, L., \& Grillon, C. (2007). Contextual-specificity of short-delay extinction in humans: Renewal of fear-potentiated startle in a virtual environment. Learning and Memory, 14, 247-253.

Badia, P., Cocker, C., \& Harsh, J. (1973). Choice of higher density signalled shock over lower density unsignalled shock. Journal of Experimental Analysis of Behavior, 20, 47-55.

Barlow, D. H. (2002). Anxiety and its disorders: The nature and treatment of anxiety and panic $\left(2^{\text {nd }}\right.$ ed). New York: Guildford Press.

Baumann, A. A., Abreu-Rodrigues, J., \& Souza, A. S. (2009). Rules and self-rules: Effects of variation upon behavioral sensitivity to change. The Psychological Record, 59, 641-670.

Boucsein, W. (2012). Electrodermal activity ( $2^{\text {nd }}$ ed.). New York: Springer.

Bouton, M. E. (2002). Context, ambiguity, and unlearning: Sources of relapse after behavioral extinction. Biological Psychiatry, 52, 976-986.

Bouton, M. E. (2004). Context and behavioral processes in extinction. Learning and Memory, $11(5), 485-494$.

Bouton, M. E., \& Bolles, R. C. (1979a). Contextual control of the extinction of conditioned fear. Learning and Motivation, 10, 445-466.

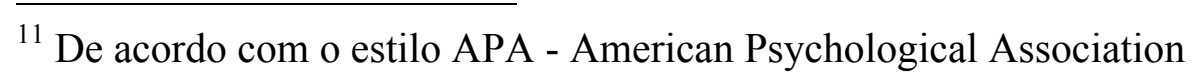


Bouton, M. E., \& Bolles, R. C. (1979b). Role of conditioned contextual stimuli in reinstatement of extinguished fear. Journal of Experimental Psychology: Animal Behavior Processes, 5, 368378.

Bouton, M. E., \& Bolles, R. C. (1980). Conditioned fear assessed by freezing and by the suppression of three different baselines. Animal Learning \& Behavior, 8, 429-434.

Bouton, M. E., \& King, D. A. (1983). Contextual control of the extinction of conditioned fear: Tests for the associative value of the context. Journal of Experimental Psychology: Animal Behavior Processes, 9, 248-265.

Bouton, M. E., \& Moody, E. W. (2004). Memory processes in classical conditioning. Neuroscience and Biobehavioral reviews, 28(7), 663-674.

Brunner, E. and Langer, F. (2000). Nonparametric analysis of ordered categorical data in designs with longitudinal observations and small sample sizes. Biometrical Journal, 42, 663-675.

Cahill, S. P., Foa, E. B., Hembree, E. A., Marshall, R. D., \& Nascasch, N. (2006). Dissemination of exposure therapy in the treatment of posttraumatic stress disorder. Journal of Trauma and Stress, 19, 597-610.

Catania, A. C. (1999). Aprendizagem: Comportamento, linguagem e cognição (4 ed). Porto Alegre: Editora Artmed.

Davis, M., Ressler, K., Rothbaum, B.O., \& Richardson, R. (2006). Effects of D-cycloserine on extinction: Translation from preclinical to clinical work. Biological Psychiatry, 60, 369-375.

Dawson, M. E., Schell, A. M., \& Filion, D. L. (2000). The electrodermal system. In J. T. Cacioppo \& L. G. Tassinary (Eds). Handbook of Psychophysiology (2 ${ }^{\mathrm{a}}$ ed.), pp.200-233. Cambridge: Cabridge Press.

Donahoe, J. W., \& Palmer, D. C. (1994) Learning and complex behavior. Boston, MA: Allyn \& Bacon. 
Duvarci, S., \& Nader, K. (2004). Characterization of fear memory reconsolidation. The Journal of Neuroscience, 24, 9269-9275.

Efting, M., \& Kindt, M. (2007). Contextual control of human fear associations in a renewal paradigm. Behaviour Research and Therapy, 45(9), 2002-2018.

Eifert, G. H. \& Schermelleh, K. (1985). Language conditioning, emotional instructions, and cognitions in conditioned responses to fear-relevant and fear-irrelevant stimuli. Journal of Behavior Therapy and Experimental Psychiatry, 16, 101-109.

Eisenberg, M., Kobilo, T., Berman, D, \& Dudai, Y. (2003). Stability of retrieved memory: Inverse correlation with trace dominance. Science, 301, 1102-1104.

Ekman, P., Sorenson, E. R. \& Friesen, W. V. (1969). Pan-cultural elements in facial displays of emotion. Science, 164(3875), 86-88.

Estes, W. K., \& Skinner, B. F. (1941). Some quantitative properties of anxiety. Journal of Experimental Psychology, 29, 390-400.

Foa, E., Franklin, M. E., \& Moser, J. (2002). Context in the clinic: How well do cognitivebehavioral therapies and medications work in combination? Biological Psychiatry, 52, 987997.

Geyer, M. A., \& Swerdlow, N. R. (1998). Measurement of startle response, prepulse inhibition, and habituation. In Crawley J. N., Skolnick, P. (eds), Current Protocols in Neuroscience. New York, John Wiley \& Sons, unit 8.7, pp 1-15.

Golkar, A., Bellander, M., Olsson, A., \& Öhman, A (2012). Are fear memories erasable? reconsolidation of learned fear with fear-relevant and fear-irrelevant stimuli. Frontiers in Behavioral Neuroscience, 6, 1-10. doi: 10.3389/fnbeh.2012.00080. eCollection 2012.

Graeff, F. G., Parente, A., Del-Ben, C. M., \& Guimarães, F. S. (2003). Pharmacology of human experimental anxiety. Brazilian Journal of Medical and Biological Research, 36, 421-432.

Hermans, D., Craske, M. G., Mineka, S., \& Lovibond, P. F. (2006). Extinction in human fear conditioning. Biological Psychiatry, 60, 361-368. 
Hoffmann, S. G. (2008). Cognitive processes during fear acquisition and extinction in animals and humans: Implications for exposure therapy of anxiety disorders. Clinical Psychology Review, $28,199-210$.

Hugdahl, K. \& Öhman, A. (1977). Effects of instructions on acquisition and extinction of electrodermal responses to fear-relevant and fear-irrelevant stimuli. Journal of Experimental Psychology, 3, 608-618.

Kindt, M., \& Soeter, M. (2013). Reconsolidation in a fear conditioning study: A test of extinction as an updating mechanism. Biological Psychology, 92, 43-50.

Kindt, M., Soeter, M., \& Vervliet, B. (2009). Beyond extinction: Erasing human fear responses and preventing the return of fear. Nature Neuroscience, 12, 256-258.

LaBar, K. S., Gatenby, J. C., Gore, J. C., LeDoux, J. E., \& Phelps, E. A. (1998). Human amygdala activation during conditioned fear acquisition and extinction: A mixed fMRI study. Neuron, 20, 937-945.

LaBar, K. S., \& Phelps, E. A. (2005). Reinstatement of conditioned fear in humans is context dependent and impaired in amnesia. Behavioral Neuroscience, 119, 677-686.

Lattal, K. M., \& Lattal, K. A. (2012). Facets of Pavlovian and operant extinction. Behavioural Processes, 90, 1-8.

Maren, S., \& Chang, C. (2006). Recent fear is resistant to extinction. Proceedings of the National Academy of Sciences, 103, 18020-18025.

Milad, M. R., Orr, S. P., Pitman, R. K., \& Rauch, S. L. (2005). Context modulation for fear extinction in humans. Psychophysiology, 42, 456-464.

Monfils, M-H., Cowansage, K. K., Klann, E., \& LeDoux, J. E. (2009). Extinction-reconsolidation boundaries: Key to persistent attenuation of fear memories. Science, 324, 951-955.

Myers, K. M., \& Davis, M. (2002). Behavioral and neural analysis of extinction. Neuron, 36, 567584. 
Myers, K. M., Ressler, K. J., \& Davis, M. (2006). Different mechanisms of fear extinction dependent on length of time since fear acquisition. Learning \& Memory, 13, 216-223.

Nader, K., Schafe, G. E., \& LeDoux, J. E. (2000). Fear memories require protein synthesis in the amygdala for reconsolidation after retrieval. Nature, 406, 722-726.

Nascasch, N., Foa, E. B., Fostick, L., Polliack, M., Dinstein, Y., Tzur, D., ... Zohar, J. (2007). Prolonged exposure therapy for chronic combat related PTSD: A case report of five veterans. CNS Spectrums, 12, 690-695.

Nelson. J. B., Sanjuan, M. C., Vadillo-Ruiz, S., Pérez, J., \& León, S. P. (2010). Experimental renewal in human participants. Journal of Experimental Psychology: Animal Behavior Processes. doi: 10.10377/a0020519.

Neumann, D. L., \& Kitlertsirivatana, E. (2010). Exposure to a novel context after extinction causes a renewal of extinguished conditioned responses: Implications for the treatment of fear. Behavior Research and Therapy, 48, 565-570.

Neumann, D. L., \& Longbottom, P.L. (2008). The renewal of extinguished fear with fear-relevant and fear-irrelevant stimuli by a context change after extinction. Behavior Research and Therapy, 46, 188-206.

Öhman, A., Fredikson, M., Hugdahl, K., \& Rimmö, P. A. (1976). The premise of equipotentiality in human classical conditioning: Conditioned electrodermal responses to potentially phobic stimuli. Journal of Experimental Psychology: General, 105, 313-337.

Olssom, A., Ebert, J. P., Banaji, M. R., \& Phelps, E. A. (2005). The role of social groups in the persistence of learned fear. Science, 309, 785-787.

Overmier, J. B. (1985). Toward a reanalysis of the causal structure of the learned helplessness syndrome. In F.R. Brush \& J.B. Overmier (Eds), Affect, Conditioning and Cognition: Essays on the determinants of Behavior (pp.211-227). Hillsdale, NJ: Erlbaum.

Oyarzún, J. P., Lopez-Barroso, D., Fuentemilla, L., Cucurell, D., Pedraza, C., Rodriguez-Fornells, A., \& Diego-Balaguer, R. (2012). Updating fearful memories with extinction training during reconsolidation: A human study using auditory aversive stimuli. PLoS One, 7(6): e38849. doi:10.1371/journal.pone.0038849. 
Pavlov, I. P. (1927). Conditioned reflexes: An investigation of the physiological activity of the cerebral cortex. Translated and edited by G. V. Anrep. London: Oxford University Press.

Pineles, S. L., Orr, M. R., \& Orr, S. P. (2009). An alternative scoring method for skin conductance responding in a differential conditioning paradigm with a long-duration conditioned stimulus. Psychophysiology, 46, 984-995.

Powers, M. B., Halpern, J. M., Ferenschak, M. P., Gillihan, S. J., \& Foa, E. B. (2010). A Metaanalytic review of prolonged exposure for posttraumatic stress disorder. Clinical Psychology Review, 30, 635-641.

R Development Core Team (2007). R: A language and environment for statistical computing. $\mathrm{R}$ Foundation for Statistical Computing, Vienna, Austria. ISBN 3-900051-07-00, URL http://www.R-project.org.

Rachamim, L., Nascasch, N., Shafran, N., Tzur, D., \& Gilboa-Schechtman, E. (2009). Exposurebased therapy for Post-Traumatic Stress Disorder in children and adults. The Israel Journal of Psychiatry and related sciences, 46(4), 274-281.

Rauch, S. L., Shin, L. M., \& Phelps, E. A. (2006). Neurocircuitry models of Posttraumatic Stress Disorder and Extinction: Human neuroimaging research - past, present, and future. Biological Psychiatry, 60, 376-382.

Rescorla, R. A. (1968). Probability of shock in the presence and absence of CS in fear conditioning. Journal of Comparative and Physiological Psychology, 68(1), 1-5.

Rescorla, R. A. (1988). Pavlovian conditioning: It's not what you think it is. American Psychologist, 43(3), 151-160.

Rescorla, R. A. (2003). Contemporary study of Pavlovian conditioning. The Spanish Journal of Psychology, 6(2), 185-195.

Rescorla, R. A., \& Heth, C. D. (1975). Reinstatement of fear to an extinguished conditioned stimulus. Journal of Experimental Psychology: Animal Behavior Processes, 1, 88-96. 
Rescorla, R.A., \& Wagner, A. R. (1972). A theory of Pavlovian conditioning: Variations in the effectiveness of reinforcement and nonreinforcement. In Classical conditioning II: Current research and theory. In A.H. Black and W.K. Prokasy (Eds), pp. 64 -99. Appleton-CenturyCrofts, New York.

Robbins, S. J. (1990). Mechanisms underlying spontaneous recovery in autoshaping. Journal of Experimental Psychology: Animal Behavior Processes, 16, 235-249.

Rosa, P. (2001). Análise Não-Paramétrica de Dados Ordinais com Medidas Repetidas. Dissertação de Mestrado, IME-USP.

Rosenfarb, I. S., Newland, M. C., Brannon, S. E., \& Howey, D. S. (1992). Effects of selfgenerated rules on the development of schedule controlled behavior. Journal of the Experimental Analysis of Behavior, 58, 107-121.

Sangha, S., Scheibenstock, A., \& Lukowiak, K. (2003). Reconsolidation of a long-term memory in Lymnaea requires new protein and RNA synthesis and the soma of right pedal dorsal 1. Journal of Neuroscience, 23, 8034-8040.

Shankman, S. A., Robison-Andrew, E. J., Nelson, B. D., Altman, S. E., \& Campbell, M. L. (2011). Effects of predictability of shock timing and intensity on aversive responses. International Journal of Psychophysiology, 80, 112-118.

Seligman, M. E. P., Maier, S. F., \& Solomon, R. L. (1971). Unpredictable and uncontrollable aversive events. In E.F. Brush (Ed.). Aversive Conditioning and Learning (pp.347-402). New York: Academic Press.

Sevenster, D., Beckers, T., \& Kindt, M. (2012). Retrieval per se is not sufficient to trigger reconsolidation of human fear memory. Neurobiology of Learning and Memory, 97, 338-345.

Schiller, D., Cain, C. K., Curley, N. G., Schwartz, J. S., Stern, S. A., LeDoux, J. E., \& Phelps, E. A. (2008). Evidence for recovery of fear following immediate extinction in rats and humans. Learning and Memory, 15, 394-402. 
Schiller, D., Kanen, J. W., LeDoux, J. E., Monfils, M-H., \& Phelps, E. A. (2013). Extinction during reconsolidation of threat memory diminishes prefrontal cortex involvement. Proceedings of the National Academy of Sciences of the United States of America, 110, 20040-20045.

Schiller, D., Monfils, M-H., Raio, C. M., Johnson, D. C., LeDoux, J. E., \& Phelps, E. A. (2010). Preventing the return of fear in humans using reconsolidation update mechanisms. Nature, 463(7277), 49-53.

Schiller, D., Raio, C. M., \& Phelps. E. A. (2012). Extinction training during the reconsolidation window prevents the recovery of fear. Journal of Visualized Experiments, 24(66), e3893, DOI: $10.3791 / 3893$.

Sidman, M. (1975). Táticas de pesquisa científica. São Paulo: Brasiliense.

Skinner, B. F. (1953). Science and human behavior. New York: The Free Press.

Society for Psychophysiological Research Ad Hoc Committee on Electrodermal Measures: Boucsen, W., Fowles, D. C., Grimmes, S., Ben-Shakhar, G., Roth, W. T., Dawson, M. E., \& Filion, D. (2012). Publication recommendations for electrodermal measurement. Psychophysiology, 49, 1017-1034.

Soeter, M., \& Kindt, M. (2011). Disrupting reconsolidation: pharmacological and behavioral manipulation. Learning and Memory, 18, 357-366.

Spence, K. W., Haggard, D. F., \& Ross, L. E. (1958). UCS intensity and the associative (habit) strength of the eyelid CR. Journal of Experimental Psychology, 55, 404-411.

Spielberger, C. D., Gorsuch, R. L., \& Lusthene, R. E. (1970). Manual for the State-Trait Anxiety Inventory. Consulting Psychologists Press, Palo Alto.

Squire, L. R. (1992). Memory and the hippocampus: A synthesis from findings with rats, monkeys, and humans. Psychological Review, 99(2), 195-231.

Squire, L. R. (2004). Memory systems of the brain: A brief history and current perspective. Neurobiology of Learning and Memory, 82, 171-177. 
Squire, L. R. (2009). Memory and the brain systems: 1969-2009. The Journal of Neuroscience, 29, 12711-12716.

Thomas, B. L., Larsen, N., \& Ayres, J. J. B. (2003). Role of context similarity in ABA, ABC, and $\mathrm{AAB}$ renewal paradigms: Implications for theories of renewal and for treating human phobias. Learning and Motivation, 34, 410-436.

Todorov, J. C. (2011). Quem tem medo de controle aversivo? Acta Comportamentalia, 19, 05-07.

United Nations Environment Programme / World Health Organization / International Radiation Protection Association. (1993). Electromagnetic fields (300 Hz to $300 \mathrm{GHz}$ ). Geneva: World Health Organization; Environmental Health Criteria 137.

Vervliet, B., Craske, M. G., \& Hermans, D. (2013). Fear extinction and relapse: State of the art. Annual Review of Clinical Psychology, 9, 215-248.

Vervliet, B. \& Greens, M. (2013). Fear generalization in humans: Impact of feature learning on conditioning and extinction. Neurobiology of Learning and Memory, http://dx.doi.org/10.1016/j.nlm.2013.10.002.

Vervliet, B., Vansteenwegen, D., Bayens, F., Hermans, D., \& Eelen, P. (2005). Return of fear in a human differential conditioning paradigm caused by a stimulus change after extinction. Behavior Research and Therapy, 43, 357-371.

Vervliet, B., Vansteenwegen, D, \& Eelen, P. (2004). Generalization of extinguished skin conductance responding in human fear conditioning. Learning and Memory, 11, 555-558.

Warren, V. T., Anderson, K. M., Kwon, C., Bosshardt, L., Jovanovic, T., Bradley, B, \& Norrholm, S. D. (2013). Human fear extinction and return of fear using reconsolidation update mechanisms: The contribution of on-line expectancy ratings. Neurobiology of Learning and Memory, http://dx.doi.org/10.1016/j.nlm.2013.10.014.

Weike, A. I., Schupp, H. T., \& Hamm, A. O. (2007). Fear acquisition requires awareness in trace but not delay conditioning. Psychophysiology, 44, 170-180. 
Westbrook, R. F., Iordanova, M., McNally, G., Richardson, R., \& Harris, J. A. (2002). Reinstatement of fear to an extinguished conditioned stimulus: Two roles for context. Journal of Experimental Psychology: Animal Behavior Processes, 28, 97-110.

Zeidan, M.A., Lebron-Milad, K., Thompson-Hollands, J., Im, J. J., Dougherty, D. D., Holt, D.J., ... S. P., Milad, M. R. (2012). Test-Retest Reliability during Fear Acquisition and Fear Extinction in Humans. CNS Neuroscience \& Therapeutics, 18, 313-317.

Zilio, D. (2010). A natureza comportamental da mente: behaviorismo radical e filosofia da mente. São Paulo: Editora Cultura Acadêmica (Unesp). 
ANEXOS 
ANEXO A - Controvérsias e especificidades do uso da atividade eletrodérmica como medida de responder condicional em estudos sobre ressurgência

O registro da chamada atividade eletrodérmica é a medida mais frequente de responder condicional em estudos sobre ressurgência em humanos (Boucsein, 2012; Dawson, Schell \& Fillion, 2000). O termo atividade eletrodérmica (EDA, do inglês electrodermal activity) refere-se a todos os fenômenos elétricos da pele, incluindo propriedades ativas e passivas que podem ser reconhecidas como relacionadas à pele e seus apêndices (Bousein, 2012; Johnson \& Lubin, 1966) 12. Apesar de seu amplo uso em pesquisas experimentais, a EDA ainda não é completamente entendida e é motivo de debate por alguns autores, de modo que alguns comentários sobre essa medida se fazem necessários (Boucsein, 2012). É importante ressaltar que não se teve por objetivo esgotar o assunto com esta seção, pois isto excederia em muito o escopo deste estudo, mas sim apresentar algumas questões importantes para o entendimento dos trabalhos na área.

Há duas maneiras de se avaliar a atividade eletrodérmica: sem o uso de uma corrente elétrica externa, método este referido como endossomático, pois todos os potenciais avaliados são originados na própria pele; ou por meio de uma corrente direta (DC, do inglês direct current) ou alternada (AC, alternating current), métodos estes referidos como exossomáticos.

$\mathrm{Na}$ literatura sobre condicionamento respondente, o mais comum é a utilização dos métodos exossomáticos, em especial o método por aplicação de corrente direta (Boucsein, 2012). Por esse motivo, esta seção introdutória teve como foco as especificidades relacionadas a este método $^{13}$. No método exossomático por corrente direta, aplica-se uma corrente elétrica cuja tensão (medida em Volts) é mantida constante, tendo-se então a observação da condutância da pele, que é medida em microsiemens ( $\mu \mathrm{S})$ (SC, do inglês skin conductance) (Boucsein, 2012; Dawson et al., 2000).

Na literatura, faz-se uma distinção entre dois componentes da atividade eletrodérmica: atividade tônica e atividade fásica (Boucsein, 2012; Dawson et al., 2000). No caso do método de

\footnotetext{
${ }^{12}$ Assim como ocorre com o condicionamento respondente, as siglas usadas para se referir aos diversos fenômenos da atividade eletrodérmica foram escolhidas a partir dos termos em inglês. Dado que essa nomenclatura é resultado de um consenso originado na década de 60 pela Sociedade de Pesquisa Psicofisiológica (Brown, 1967), sendo amplamente utilizada na literatura, optamos por mantê-la.

${ }^{13}$ Ao leitor interessado em compreender a fundo os aspectos técnicos envolvidos em outros métodos de mensuração da atividade eletrodérmica, recomenda-se as leituras de Boucsein (2012), Dawson et al. (2000) e Society for Psychophysiological Research Ad Hoc Committee on Electrodermal Measures, 2012.
} 
avaliação por aplicação de corrente direta, define-se atividade tônica como o nível absoluto de condutância da pele (SCL, do inglês skin conductance level) em um certo momento na ausência de uma resposta fásica mensurável (Boucsein, 2012; Dawson et al., 2000). Atividade fásica é definida como uma mudança de curta duração na EDA que poderia ser chamada de resposta de condutância da pele (SCR, do inglês skin conductance response) (Boucsein, 2012; Dawson et al., 2000; Society for Psychophysiological Research Ad Hoc Committee on Electrodermal Measures, 2012).

Uma questão importante de ser destacada é como o termo "resposta" é utilizado na literatura sobre EDA. Embora esse termo pressuponha uma relação necessária entre um estímulo e uma mudança da atividade eletrodérmica, ele é utilizado também quando há uma alteração na condutância da pele, mas não há um estímulo evidentemente relacionado a essa alteração. Dito de outro modo, podem ocorrer mudanças na atividade eletrodérmica na ausência de estímulos identificáveis e essa atividade tem sido chamada na literatura de "resposta". Contudo, como não há estímulos óbvios eliciando essas alterações na condutância da pele, utiliza-se o termo "resposta espontânea" ou "não específica" (NS.SCR, do inglês non-specific skin condutance responses).

Em um registro da atividade eletrodérmica por corrente direta, as respostas de condutância da pele são sempre monofásicas (isto é, seus valores são sempre positivos) e podem ser identificadas pelo seu formato característico: uma deflexão do registro em que há uma subida íngreme e uma recuperação mais achatada. Em outras palavras, por uma mudança súbita na condutância da pele na qual o tempo de ascensão é menor que o tempo de recuperação (Boucsein, 2012; Dawson et al., 2000; Society for Psychophysiological Research Ad Hoc Committee on Electrodermal Measures, 2012). Um aspecto importante é que uma recuperação total da resposta demora muito para ocorrer, ou porque o suor eliciado conduz mais eletricidade ou os dutos de suor esvaziam lentamente, ou ambos (Society for Psychophysiological Research Ad Hoc Committee on Electrodermal Measures, 2012). Assim, o critério de recuperação máxima normalmente utilizado é o de $63 \%$ de recuperação, tomando-se por base o pico da resposta e o nível de condutância da pele anterior à mudança abrupta (Society for Psychophysiological Research Ad Hoc Committee on Electrodermal Measures, 2012).

As respostas de condutância da pele podem ser medidas a partir de diversos parâmetros, tais como: a) frequência, que é o número de respostas em uma dada janela de tempo (SCR freq.); b) amplitude, que é a altura de uma resposta particular (SCR amp.); c) latência, que se refere ao intervalo entre o início de um estímulo e o início de uma resposta de condutância da pele (SCR lat.); d) tempo de elevação, que é o tempo entre o início da resposta e o seu ponto mais alto (SCR ris.t.); e) tempo de recuperação, que é o intervalo necessário para resposta recuperar $50 \%$ (SCR. 
rec.t/2) ou 63\% (SCR rec. t.) de sua amplitude. Dentre todos esses parâmetros, o mais utilizado para mensurar condicionamento respondente é a amplitude (Boucsein, 2012; Dawson et al., 2000).

Para se avaliar amplitude de condutância da pele, alguns critérios são necessários. Em primeiro lugar, é comum usar um critério mínimo de resposta, ou seja, um critério quanto à deflexão mínima em $\mu \mathrm{S}$ que deve ser observada para se considerar que uma resposta ocorreu (Boucsein, 2012; Dawson et al., 2000; Society for Psychophysiological Research Ad Hoc Committee on Electrodermal Measures, 2012). Nesse caso, ao escolher um critério mínimo, estabelece-se que mudanças abaixo dele não serão contadas como respostas, sendo muitas vezes registradas com o valor zero (0) (e.g., Kindt \& Soeter, 2013; Schiller et al., 2013).

Historicamente, o critério mínimo de resposta dependeu muito mais da resolução dos registros (o que por sua vez depende dos métodos de aquisição). Por exemplo, em avaliações manuais de registros impressos (antes do advento dos computadores), era comum utilizar uma amplitude mínima de $0.05 \mu \mathrm{S}$ como critério mínimo porque essa era a menor mudança que se podia identificar visualmente. Atualmente, a definição dos critérios mínimos tem caído para 0.01 $\mu \mathrm{S}$ pelo fato dos computadores serem capazes de detectar mudanças cada vez menores (por exemplo, no programa utilizado nesta pesquisa, era possível determinar mudanças de até $0,001 \mu \mathrm{S}$. Contudo, conforme apontado por Dawson et al. (2000), embora os aparelhos sejam capazes de detectar mudanças cada vez mais sutis na condutância da pele, ainda não se determinou se mudanças muito discretas são comportamentalmente ou fisiologicamente relevantes.

Um aspecto que os pesquisadores levam em consideração ao escolher um critério mínimo diz respeito às condições experimentais. Por exemplo, se é permitido (ou solicitado) ao sujeito mover-se, o que tende a produzir variações no registro, o pesquisador comumente escolhe um valor mais alto como critério mínimo de resposta. Do mesmo modo, o critério é mais alto quando há interferência por sinais de outros aparelhos (tal como ocorre em pesquisas de neuroimagem em que o campo eletromagnético dos aparelhos interfere sobre o registro da EDA) (Boucsein, 2012; Dawson et al., 2000).

Em alguns estudos sobre ressurgência do responder condicional aqui avaliados, o critério mínimo de resposta utilizado foi de $0.02 \mu \mathrm{S}$ (Kindt \& Soeter, 2013; Schiller et al., 2008; Schiller et al., 2013; Schiller et al., 2010), porém há também pesquisas com critério mínimo de 0,05 $\mu \mathrm{S}$ (Effting \& Kindt, 2007: Neumann \& Longbottom, 2008; Neumann \& Kitlertsirivatana, 2010). Por outro lado, há uma série de experimentos nos quais não se relata um critério mínimo para se considerar que houve uma SCR (Alvarez, Johnson \& Grillon, 2007; Milad, Orr \& Pitman, 2005; Sevenster, Becker \& Kindt, 2012). Em alguns desses casos, o critério mínimo não é citado porque os experimentadores escolheram mensurar a diferença entre o menor e o maior nível de 
condutância da pele dentro de uma janela de tempo, não categorizando nenhuma resposta com o valor zero (Agren et al., 2013; Oyarzún et al., 2013; Milad et al., 2005; Vervliet, Vansteenwegen, Baeyens, Hermans e\& Eelen, 2005; Vervliet, Vansteenwegen \& Eelen, 2004). Por exemplo, em Agren et al. (2013), foram avaliadas as diferenças entre os pontos mais baixos e os pontos mais altos do registro em um intervalo de tempo específico após a apresentação dos CSs. O valor resultado era comparado estatisticamente com o valor zero, sendo que uma diferença estatisticamente significante era interpretada como ocorrência de uma resposta.

Conforme especificado anteriormente, podem ocorrer mudanças na condutância da pele na ausência de estímulos identificáveis, sendo que essa atividade tem sido referida pelo termo "resposta espontânea" ou "não específica" (NS-SCR) (Boucsein, 2012; Society for Psychophysiological Research Ad Hoc Committee on Electrodermal Measures, 2012). A observação dessa atividade eletrodérmica tem sido interpretada como sugestiva de que nem sempre as SCRs estão sob controle dos estímulos apresentados pelo experimentador ao longo das sessões experimentais (Boucsein, 2012; Society for Psychophysiological Research Ad Hoc Committee on Electrodermal Measures, 2012). Dito de outro modo, SCRs podem ser eliciadas por estímulos outros que não os CSs programados, tais como ruídos do laboratório etc, ou então, por estímulos que não podem ser prontamente identificados. Esse aspecto é extremamente relevante para pesquisas que envolvem condicionamento respondente, pois a análise é justamente da relação entre estímulos e respostas. Deste modo, a avaliação do condicionamento da SCR exige que se estabeleça uma janela de tempo em relação ao estímulo apresentado, isto é, uma latência mínima e máxima, dentro da qual a(s) resposta(s) será(ão) considerada(s) como relacionada(s) à sua apresentação.

Em primeiro lugar, é necessário que haja um intervalo mínimo entre o início do estímulo apresentado e o início da resposta para se considerar que ambos estão relacionados (isto é, para se concluir que a resposta foi eliciada pelo estímulo). A necessidade desse intervalo é explicada por alguns autores pelo fato de haver atrasos temporais no registro imanentes ao sistema de avaliação, quais sejam: tempo de processamento de sinal, tempo de condução de sinais elétricos dentro do sistema nervoso autonômico até as glândulas de suor e penetração do suor nos dutos da epiderme (Boucsein, 2012; Society for Psychophysiological Research Ad Hoc Committee on Electrodermal Measures, 2012). Na literatura sobre ressurgência do comportamento respondente, alguns autores consideram relacionadas à um estímulo, respostas cujo início se dá $1 \mathrm{~s}$ após o início do CS (e.g., Effting \& Kindt, 2007; Kindt \& Soeter, 2013; LaBar \& Phelps, 2005; Neumann \& Longbottom, 2008; Neumann \& Kitlertsirivatana, 2010; Soeter \& Kindt, 2011; Vervliet et al., 2005; Vervliet et 
al., 2004), porém há autores que aceitam latências menores, de 0,5s (Oyarzún et al., 2013; Schiller et al., 2008; Schiller et al., 2013; Schiller et al., 2010).

Se por um lado a escolha da latência mínima não gera muito debate, o mesmo não pode ser dito quanto à escolha do final do intervalo dentro do qual consideram-se respostas como sendo relacionadas a um estímulo. Esta última escolha depende, entre outras coisas, do tratamento dado ao aparecimento de múltiplas respostas após o CS, o que por sua vez tem relação com a duração dos CSs no experimento (Boucsein, 2012; Lovibond, 1992; Pineles, Orr \& Orr., 2009).

Desde estudos clássicos conduzidos na década de 50, sabe-se que múltiplas SCRs podem ser eliciadas quando a duração do CS é de 5 s ou mais (Prokasy \& Ebel, 1967). Essa observação gerou um debate se essas múltiplas respostas poderiam ser tratadas como independentes ou se todas covariavam em função das mesmas manipulações experimentais (Dengerink \& Taylor, 1971; Lockhart, 1966; Öhman, 1971; Stewart, Stern, Winokur \& Fredman, 1961). Um trabalho de grande influência nesse sentido foi o de Prokasy e Ebel (1967), que fizeram um condicionamento que envolvia um tom de $8 \mathrm{~s}$ (que teria função de CS) e um estímulo elétrico de 0,2 $\mathrm{s}$ (que teria função de US e era apresentado ao final da apresentação do CS). Esses pesquisadores dividiram as múltiplas respostas eliciadas pelo CS em categorias distintas com base em sua latência: a) uma primeira resposta (ou a maior, no caso de ocorrerem mais de uma resposta) num intervalo entre 1,35-4,95 s após início do CS, sendo denominada resposta do primeiro intervalo (FIR, do inglês first-interval response) e b) uma segunda resposta (ou a maior resposta) cujo início se dava entre 4.95 a 9.53 s após início do CS, denominada de resposta do segundo intervalo (SIR, do inglês, second-interval response). No trabalho de Prokasy e Ebel (1967), eram identificadas ainda respostas cujo início se dava entre 9.53 s a 14.55 s após início do CS. Estas últimas respostas eram denominadas de respostas incondicionais do terceiro intervalo quando havia pareamento com o US (TUR, do inglês third-interval unconditioned responses) ou respostas de omissão do terceiro intervalo, quando não havia pareamento com o US (TOR, do inglês third-interval omission responses).

A distinção entre FIR e SIR decorrente do trabalho de Prokasy e Ebel (1967) foi adotada por muitos pesquisadores, sendo que há uma hipótese de que essas respostas refletem aspectos distintos do condicionamento respondente. De acordo com Öhman (1971), a resposta do primeiro intervalo (FIR) seria uma resposta de orientação, isto é uma resposta fásica ao CS que está presente desde a sua primeira apresentação, antes do pareamento, refletindo novidade e habituando ao longo do tempo; por outro lado, a resposta do segundo intervalo (SIR) representaria a "verdadeira" resposta condicional, que não apresenta habituação e vai aumentando na medida em que ocorrem os pareamentos entre CS e US (Dengerink \& Taylor, 1971; Lockhart, 1966; 
Öhman, 1971; Stewart, Stern, Winokur \& Fredman, 1961). Contudo, apesar da hipótese de Öhman (1971), sabe-se por estudos experimentais que a demonstração de condicionamento se dá muito mais facilmente para a FIR do que para a SIR (Pineles et al., 2009). Além disso, não há evidências de que a FIR e SIR sejam de fato respostas totalmente distintas, dado que é possível observar condicionamento tanto da SIR como FIR (Pineles et al., 2009).

Apesar da questão sobre a utilidade da separação entre FIR e SIR não estar totalmente resolvida na literatura, ela foi adotada em muitos trabalhos sobre condicionamento respondente nos quais os CSs têm uma duração de pelo menos 8s (Effting \& Kindt, 2007; LaBar, Gatenby, Gore, LeDoux \& Phelps, 1998). Nesses casos, as respostas FIR e SIR foram avaliadas separadamente (e.g., Effting \& Kindt, 2007). Em outros casos, mesmo com CSs de 8 s de duração, os experimentadores optaram por examinar apenas a FIR (Neumann \& Longbottom, 2008; Neumann \& Kitlertsirivatana, 2010; Vervliet et al., 2005; Vervliet et al., 2004). Em experimentos nos quais os CSs são mais curtos, variando de $4 \mathrm{~s}$ a $6 \mathrm{~s}$, é comum também a avaliação somente da FIR, isto é, de respostas cujo início se dá entre $0,5 \mathrm{~s}$ a $5 \mathrm{~s}$ após o início do CS (LaBar \& Phelps, 2005; Oyarzún et al., 2013; Schiller et al., 2008; Schiller et al., 2013; Schiller et al., 2010). Contudo, é notável aqui o fato de que há uma variação no intervalo usado para se considerar que uma resposta estava relacionada à um estímulo nesses estudos com CSs mais curtos. Por exemplo, em Schiller et al. (2010), eram selecionadas respostas cujo início se dava entre 0,5 s e 4,5 s após início do CS, enquanto que Oyarzún et al., (2013) descrevem que avaliaram a diferença entre o pico e a base da primeira resposta que ocorria entre $0,5 \mathrm{~s}$ a $6 \mathrm{~s}$ após o início do CS.

Outra questão técnica e metodológica importante a ser ressaltada é que a avaliação das respostas de condutância da pele é feita no período de extinção em alguns estudos, isto é, avalia-se SCRs somente nas ocasiões em que a apresentação do CS não termina com a apresentação de um US (Oyarzún et al., 2012; Schiller et al., 2008; Schiller et al., 2013; Schiller et al., 2010). Esse delineamento se aproxima mais dos estudos com ratos, nos quais as CRs são avaliadas no período de extinção (Bouton \& Bolles, 1979a, 1979b; Rescorla, 1968; Rescolar \& Heth, 1975). No entanto, em sua grande maioria, os estudos sobre condicionamento em humanos avaliam todas as apresentações de CS, incluindo as que são pareados com o US. Nesses casos, seleciona-se tudo o que ocorre durante o intervalo de apresentação do CS antes da apresentação do US (Effting \& Kindt, 2007; Kindt \& Soeter, 2013; LaBar et al., 1998; Neumann \& Longbottom, 2008; Neumann \& Kitlertsirivatana, 2010; Soeter \& Kindt, 2011; Vervliet et al., 2005; Vervliet et al., 2004).

Um outro método, usado mais recentemente, para avaliar o condicionamento da SCR é examinar tudo o que ocorre no intervalo durante a apresentação do CS (ou entre a apresentação do CS e US, nos casos em que estes estímulos são pareados) (Kindt e Soeter, 2013; Milad et al., 
2005; Orr et al., 2000; Severster et al., 2012; Soeter \& Kindt, 2011). Nesse método, resposta é definida pelo "maior pico de SCR independentemente de onde esse pico estaria no intervalo CSUS" (EIR, do inglês entire-interval response). Uma diferença importante entre EIR e o método de divisão das respostas em FIR e SIR é que no segundo são incluídas na análise respostas cujo início está dentro do intervalo, mas o pico está fora até um intervalo limite; o EIR inclui respostas cujo início e pico estão dentro do intervalo. No método EIR, analisa-se a diferença entre a média do nível de condutância da pele nos 2 s que antecedem a apresentação do CS e o maior nível de condutância da pele observado durante a apresentação do CS (excluído o período em que o CS ocorre junto com o US).

Segundo Pineles et al. (2009), o método EIR é melhor porque não se presume onde a resposta vai ocorrer no intervalo CS-US. Fora isso, o EIR evita o dilema conceitual de onde estabelecer a fronteira entre FIR e SIR a depender da duração do CS. Costumeiramente, no método SIR e FIR, dividia-se o período do CS em duas metades (por exemplo, em CSs de $8 \mathrm{~s}$, dividia-se em dois período de aproximadamente $4 \mathrm{~s}$ ), o que poderia ser considerado como arbitrário (Pineles et al., 2009).

Uma outra questão diz respeito ao método de observação da SCR. Pode-se identificar SCRs por duas formas: análises automatizadas e análises manuais. Em uma análise automatizada, o experimentador programa um computador para aplicar um algoritmo de análise de dados (por exemplo, encontrar respostas com base na distinção FIR/SIR) (e.g., Boucsein, 2012; Pineles et al., 2009). Por análise manual, entende-se aquela em que o experimentador determina quais partes do registro da RCP podem ser considerados como respostas e quais não. Embora muitos estudos utilizem-se de métodos computacionais, é notável que estudos importantes da área optem pelo uso de análises manuais (e.g., LaBar et al., 1998; Schiller et al., 2008; Schiller et al., 2013; Schiller et al., 2010).

Alguns comentários se fazem necessários quanto às análises manuais. A depender do como o experimento é programado, o pesquisador pode ter um registro em que é possível identificar a natureza do evento apresentado ao sujeito. Ou seja, pode-se saber, por exemplo, se o estímulo apresentado em certo momento foi pareado ao US anteriormente (e na presença do qual, teoricamente, o sujeito deveria apresentar SCRs de maior amplitude em uma dada fase experimental). Em comunicação pessoal feita pela Dra. Daniela Schiller, ressaltou-se que o conhecimento da natureza dos estímulos quando uma avaliação manual é feita pode influenciar no modo como o experimentador avalia as respostas. Ou seja, pode ocorrer do experimentador ficar sob controle da hipótese e não apenas dos dados em si. Portanto, é recomendável que o experimentador faça essa avaliação dos registros da sessão sem ter acesso à natureza do evento 
que ocorreu. Para isso, pode-se utilizar apenas um sinal de que um evento ocorreu sem referência à sua natureza (isto é, se foi pareado ao US ou não anteriormente). Com esses dados em mãos, fazse uma avaliação das amplitudes das SCRs e, posteriormente, o experimentador confronta a sua análise com as informações completas sobre a natureza do evento apresentado frente ao qual ocorreu a resposta.

Embora a necessidade de uma avaliação "cega" tenha sido destacada verbalmente em dois laboratórios com o qual tivemos contato (Laboratório de Neurociência Afetiva de Schiller, Friedman Brain Institute; Laboratório Phelps, Universidade de Nova Iorque), é notável o fato de que isso quase não ser citado na literatura. Na revisão bibliográfica que fizemos, encontramos apenas dois trabalhos que citam essa questão quando as avaliações são feitas manualmente (LaBar et al., 1998; Lovibond, 1992). Esse cuidado não é relatado em experimentos recentes nos quais utilizaram-se avaliações manuais (LaBar \& Phelps, 2005; Schiller et al., 2008; Schiller et al., 2013; Schiller, Raio \& Phelps, 2012). Além disso, em outros tantos trabalhos, os autores não deixam claro o tipo de análise utilizado (e.g., Effting \& Kindt, 2007).

A última questão que merece destaque no uso da atividade eletrodérmica em estudo sobre condicionamento respondente diz respeito aos delineamentos utilizados. Desde os primeiros estudos sobre atividade eletrodérmica, ficou demonstrado que não existe um estímulo "neutro" para a SCR (Boucsein, 2012). Isto é, há eliciação de SCRs pelos tons, luzes ou imagens usadas como CSs antes dos mesmos serem pareados ao US. Esse responder inicial, que habitua ao longo do tempo, tem sido denominado por alguns autores de "resposta de orientação" (Öhman, 1971). Segundo Boucsein (2012), alguns autores acreditam ser possível garantir "neutralidade" do CS antes do condicionamento, o que seria atingindo expondo-se o participante ao estímulo diversas vezes antes do condicionamento. Deste modo, ocorreria uma habituação das respostas de orientação. Contudo, a habituação total do CS raramente é obtida para toda a amostra, dado que há uma variabilidade entre sujeitos (Boucsein, 2012). Por este motivo, o condicionamento da SCR tem sido definido como o aumento relativo do responder ao CS devido à sua associação com o US, o que pode ser atingido por meio de dois delineamentos: delineamento entre sujeitos e delineamento intrasujeitos (Bousein, 2012).

No delineamento entre sujeitos, o experimentador compara dois grupos de participantes, sendo um deles exposto a CSs e USs pareados (grupo experimental) e o outro exposto aos mesmos estímulos, porém estes sendo apresentados randomicamente ou de modo que sejam completamente não-pareados (grupo controle) (Boucsein, 2012). Neste caso, diz-se que houve condicionamento quando as respostas frente ao CS são maiores no grupo experimental em comparação ao grupo controle. Essa abordagem para produzir condicionamento da atividade 
eletrodérmica em humanos é baseada nos trabalhos de Rescorla (1968) em que são utilizados ratos como sujeitos.

O delineamento intrasujeitos é feito comparando-se as respostas de um participante frente a um estímulo não pareado ao US (comumente denominado como CS-) com as respostas do mesmo participante frente a um ou mais estímulos pareados ao US (denominados $\mathrm{CSs}+$ ). Este delineamento é comumente referido na literatura como condicionamento diferencial (Pineles et al., 2009). Neste caso, diz-se que houve condicionamento quando as respostas frente ao CS+ são maiores do que as respostas frente ao CS-. De acordo com Bousein (2012), o delineamento intrasujeitos é mais vantajoso que o delineamento entre sujeitos porque tem maior sensibilidade, fazendo-se necessário um menor número de sujeitos para demonstração do fenômeno de condicionamento. De fato, este é o delineamento mais usado na literatura, inclusive nos estudos aqui revisados.

\section{REFERÊNCIAS BIBLIOGRÁFICAS ${ }^{14}$}

Agren, T., Engman, J., Frick, A., Björkstrand, J., Larsson, E., Furmark, T., \& Fredrikson, M. (2012). Disruption of reconsolidation erases a fear memory trace in the Human amygdala. Science, 337, 1550-1552.

Alvarez, R. P., Johnson, L., \& Grillon, C. (2007). Contextual-specificity of short-delay extinction in humans: Renewal of fear-potentiated startle in a virtual environment. Learning and Memory, 14, 247-253.

Boucsein, W. (2012). Electrodermal activity (2 ${ }^{\text {nd }}$ ed) New York: Springer.

Bouton, M. E., \& Bolles, R. C. (1979a). Contextual control of the extinction of conditioned fear. Learning and Motivation, 10, 445-466.

Bouton, M. E., \& Bolles, R. C. (1979b). Role of conditioned contextual stimuli in reinstatement of extinguished fear. Journal of Experimental Psychology: Animal Behavior Processes, 5, 368378.

${ }^{14}$ De acordo com o estilo APA - American Psychological Association 
Brown, C. C. (1967). A proposed standard nomenclature for psychophysiological measures. Psychophysiology, 4, 260-264.

Dawson, M. E., Schell, A. M., \& Filion, D. L. (2000). The electrodermal system. In J. T. Cacioppo \& L. G. Tassinary (Eds). Handbook of Psychophysiology (2 ${ }^{\mathrm{a}}$ ed.), pp.200-233. Cambridge: Cabridge Press.

Dengerink, H. A., \& Taylor, S. P. (1971). Multiple responses with differential properties in delayed galvanic skin response conditioning: A review. Psychophysiology, 8, 348-360.

Efting, M., \& Kindt, M. (2007). Contextual control of human fear associations in a renewal paradigm. Behaviour Research and Therapy, 45(9), 2002-2018.

Johnson, L. C., \& Lubin, A. (1966). Spontaneous electrodermal activity during waking and sleeping. Psychophysiology, 3, 8-17.

Kindt, M., \& Soeter, M. (2013). Reconsolidation in a fear conditioning study: A test of extinction as an updating mechanism. Biological Psychology, 92, 43-50.

LaBar, K. S., Gatenby, J. C., Gore, J. C., LeDoux, J. E., \& Phelps, E. A. (1998). Human amygdala activation during conditioned fear acquisition and extinction: A mixed fMRI study. Neuron, 20, 937-945.

LaBar, K. S., \& Phelps, E. A. (2005). Reinstatement of conditioned fear in humans is context dependent and impaired in amnesia. Behavioral Neuroscience, 119, 677-686.

Lockhart, R. A. (1966). Comments regarding multiple response phenomena in long interstimulus interval conditioning. Psychophysiology, 3, 108-114.

Lovibond, P. F. (1992). Tonic and phasic electrodermal measures of human aversive conditioning with long duration stimuli. Psychophysiology, 29, 621-632.

Milad, M. R., Orr, S. P., Pitman, R. K., \& Rauch, S. L. (2005). Context modulation for fear extinction in humans. Psychophysiology, 42, 456-464. 
Neumann, D. L., \& Kitlertsirivatana, E. (2010). Exposure to a novel context after extinction causes a renewal of extinguished conditioned responses: Implications for the treatment of fear. Behavior Research and Therapy, 48, 565-570.

Neumann, D. L., \& Longbottom, P.L. (2008). The renewal of extinguished fear with fear-relevant and fear-irrelevant stimuli by a context change after extinction. Behavior Research and Therapy, 46, 188-206.

Öhman, A. (1971). Differentiation of conditioned and orienting response components in electrodermal conditioning. Psychophysiology, 8, 7-22.

Orr, S. P., Metzger, L. J., Lasko, N. B., Macklin, M. L., Peri, T., \& Pitman, P. K. De novo conditioning in trauma-exposed individuals with and without post-traumatic stress disorder. Journal of Abnormal Psychology, 109, 290-298.

Oyarzún, J. P., Lopez-Barroso, D., Fuentemilla, L., Cucurell, D., Pedraza, C., Rodriguez-Fornells, A., \& Diego-Balaguer, R. (2012). Updating fearful memories with extinction training during reconsolidation: A human study using auditory aversive stimuli. PLoS One, 7(6): e38849. doi:10.1371/journal.pone.0038849.

Pineles, S. L., Orr, M. R., \& Orr, S. P. (2009). An alternative scoring method for skin conductance responding in a differential conditioning paradigm with a long-duration conditioned stimulus. Psychophysiology, 46, 984-995.

Prokasy, W. F., \& Ebel, H. C. (1967). Three components of the classicaly conditioned GSR in human subjects. Journal of Experimental Psychology, 73, 247-256.

Rescorla, R. A. (1968). Probability of shock in the presence and absence of CS in fear conditioning. Journal of Comparative and Physiological Psychology, 68(1), 1-5.

Rescorla, R. A., \& Heth, C. D. (1975). Reinstatement of fear to an extinguished conditioned stimulus. Journal of Experimental Psychology: Animal Behavior Processes, 1, 88-96.

Schiller, D., Cain, C. K., Curley, N. G., Schwartz, J. S., Stern, S. A., LeDoux, J. E., \& Phelps, E. A. (2008). Evidence for recovery of fear following immediate extinction in rats and humans. Learning and Memory, 15, 394-402. 
Schiller, D., Kanen, J. W., LeDoux, J. E., Monfils, M-H., \& Phelps, E. A. (2013). Extinction during reconsolidation of threat memory diminishes prefrontal cortex involvement. Proceedings of the National Academy of Sciences of the United States of America, 110, 20040-20045.

Schiller, D., Monfils, M-H., Raio, C. M., Johnson, D. C., LeDoux, J. E., \& Phelps, E. A. (2010). Preventing the return of fear in humans using reconsolidation update mechanisms. Nature, 463(7277), 49-53.

Schiller, D., Raio, C. M., \& Phelps. E. A. (2012). Extinction training during the reconsolidation window prevents the recovery of fear. Journal of Visualized Experiments, 24(66), e3893, DOI: $10.3791 / 3893$.

Sevenster, D., Beckers, T., \& Kindt, M. (2012). Retrieval per se is not sufficient to trigger reconsolidation of human fear memory. Neurobiology of Learning and Memory, 97, 338-345.

Society for Psychophysiological Research Ad Hoc Committee on Electrodermal Measures: Boucsen, W., Fowles, D. C., Grimmes, S., Ben-Shakhar, G., Roth, W. T., Dawson, M. E., \& Filion, D. (2012). Publication recommendations for electrodermal measurement. Psychophysiology, 49, 1017-1034.

Soeter, M., \& Kindt, M. (2011). Disrupting reconsolidation: pharmacological and behavioral manipulation. Learning and Memory, 18, 357-366.

Stewart, M. A., Stern, J. A., Winokur, G., \& Fredman, S. (1961). An analysis of GSR conditioning. Psychological Review, 68, 60-67.

Vervliet, B., Vansteenwegen, D., Bayens, F., Hermans, D., \& Eelen, P. (2005). Return of fear in a human differential conditioning paradigm caused by a stimulus change after extinction. Behavior Research and Therapy, 43, 357-371.

Vervliet, B., Vansteenwegen, D, \& Eelen, P. (2004). Generalization of extinguished skin conductance responding in human fear conditioning. Learning and Memory, 11, 555-558. 
ANEXO B - Questionário de triagem

INSTITUTO DE PSICOLOGIA - DEPARTAMENTO DE PSICOLOGIA EXPERIMENTAL (PSE) DA USP - LABORATÓRIO DE ANÁLISE BIOCOMPORTAMENTAL

\section{QUESTIONÁRIO DE TRIAGEM}

Sujeito no:

Sexo:

Idade:

1. Você tem epilepsia ou teve convulsão?

2. Você teve desmaio ou síncope? Se sim, descrever a ocasião.

3. Teve traumatismo craniano grave (seguido de perda de consciência)?

4. Tem problema de audição ou zumbido nas orelhas?

5. Está grávida ou tem a chance de estar?

6. Tem algo metálico no cérebro/crânio (exceto titânio)? (exemplo, clipes, placas etc.).

7. Tem implante coclear?

8. Tem neuroestimulador implantável (exemplo, epidural, subdural)

9. Tem marca -passo cardíaco ou outro metal no corpo?

10. Tem algum dispositivo de infusão no corpo?

11. Está tomando algum remédio? (Por favor liste)

12. Teve alguma cirurgia na medula? 
ANEXO C - Termo de consentimento livre e esclarecido - página 1

\section{INSTITUTO DE PSICOLOGIA - DEPARTAMENTO DE PSICOLOGIA EXPERIMENTAL (PSE) DA USP - LABORATÓRIO DE ANÁLISE BIOCOMPORTAMENTAL}

\section{TERMO DE CONSENTIMENTO LIVRE E ESCLARECIDO}

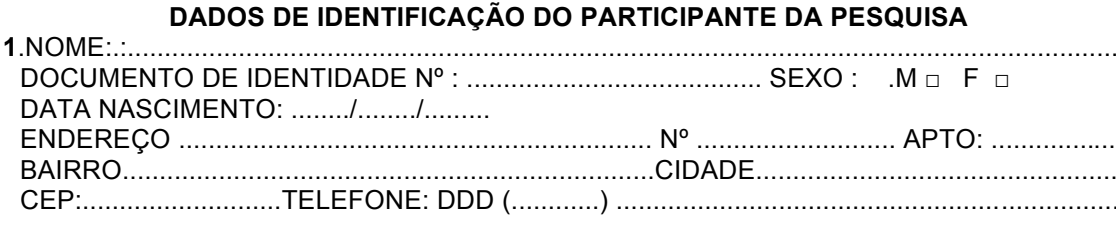

\section{DADOS SOBRE A PESQUISA}

PESQUISADOR: PEDRO FONSECA ZUCCOLO TÍTULO DA PESQUISA: CONDICIONAMENTO RESPONDENTE AVERSIVO: EFEITOS DAS APRESENTAÇÕES DO CS DURANTE PROCEDIMENTO DE EXTINÇÃO SOBRE A RESSUGÊNCIA DA CR

Este estudo visa investigar como as pessoas lidam com eventos desagradáveis em suas vidas. Para tanto, vamos realizar um experimento no qual voluntários se submeterão a uma situação levemente desconfortável e observaremos como eles reagem a ela, logo depois da sua ocorrência e após 24/ 48 horas.

Para criar essa situação de desconforto será utilizada uma breve e pouco intensa estimulação elétrica aplicada no pulso direito dos participantes. A intensidade dessa estimulação será determinada pelos próprios participantes antes do experimento. Para isso, eles experimentarão uma estimulação elétrica muito suave, que será aumentada gradativamente até ele determine que é desconfortável, porém não dolorosa. Independentemente do julgamento que o voluntário fizer, a estimulação não passará de um grau máximo previamente estipulado pelo pesquisador com base em estudos científicos. $A$ faixa de intensidade utilizada nesse estudo está demonstrada que não causa qualquer tipo de dano ou prejuízo, de ordem física ou psicológica. Portanto, caso aceite fazer parte deste estudo, você pode esperar se expor apenas a um pequeno desconforto durante sua participação, porém não haverá quaisquer danos à sua saúde. Tal procedimento foi aprovado pelo Comitê de Ética em pesquisa da Faculdade de Filosofia, Ciências e Letras de Ribeirão Preto-USP. 
ANEXO C - Termo de consentimento livre e esclarecido - página 2

Os participantes terão três encontros com o pesquisador, durante os quais farão uma tarefa que dura em torno de 20 minutos. Enquanto fazem essa atividade, eles receberão a estimulação elétrica de tempos em tempos, sendo registradas suas reações por meio de um equipamento conectado à mão esquerda. Não haverá procedimentos alternativos ou mudanças no protocolo de pesquisa: uma vez iniciado o estudo, será feito exatamente o que está descrito acima, sem adições ou subtrações. Você não tem qualquer obrigatoriedade de participar deste estudo caso opte por não fazê-lo e estará totalmente livre para desistir de realizar os testes em qualquer momento da pesquisa. Isso poderá feito sem qualquer necessidade de explicação ou prejuízo à sua pessoa.

Em qualquer etapa da pesquisa, você terá acesso ao profissional responsável pela pesquisa para esclarecimento de eventuais dúvidas. O investigador é Pedro Fonseca Zuccolo, que pode ser encontrado no endereço Av. Prof. Melo Moraes Bloco, 1721, Bloco A, Sala A-6 - Butantã, tel. (11) 3091-4358 (falar com Sônia). Esta pesquisa faz parte do Mestrado do referido pesquisador, sob orientação da Profa. Dra. Maria Helena Leite Hunzinker.

Direito de confidencialidade - As informações obtidas serão analisadas em conjunto com os dados de outros participantes, sem que cada indivíduo possa ser identificado no momento da divulgação da pesquisa. Você tem o direito de ter acesso às informações colhidas no estudo quando do seu término. Para tanto, basta procurar o pesquisar no endereço fornecido acima ou pelos telefones de contato.

A sua participação não the trará qualquer benefício direto, financeiro ou de outra natureza. Contudo, é importante que saiba que a sua colaboração representa uma contribuição inestimável que vai possibilitar a maior compreensão das reações humanas a situações desagradáveis. Caso você tenha despesas para participar da pesquisa (tais como, transporte), elas serão cobertas pelo pesquisador.

Acredito ter sido suficientemente informado a respeito dos objetivos, procedimentos, riscos e benefícios relacionados à pesquisa "CONDICIONAMENTO RESPONDENTE AVERSIVO: EFEITOS DAS APRESENTAÇÕES DO CS DURANTE PROCEDIMENTO DE EXTINÇÃO SOBRE A RESSUGÊNCIA DA CR". 
ANEXO C - Termo de consentimento livre e esclarecido - página 3

\section{CONSENTIMENTO}

Eu discuti com Pedro Fonseca Zuccolo sobre a minha decisão em participar neste estudo. Ficaram claros para mim quais são os propósitos da pesquisa, os procedimentos a serem realizados, seus desconfortos e riscos, as garantias de confidencialidade e de esclarecimentos permanentes. Ficou claro também que minha decisão por participar do estudo é voluntária e isenta de despesas. Concordo voluntariamente em participar deste estudo e poderei retirar o meu consentimento a qualquer momento, antes ou durante o mesmo, sem penalidades ou prejuízo ou perda de qualquer benefício que eu possa ter adquirido.

Data:

Assinatura do participante

(Somente para o responsável do projeto)

Declaro que obtive de forma apropriada e voluntária o Consentimento Livre e Esclarecido deste participante para sua colaboração neste estudo.

Data: 
ANEXO D - Notas sobre o uso de estimulação elétrica em pesquisas com participantes humanos

Como o objetivo desta pesquisa era iniciar uma linha de investigação sobre condicionamento respondente aversivo em nosso laboratório e o estímulo mais utilizado para isso é a estimulação elétrica, nos confrontamos com uma série de questionamentos por parte do nosso próprio laboratório, assim como por parte de membros do comitê de ética e do assessor da FAPESP que avaliaram este projeto. Todos esses questionamentos foram de extrema importância para o amadurecimento desta pesquisa e nos obrigou a buscar informações a respeito da segurança envolvida no uso de estimulação elétrica em seres humanos. Na ocasião do exame de qualificação, foi sugerido que o resultado de tal pesquisa fosse apresentado brevemente ao final do trabalho. Esta seria uma maneira de informar o leitor sobre as informações que dizem respeito à segurança no uso desse estímulo no presente projeto.

Em primeiro lugar, por se tratar de pesquisa que emprega procedimentos que podem causar desconforto, dada a presença da estimulação elétrica, é natural que se questione a eventual necessidade de se analisar quadros clínicos que não podem ser submetidos a esse procedimento. Tendo em vista este ponto, procuramos via email algumas das autoras do trabalho original que pretendíamos replicar (Dra. Daniela Schiller e Dra. Rachel Phelps). Conseguimos entrar em contato com a Dra. Schiller, a partir do que foi possível conseguir um relato de que o procedimento que pensamos adotar é seguro e nunca na experiência dessa autora causou qualquer evento adverso ou prejuízo aos participantes.

Nos trabalhos de Schiller e colaboradores e de outros laboratórios nos Estados Unidos, não há menção a qualquer tipo de triagem com participantes em relação a quadros clínicos para os quais o uso da estimulação elétrica nos parâmetros propostos é proscrita (Lim \& Pessoa, 2008, Schiller et al., 2008 Schiller et al., 2010; Shankman, Robison-Andrew, Nelson, Altman \& Campbell, 2011). Nesses casos, os participantes foram recrutados por meio de anúncios ou dentre estudantes universitários e os únicos critérios de exclusão se referiam a impossibilidade de medir a respostas de condutância da pele (participantes que não apresentavam respostas de condutância da pele frente ao choque eram excluídos). Há, por outro lado, trabalhos em que se faz uma triagem psiquiátrica e de condições médicas usando questionários (e.g., Grillon, Baas, Lissek, Smith \& Milstein, 2004; Kindt \& Soeter, 2013), 
Contudo, nesses trabalhos, a justificativa para a triagem dos participantes geralmente não tem relação relativa a segurança dos procedimentos, mas sim para garantir melhor controle de variáveis. A exceção é quando os autores fazem usos de fármacos, quando então se faz necessário uma avaliação médica (e.g., Kindt, Soeter \& Vervliet, 2009). Destaque-se que todos esses trabalhos citados foram aprovados por comitês de ética em pesquisa com humanos e foram publicados em revistas de alto rigor científico que exigem que as investigações estejam dentro de padrões éticos. É merecedor de destaque que a pesquisa da própria Dra. Daniela Schiller foi publicada na revista Nature, uma das publicações científicas mais respeitadas e rigorosas da atualidade.

Apesar desses aspectos, consideramos que seria importante, como uma forma de cuidado extra com os participantes, realizar uma triagem destes antes de sua inserção no protocolo experimental. Para tanto, escolhemos critérios de segurança estabelecidos para as técnicas de neuromodulação. As técnicas de neuromodulação consistem na aplicação de campos magnéticos ou elétricos em regiões específicas do corpo (diretamente no encéfalo ou em extremidades do corpo) para fins terapêuticos (George \& Aston-Jones, 2010). Dentre as técnicas de neuromodulação, o procedimento que mais se aproxima do que está sendo proposto nesta pesquisa é a estimulação elétrica transcutânea dos nervos, que consiste na aplicação de uma corrente elétrica através da pele (Kitchen, 2003). Um aspecto importante a ser destacado é que a estimulação elétrica transcutânea de nervos é feita com uma duração muito maior do que a que estamos propondo aqui: enquanto utilizaremos uma estimulação de duração de $200 \mathrm{~ms}$, a estimulação transcutânea é feita geralmente por um período de duas horas.

A estimulação elétrica transcutânea de nervos é contraindicada em sujeitos com marcapasso, cardiopatia grave, lesões cutâneas, epilepsia ou gestantes. Esses foram nossos critérios de exclusão. O método utilizado para isso foi um questionário, aplicado aos participantes quando da ocasião da apresentação do termo de consentimento. A montagem desse questionário foi baseada em Rossi Hallett, Rossini e Pascual-Leone (2009), que estabeleceram critérios de segurança para sujeitos que seria submetidos a procedimentos de neuromodulação. O questionário consta no ANEXO B desta dissertação.

Outro ponto importante a ser discutido diz respeito à intensidade da estimulação elétrica. Em nosso estudo, ela variou entre 10 e $60 \mathrm{~V}$ porque esta foi a intensidade usada no 
trabalho original Schiller et al. (2010). Um questionamento relevante quanto a esse ponto é se essa faixa de estimulação elétrica é segura e não causa prejuízos / danos ao organismo.

Tendo em vista a voltagem que utilizamos (10-60 V) e a resistência da pele humana, a corrente elétrica aplicada aos participantes fica entre $1 \mathrm{~mA}$ a $4 \mathrm{~mA}$. De acordo com uma revisão de investigações sobre os efeitos da estimulação elétrica em humanos feita pela Organização Mundial da Saúde (OMS) em parceria com o Programa Ambiental das Nações Unidas e a Associação internacional de Proteção à Radiação, o limiar de corrente que produz contração involuntária de grandes grupos musculares gira em torno de 8 a $16 \mathrm{~mA}$ e um choque grave, que produz dificuldades de respiração gira em torno de 12 a $23 \mathrm{~mA}$ (UNEP/WHO/IRPA 1993). Além disso, em 1998, o Instituto Nacional de Saúde e Segurança Ocupacional, nos Estados Unidos, (National Institute for Occupational Safety and Health, NIOSH) publicou um relato segundo o qual o limiar de estimulação elétrica necessário para fibrilação ventricular é da ordem de $100 \mathrm{~mA}$ e o limiar para produção rápida de queimaduras, rompimento da pele, danos em tecidos e parada cardiorespiratória é da ordem de $2.000 \mathrm{~mA}$ (NIOSH, 1998). Outro dado de interesse se relaciona com a densidade da corrente que foi aplicada, isto é, com a quantidade de corrente elétrica por área do corpo. Tendo em vista que a área do eletrodo que utilizamos é de $2 \mathrm{~mm}$, a densidade da corrente usada neste experimento ficou em torno de $5 \mathrm{~mA} / \mathrm{cm}^{2}$ a $20 \mathrm{~mA} / \mathrm{cm}^{2}$. Em estudos com animais, correntes elétricas de 25 $\mathrm{mA} / \mathrm{cm}^{2}$ não causaram prejuízos em tecido nervoso mesmo quando aplicada por várias horas (McCreery, Agnew, Yeun \& Bullara, 1990).

Dessa forma, baseando-se nos dados expostos acima, é possível dizer que a intensidade de estimulação elétrica que usamos, embora possa ser desconfortável, está dentro de limiares seguros para seres humanos. De fato, esse procedimento tem sido aplicado por diversos laboratórios no Estados Unidos, onde há uma grande preocupação com os padrões éticos de estudos com participantes humanos (Grillon et al., 2004; Lim \& Pessoa, 2008; Schiller et al., 2008; Schiller et al., 2010; Shankman et al., 2011).

É importante ainda ressaltar ainda nesta pesquisa utilizou-se de um procedimento muito aceito na literatura em que os níveis de estimulação são regulados pelos próprios participantes. É sabido na literatura que a tolerância para dor varia de sujeito para sujeito (Rollman \& Harris, 1987). Por esse motivo, virou rotina em estudos na área fazer com que o participante determine a intensidade da estimulação elétrica. Em nosso caso, isso foi feito apresentando inicialmente uma estimulação muito leve $(10 \mathrm{~V})$, a qual foi aumentada até que o 
sujeito a considerasse desconfortável porém não dolorosa. De fato, como pode ser visto na discussão desta dissertação, em muitos casos o que acontece é justamente o oposto do que se esperaria ao usar esse estímulo: muitos participantes acabam apresentando uma habituação à estimulação elétrica, e outros tanto sequer apresentam evidências de condicionamento respondente (e.g., Effting \& Kindt, 2007; Neumann \& Longbottom, 2008).

Paralelamente a esta pesquisa, recebemos um parecer médico de dois profissionais que trabalham com pesquisa (Dr. Clemente Isnard Ribeiro de Almeida e Dr. Décio Brunoni), sendo o segundo especialista em estimulação craniana por corrente contínua. Ambos os profissionais nos asseguraram que o modo pelos quais planejamos utilizar a estimulação elétrica não traria danos aos participantes da pesquisa (ANEXO F).

Temos clareza de as considerações acima não abarcam todos os questionamentos possíveis a respeito do uso de estimulação elétrica em pesquisas com humanos. No entanto, a estimulação elétrica é usada na grande maioria dos estudos da área que pretendemos investigar. Dadas as informações coletadas na literatura e com profissionais médicos, optamos por utilizá-la como estímulo aversivo para realizar esta pesquisa.

\section{REFERÊNCIAS BIBLIOGRÁFICAS ${ }^{15}$}

Efting, M., \& Kindt, M. (2007). Contextual control of human fear associations in a renewal paradigm. Behaviour Research and Therapy, 45(9), 2002-2018.

George, M. S.\& Aston-Jones, G. (2010). Non-invasive techniques for probing neurocircuitry and treating illness: Vagus nerve stimulation (VNS), transcranial magnetic stimulation (TMS), and transcranial direct current stimulation (tDCS). Neuropsychopharmacology, 35, 301-316.

Grillon, C., Baas, J. P., Lissek, S., Smith, K. \& Milstein, J. (2004). Anxious responses to predictable and unpredictable aversive events. Behavioral Neuroscience, 118, 916-924.

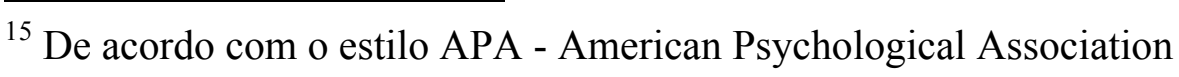


Kindt, M., \& Soeter, M. (2013). Reconsolidation in a fear conditioning study: A test of extinction as an updating mechanism. Biological Psychology, 92, 43-50.

Kindt, M., Soeter, M., \& Vervliet, B. (2009). Beyond extinction: Erasing human fear responses and preventing the return of fear. Nature Neuroscience, 12, 256-258.

Kitchen, S. (2003). Eletroterapia prática baseada em evidências. São Paulo: Manole.

Lim, S.-L. \& Pessoa, L. (2008). Affective learning increases sensitivity to graded emotional faces. Emotion, 8, 96-103.

McCreery, D. B., Agnew, W. F., Yeun, T. G. \& Bullara, L. (1990). Charge density and charge per phase as cofactors in neural injury induced by electrical stimulation. IEEE transactions on Bio-Medical Engineering, 37, 996-1001.

National Institute for Occupational Safety and Health. (1998). Workers death by electrocution: A summary of NIOSH Surveillance and Investigative Findings. Cincinnati: National Institute for Occupational Safety and Health.

Neumann, D. L., \& Longbottom, P.L. (2008). The renewal of extinguished fear with fear-relevant and fear-irrelevant stimuli by a context change after extinction. Behavior Research and Therapy, 46, 188-206.

Rollman, G. B. \& Harris, G. (1987). The detectability, discriminability, and perceived magnitude of painful electrical shock. Perception \& Psychophysics, 42, 257-268.

Rossi, S., Hallett, M., Rossini, P. M. \& Pascual-Leone, A. (2009). Safety, ethical considerations, and application guidelines for the use of transcranial magnetic stimulation in clinical practice and research. Clinical Neurophysiology, 120, 2008-2039.

Schiller, D., Cain, C. K., Curley, N. G., Schwartz, J. S., Stern, S. A., LeDoux, J. E., \& Phelps, E. A. (2008). Evidence for recovery of fear following immediate extinction in rats and humans. Learning and Memory, 15, 394-402.

Schiller, D., Monfils, M-H., Raio, C. M., Johnson, D. C., LeDoux, J. E. \& Phelps, E. A. (2010). Preventing the return of fear in humans using reconsolidation update mechanisms. Nature, 463(7277), 49-53. 
Shankman, S. A., Robison-Andrew, E. J., Nelson, B. D., Altman, S. A. \& Campbell, M. L. (2011). Effect of predictability of shock timing and intensity on aversive responses. International Journal of Psychophysiology, 80, 112-118.

United Nations Environment Programme / World Health Organization / International Radiation Protection Association. (1993). Electromagnetic fields (300 Hz to $300 \mathrm{GHz}$ ). Geneva: World Health Organization; Environmental Health Criteria 137. 
ANEXO E - Carta de aprovação do projeto pelo Comitê de Ética em Pesquisa da FFCLRPSP em 19/12/2011

Prezado Pesquisador,

Comunicamos a V. Sa. que o trabalho intitulado "EXTINÇÃo DO CONDICIONAMENTO RESPONDENTE DENTRO DO PERÍODO DE RECONSOLIDAÇÃO DA MEMÓRIA: UMA REPLICAÇÃO DIRETA DE SCHILLER E COLABORADORES (2011)" fOi reanalisado pelo Comitê de Ética em Pesquisa da FFCLRP-USP, em sua $103^{a}$ Reunião, realizada em 15.12.11, e enquadrado na categoria: APROVADO, de acordo com o Processo CEP-FFCLRP n 594/2011 - 2011.1.1817.59.3.

Atenciosamente,

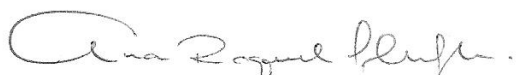

Prof. ${ }^{a}$ Dr. $^{a}$ ANA RAQUEL LUCATO CIANFLONE

Coordenadora

\section{Ao Senhor}

Pedro Fonseca Zuccolo

Mestrando do Programa de Pós-Graduação em Psicologia Experimental do Instituto de Psicologia - USP

Com cópia para a orientadora:

Prof.. ${ }^{a}$ Dr. ${ }^{a}$ Maria Helena Leite Hunziker

Departamento de Psicologia Experimental do Instituto de Psicologia - USP

CEP - Comitê de Ética em Pesquisa da FFCLRP

Fone: (16) 3602-4811

Fax: (16) 3633-2660 (direto) ou 3633-5015

Avenida Bandeirantes, 3900 - bloco 3 - sala 16 - 14040-901 - Ribeirão Preto - SP - Brasil

Homepage: http://www.ffclro.usp.br - e-mail: coetp@ffclrp.usp.br 


\section{ANEXO F - Pareceres médicos a respeito do uso da estimulação elétrica em participantes}

\section{humanos}

São Paulo, 13 de dezembro de 2011.

Ref: Esclarecimentos quanto ao protocolo de pesquisa "Condicionamento respondente aversivo: Efeitos das apresentações do CS, durante procedimento de extinção, sobre a ressurgência da CR" do aluno de Mestrado Pedro Fonseca Zuccolo.

Ao Comitê de Ética em Pesquisa da FFCLRP-USP

Primeiramente, quero agradecer a oportunidade dada por este comitê para contribuir com o desenvolvimento acadêmico e da ética em pesquisa em seres humanos. Como médico e pesquisador, tenho utilizado técnicas de estimulação cerebral não-invasiva através de correntes elétricas diretas, de baixa voltagem para o tratamento de transtornos neuropsiquiátricos, e possuo familiaridade no uso deste tipo de corrente elétrica para fins investigativos.

Após examinar cuidadosamente o protocolo de pesquisa em questão, posso afirmar que todas as precauções para que o mesmo seja realizado com segurança para os participantes foram tomadas. Os critérios de inclusão e exclusão são adequados, evitando, por exemplo, a inclusão de sujeitos com marca-passos ou que possuam próteses metálicas. A carga total (corrente elétrica pelo tempo) a ser empregada é de baixa intensidade, procurando provocar não uma sensação dolorosa e sim desconfortável, não constituindo risco para a saúde dos participantes. Vale lembrar que o objetivo da investigação deste projeto é estudar condicionamento respondente com estímulos aversivos, sendo que o uso de correntes elétricas de baixa intensidade é apenas um método (comumente utilizado neste campo de investigação) para gerar um estimulo aversivo, sendo bastante usado por se tratar de um método ao mesmo tempo seguro e adequado para manipulação de protocolos experimentais.

Desta maneira, e de acordo com meu melhor entendimento, acredito que este protocolo contempla os requisitos necessários para a escolha de voluntários sem risco para a saúde, podendo ser executado, sem modificações, com segurança para todos os participantes.

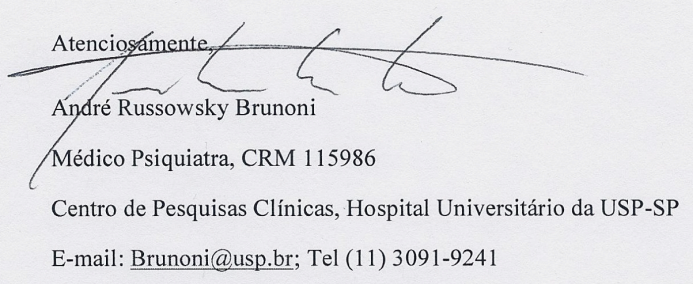


ANEXO F - Pareceres médicos a respeito do uso da estimulação elétrica em participantes

humanos

Parecer para o Comitê de Ética em Pesquisa envolvendo seres humanos da Faculdade de Filosofia Ciência e Letras de Ribeirão Preto (FFCLRP) da Universidade de São Paulo :

São Paulo, 12 de dezembro de 2012

Questionado sobre a inocuidade da aplicação de corrente galvânica na pele posso afirmar que:

A estimulação elétrica para estímulo transcutâneo de nervos conhecida como TENS é utilizada de rotina na prática médica sem conseqüências para a saúde desde que utilizada de forma apropriada. Os equipamentos para essa finalidade utilizam corrente galvânica com voltagem de zero a 110 Volt com amperagem variável de zero a $80 \mathrm{~mA}$ apresentado em pulsos de $2 \mathrm{~Hz}$ a $120 \mathrm{~Hz}$ como o TENYS-ET (TENS)C (KLD Equipment,Ampara, São Paulo) ou GF-3 TENS Transcutaneous Electrcal Nerve Stimulator. GRAHAM-FIELD,INC, 400 Rabro Drive East. Hauppauge, NY 11788 A contra-indicação de procedimentos com aplicação de corrente galvânica na pele é fazer a estimulação próxima aos corpos carotídeos, o que não acontece com a estimulação da pele do pulso bem como a possibilidade de intolerância alérgica aos eletrodos.

O trabalho em questão se propõe a fazer estimulação com um estimulador da marca Grass Medical Instruments (West Warrick, Rhode Island) entre 10V e $60 \mathrm{~V}$ na pele do pulso sem citar a amperagem, que não deve passar de $80 \mathrm{~mA}$.

A proposta de etimulação está dentro de dos limites de segurança podendo se assegurar aos participantes do experimento que o estímulo é inócuo podendo apenas ser observada irritação da pele diante da qual deve ser interrompido o
experimento.

Leernar an Alide.

Clemente Isnard Ribeiro de Almeida

Doutorado pela USP de São Paulo, livre docente e titular pela Faculdade de Medicina de Jundiaí. Orientador da pós-graduação da faculdade de Ciências Médicas da Santa Casa de São Paulo. 